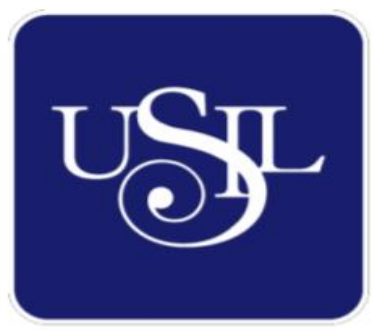

UNIVERSIDAD

SAN IGNACIO

DE LOYOLA

FACULTAD DE CIENCIAS EMPRESARIALES

Carrera de Administración

\title{
LAS PRÁCTICAS DE GESTIÓN FINANCIERA Y LA RENTABILIDAD DE LOS FABRICANTES MYPES DE CALZADO DE COMAS 2020
}

Tesis para optar el Título Profesional de Licenciado en Administración

\section{EVELYN JAZMÍN MORÁN VENERO MILAGROS DEL PILAR POÉMAPE MAYHUA}

\author{
Asesor: \\ Mg. Oscar Federico Muro Doig
}

Lima - Perú

2020 


\section{Índice}

Índice.

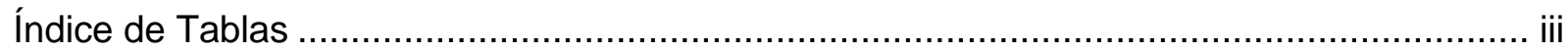

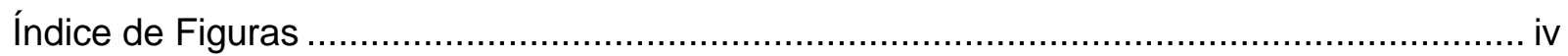

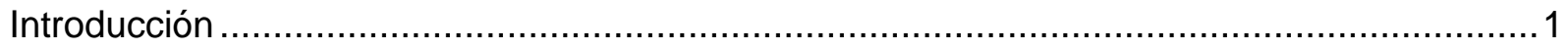

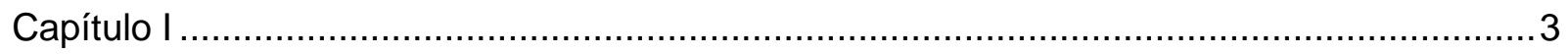

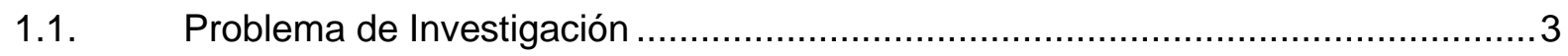

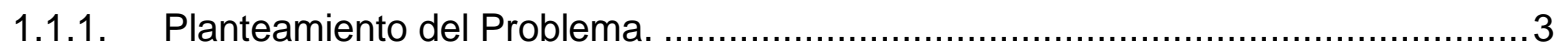

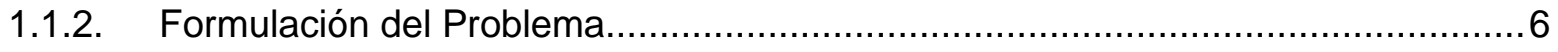

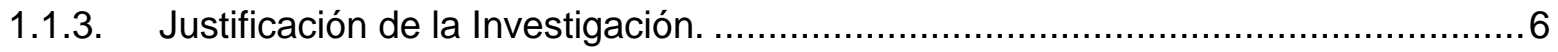

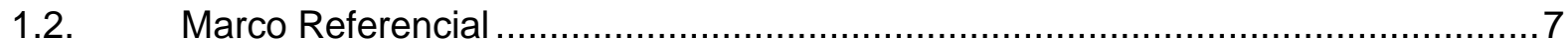

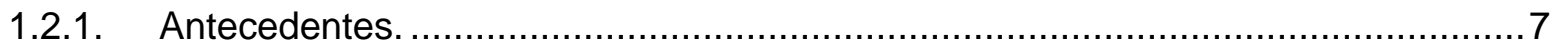

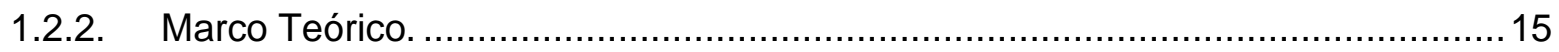

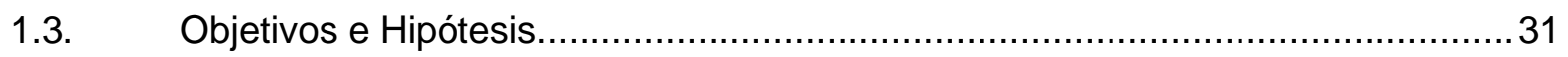

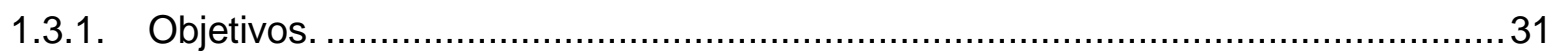

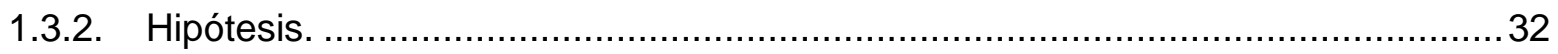

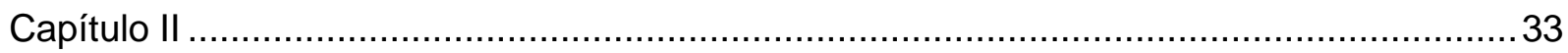

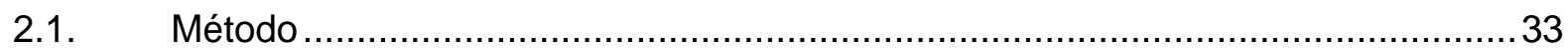

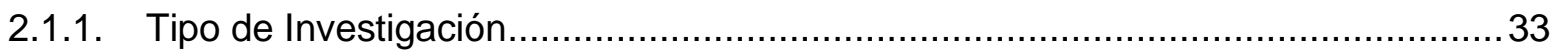

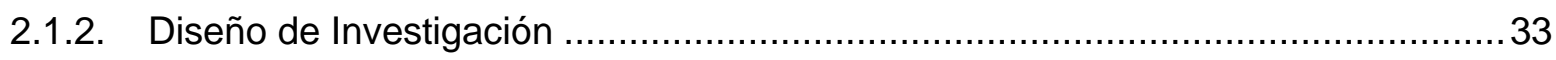

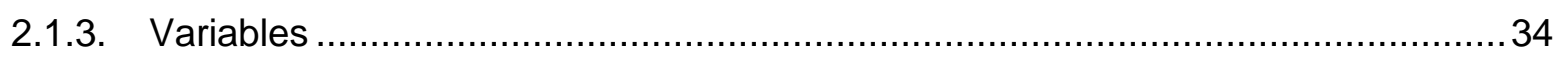

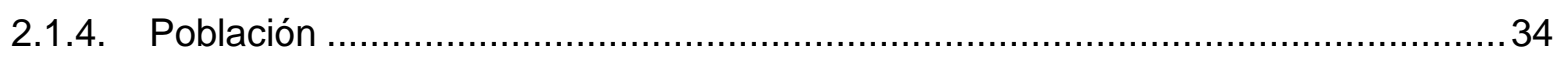

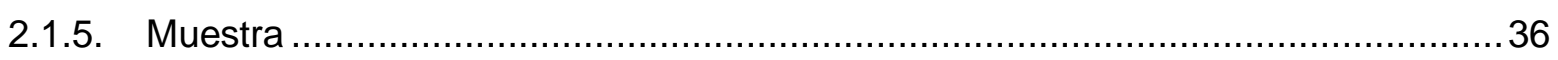

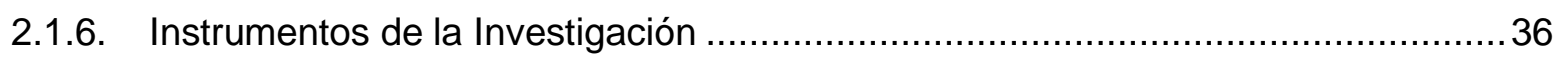

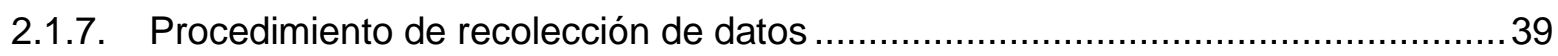

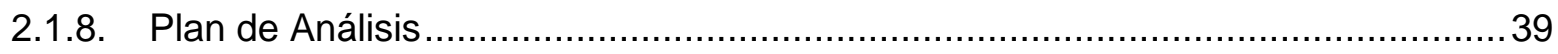

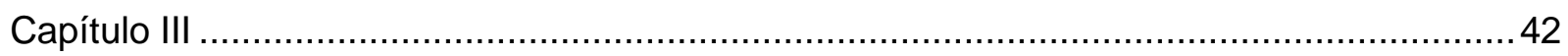

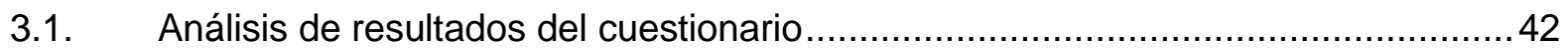

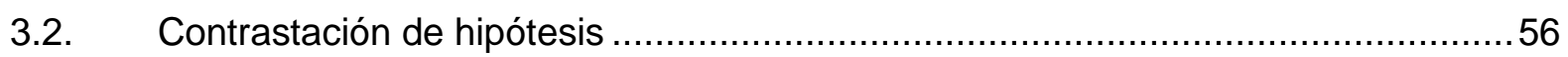

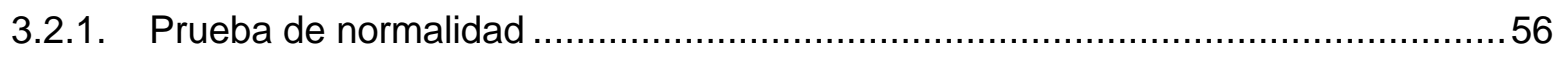

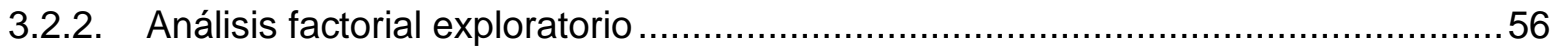

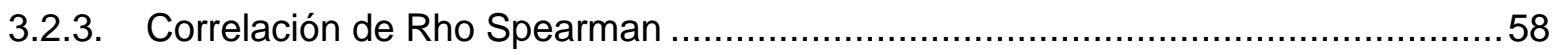

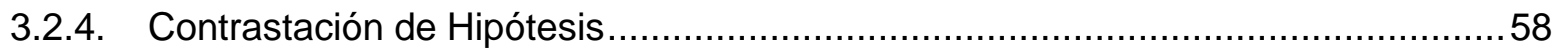




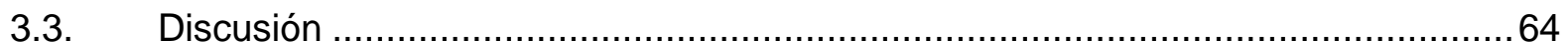

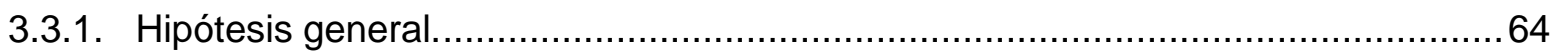

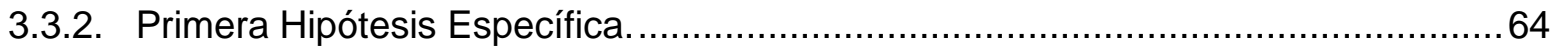

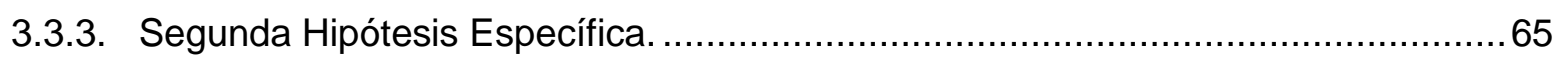

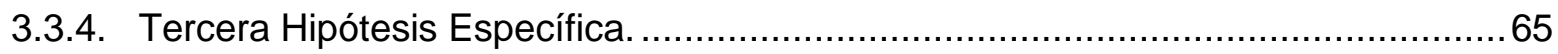

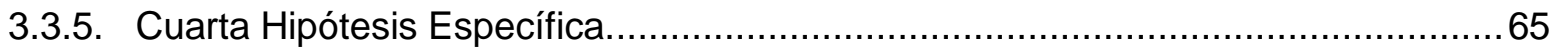

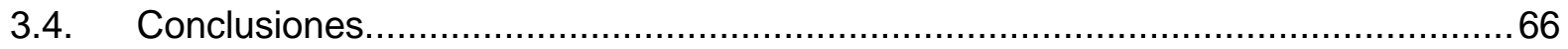

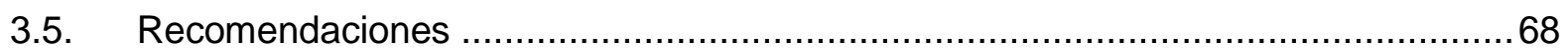

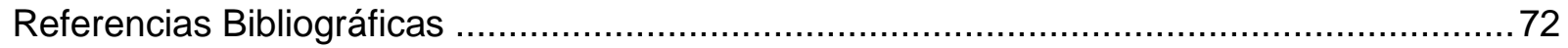

ANEXOS

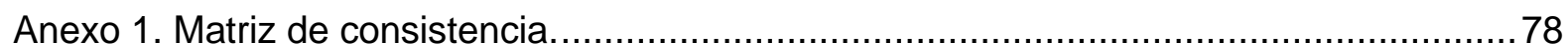

Anexo 2. Cuestionario de Prácticas de Gestión Financiera ............................................. 79

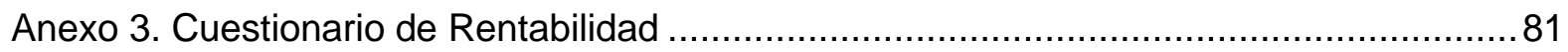

Anexo 4. Coeficiente V de Aiken - Prácticas de gestión financiera ................................... 82

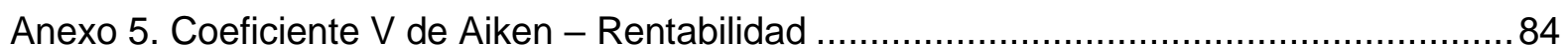

Anexo 6. Alpha de Cronbach de Prácticas de gestión del capital de trabajo .......................85

Anexo 7. Alpha de Cronbach de Sistema de información contable - práctica de análisis de

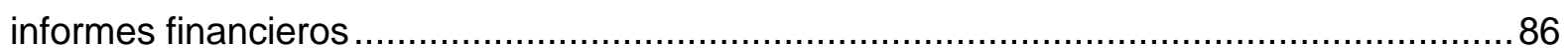

Anexo 8. Alpha de Cronbach de Gestión de estructura de capital-financiamiento...............87

Anexo 9. Alpha de Cronbach de Presupuesto de capital - gestión de activos no corrientes.

Anexo 10. Alpha de Cronbach de Rentabilidad.

Anexo 11. Prueba de normalidad Kolmogorov-Smirnov de Prácticas de gestión financiera90

Anexo 12. Prueba de normalidad Kolmogorov-Smirnov de Rentabilidad...........................93

Anexo 13. Análisis Factorial de Prácticas de gestión financiera .......................................94

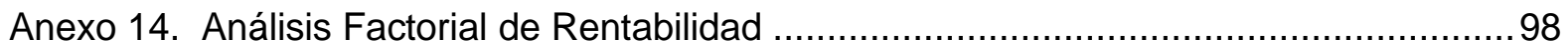

Anexo 15. Correlaciones Spearman........................................................................ 100

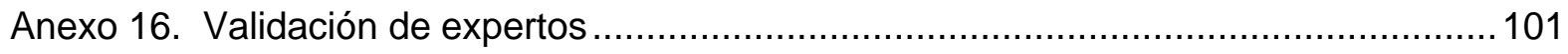




\section{Índice de Tablas}

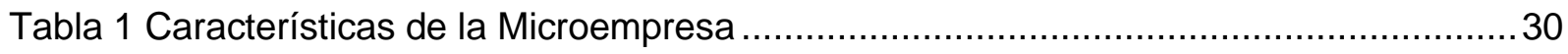

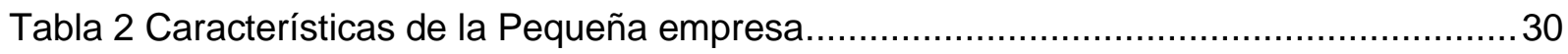

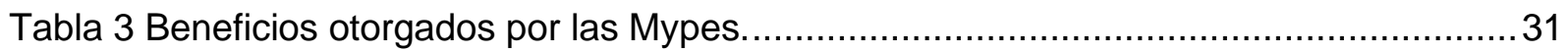

Tabla 4 Cantidad de contribuyentes registrados según Distrito y Actividad Económica. .......36

Tabla 5 Ficha técnica Cuestionario Prácticas de gestión financiera...................................37

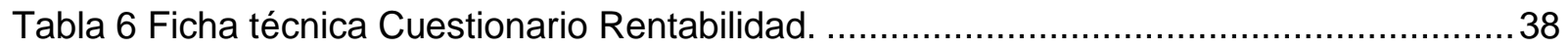

Tabla 7 PGF1. La empresa cuenta con un sistema de gestión de capital de trabajo. ............ 42

Tabla 8 PGF2. Mantiene registros de inventario que se actualizan regularmente. ................. 43

Tabla 9 PGF3. La empresa mantiene saldos de efectivo óptimos en todo momento. ............43

Tabla 10 PGF4. Mantiene registros adecuados y oportunos para todas las cuentas por pagar, catalogando a sus acreedores según sus condiciones de pago.

Tabla 11 PGF5. Asegura que haya suficiente flujo de efectivo para satisfacer las necesidades diarias.

Tabla 12 PGF6. Prepara pronósticos de flujo de efectivo para identificar futuros excedentes y déficits.

Tabla 13 PGF7. Los estados financieros de la empresa se preparan de acuerdo con los estándares de contabilidad financiera.

Tabla 14 PGF10. El estado financiero está preparado de acuerdo con las Normas Internacionales de Información Financiera para las MYPES.

Tabla 15 PGF11. La empresa utiliza información contable para la toma de decisiones. ....... 46

Tabla 16 PGF12. Genera informes periódicos para la toma de decisiones. .........................47

Tabla 17 PGF13. La empresa tiene conocimiento de su estructura de capital. ..................... 47

Tabla 18 PGF14. La estructura de capital de la empresa es adecuada.

Tabla 19 PGF15. La empresa ha utilizado eficientemente la línea de crédito de acuerdo con sus capacidades.

Tabla 20 PGF16. La empresa depende únicamente del capital social.

Tabla 21 PGF18. La empresa no tiene ninguna dificultad en aumentar el capital social en comparación con la deuda.

Tabla 22 PGF19. La empresa puede aumentar el capital de deuda fácilmente en comparación con el capital social.

Tabla 23 PGF20. La empresa cuenta con asesoramiento profesional en inversiones de capital. 
Tabla 24 PGF21. La empresa utiliza la técnica de presupuesto de capital como recuperación de la inversión.

Tabla 25 PGF22. La empresa utiliza técnicas de presupuesto de capital como flujo de caja descontado.

Tabla 26 PGF23. La empresa aplica técnicas de presupuesto de capital en la toma de decisiones. 52

Tabla 27 PGF24. La empresa mantiene un registro adecuado de activos no corrientes. ......52

Tabla 28 R1. Las ventas de la empresa han crecido.......................................................... 53

Tabla 29 R2. El retorno de los activos de la empresa ha aumentado.................................53

Tabla 30 R3. El rendimiento del capital de la empresa ha aumentado.................................54

Tabla 31 R4. El retorno de la inversión de la empresa ha aumentado. ................................54

Tabla 32 R5. Las ganancias de la empresa han crecido...............................................5

Tabla 33 R6. La cuota de mercado de la empresa ha mejorado ....................................... 55

Tabla 34 Resultado de Rho de Spearman - Hipótesis General.........................................59

Tabla 35 Resultado de Rho Spearman - Primera Hipótesis específica ..................................60

Tabla 36 Resultado de Rho de Spearman - Segunda Hipótesis específica............................61

Tabla 37 Resultado de Rho de Spearman - Tercera Hipótesis Específica. ...............................62

Tabla 38 Resultado de Rho de Spearman - Cuarta Hipótesis Específica.................................63

\section{Índice de Figuras}

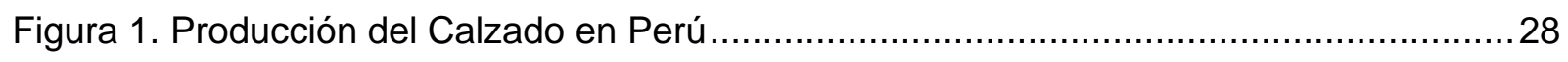

Figura 2. Destino de la producción nacional de calzado de Perú en 2018 ..........................28

Figura 3. Precio medio del calzado en Países de Latinoamérica 2018 ................................29

Figura 4. Número de fabricantes de calzado en los 3 principales distritos ..........................29 


\section{Introducción}

La presente investigación establece estudiar "Las prácticas de gestión financiera y la rentabilidad de los fabricantes Mypes de calzado de Comas 2020"; los datos estadísticos proporcionados por Sunat (2019) indican que Comas es el distrito que representa la mayor cantidad de empresas dedicadas a esta actividad económica. Según los autores Fernández; Naquiche y Rojas (2018) señalan que la gestión financiera es parte fundamental para una empresa, puesto que incide en la rentabilidad del negocio; sin embargo, la inadecuada gestión de esta genera descontrol sobre los recursos financieros empleados por las empresas, lo que conlleva a presentar dificultades como la falta de liquidez, no poder solventar los gastos, como también problemas para afrontar sus deudas con los acreedores; por tanto, dadas las deficiencias de la gestión financiera, las empresas no son rentables, lo que impide el crecimiento, la continuidad de sus operaciones o en el peor de los casos el cierre del negocio.

Es necesario recalcar que las prácticas de gestión financiera proporcionan información pertinente para conocer la situación actual de la empresa, para que de esta manera los gerentes puedan tomar mejores decisiones que contribuyan a la rentabilidad y crecimiento de la empresa.

En el capítulo I de la investigación, se plantea el problema que existe en las empresas del sector calzado ubicadas en el distrito de Comas; el estudio pretende determinar cómo se relacionan las prácticas de gestión financiera con la rentabilidad de las Mypes fabricantes de calzado de Comas; se esclarece la justificación del presente estudio; se presentan los diversos antecedentes internacionales y nacionales relacionados con el tema; en el marco teórico se cita a diversos autores, quienes explican las definiciones sobre la variable "prácticas de gestión financiera" y "rentabilidad", asimismo se proponen los objetivos generales y específicos, que servirán para el planteamiento de las hipótesis.

En el capítulo II de esta investigación, se desarrolla el aspecto metodológico, precisando que se empleó el método cuantitativo, con tipo de investigación correlacional y diseño no experimental de corte transversal; en este mismo capítulo, se definen las dos variables propuestas, se describe el tamaño de la población y la muestra representativa, el cual consta de Mypes fabricantes de calzado en el distrito de Comas; el instrumento utilizado fue el cuestionario, para así recolectar los datos requeridos; por otro lado, se menciona el procedimiento de recolección de datos y el plan de análisis. 
En el capítulo III de la investigación, se expone la interpretación de cada pregunta realizada en el cuestionario, esto es un análisis de los resultados; se desarrolla la contrastación de hipótesis, para lo cual, los datos se procesaron en el Software SPSS 25, se procedió a determinadas pruebas que se especifican en el mismo capítulo; cabe precisar que, para este estudio se utilizó la correlación Rho de Spearman; la discusión se realiza con los resultados obtenidos de esta investigación; se presenta las conclusiones y recomendaciones que contribuyen para que las empresas comprendan la importancia del tema.

Para finalizar, se citan las referencias bibliográficas que se utilizaron para la investigación; los anexos donde se muestra la matriz de consistencia, el instrumento (cuestionario) que corresponden a cada variable, las pruebas que se realizaron en el estudio y por último las validaciones de los cuestionarios de los tres expertos. 


\section{Capítulo I}

\subsection{Problema de Investigación}

\subsubsection{Planteamiento del Problema.}

En los últimos años, el sector de calzado se ha visto amenazado por las importaciones chinas, convirtiéndose en uno de los principales competidores para las industrias nacionales de calzado; a pesar de eso, el sector de calzado es una de las industrias más relevantes para el país. El Instituto de Comercio Exterior (2019) señala que el Perú es el cuarto mayor productor de calzado de América del Sur, por detrás de Brasil, Argentina y Colombia y según Chávez (2019), gerente del Centro de Comercio Exterior (CCEX) de la Cámara de Comercio de Lima (CCL), menciona que el sector de calzado aporta el $1.4 \%$ del PBI manufacturero.

Según el Instituto de Comercio Exterior (2019), la mayor producción de calzado se concentra en Lima con una participación del $60 \%$, seguido del $20 \%$ de Trujillo y Arequipa con un 15\%. La mayor concentración de empresas fabricantes de calzado de Lima se encuentran en los distritos de Comas, San Juan de Lurigancho y San Martín de Porres. (La Superintendencia Nacional de Aduanas y de Administración Tributaria, 2019)

Según Mendoza (2017), menciona que la inadecuada gestión financiera es uno de los principales factores que conduce al cierre o quiebre de las empresas fabricantes de calzado, por lo que el éxito de una empresa radica en el manejo efectivo de las finanzas, ya que ayuda a la toma de decisiones orientadas a generar ganancias. Los fabricantes de calzado no realizan un adecuado análisis de la gestión financiera, lo que conlleva a no contar con un equilibrio financiero óptimo para la rentabilidad del negocio; puesto que presentan dificultades en el manejo de las herramientas financieras, originando una mala gestión financiera provocando así, una deficiencia en el uso de los recursos de la empresa, como el incremento de las deudas, falta de liquidez, insolvencia, entre otros.

Diversas empresas del sector de calzado consideran como una de sus principales problemáticas la falta de capital de trabajo, puesto que les impiden financiar sus actividades económicas, donde su principal limitante es la falta de liquidez monetaria; es por ello que suelen recurrir constantemente al financiamiento para poder contar con capital de trabajo y así puedan continuar con el desarrollo de sus operaciones; al recurrir al financiamiento externo, 
las empresas suelen endeudarse más de la cuenta y presentan dificultades para cumplir con el pago de sus créditos. Por dicho motivo, los fabricantes de calzado se han visto afectados por las malas gestiones de capital de trabajo, ya que no garantizan la liquidez para el capital de trabajo; no pueden disminuir ni prescindir del capital de trabajo, puesto que ese recurso garantiza la continuidad de su negocio, afectando la rentabilidad, la liquidez y el riesgo de la empresa. (Mendoza, 2017)

Según la Ministra de la Producción del Perú, Barrios (2019), señala que uno de los grandes problemas a los que se enfrentan los fabricantes de calzado es la inversión en activo fijos, pues no cuentan con el presupuesto necesario para realizar dichas inversiones, ya que invertir en activos no corrientes (activos fijos) significa salidas significativas de dinero; esta problemática se ha vuelto una gran limitante para las empresas de este rubro, puesto que no cuentan con los recursos suficientes o adecuados para realizar sus labores operativos; lo que conlleva a que no sean competitivos e innovadores por falta de recursos tecnológicos; a pesar de los servicios tecnológicos y de la asistencia técnica que brinda CITECCAL de Lima para las empresas de calzado; algunos fabricantes aún prefieren invertir en activos fijos y muchas de estas empresas no realizan una análisis correcto sobre las decisiones de inversión, lo que conlleva a que tengan serios problemas de liquidez o incluso podría llevar a la empresa a la bancarrota si la inversión llegará a fallar.

Según Citeccal (2017), la cultura de calzado está ligado a personas no profesionales que abren su fábrica de calzados en casa, o es algún trabajador que aprendió a fabricar calzado y decidió abrir su propio taller, esta falta de profesionalismo origina que los fabricantes no puedan manejar adecuadamente sus finanzas y suelen sobre endeudarse, lo que origina que no logren una adecuada estabilidad de su estructura de capital.

Los problemas que se presentan en las empresas de calzado radica por no usar indicadores que les permita conocer la situación financiera, lo cual obstaculiza el funcionamiento del negocio, cuando las empresas no determinan eficientemente los ingresos y egresos de efectivo, los conlleva a no poder solventar sus gastos y cumplir adecuadamente con sus obligaciones exigibles, peor aún, si no tienen un respaldo que garantice el cumplimiento de la deuda, terminan siendo considerados como un riesgo para las entidades financieras a la hora de otorgar préstamos debido a la incapacidad de pago; los microempresarios pueden indicar que la empresa está en crecimiento por la adquisición de activos pero no tienen un control 
sobre las compras realizadas y no se evalúa si la inversión está generando ganancias o inestabilidad que al final repercute sobre la rentabilidad; por lo que se debe eliminar estas deficiencias para que mediante herramientas financieras se permita mejorar la rentabilidad de la empresa. (Onton, S.,Pérez, G., \& Santana, F., 2019)

Otras de las problemáticas a las que se enfrentan los fabricantes de calzado, es su sistema información contable; puesto que suelen anotar sus datos contables en cuadernos o en hojas; y este sistema al no ser computarizado, origina que no puedan realizar una adecuada elaboración y análisis de sus informes contables y financieros; en algunos casos, los fabricantes toman decisiones del negocio sin considerar dicha información de la empresa, lo cual conlleva a no tomar adecuadas decisiones para el negocio, perjudicando su rentabilidad y el manejo de diferentes áreas. (Dávalos, S., 2018)

Con respecto a las Mypes fabricantes de calzado de Comas, uno de los principales problemas a los que se enfrentan, es la inadecuada gestión financiera, ya que suelen presentar dificultades en el manejo de las herramientas financieras afectando su estabilidad económica y financiera a largo plazo. Uno de los principales factores de la inadecuada gestión financiera, son las inadecuadas gestiones del capital de trabajo, donde las Mypes suelen recurrir constantemente al financiamiento para contar con capital de trabajo y así continuar con sus operaciones diarias; otro de los factores es que muchas de las Mypes no cuentan con los recursos suficientes para invertir en activos fijos, debido a que estos activos son muy costosos para los fabricantes de calzado, lo cual, se vuelve una limitante para ser competitivos e innovadores, debido a que no cuentan los recursos necesarios para sus procesos operativos; otro de los factores, es establecer una estructura de capital óptima para los fabricantes, debido a que no logran un equilibrio entre la deuda externa y el aporte de capital, ya que suelen recurrir constantemente al financiamiento y luego presentan dificultades para cumplir con sus obligaciones; otro de los factores a los que se enfrente las Mypes son las decisiones de inversión, ya que en muchos casos no suelen evaluar el rendimiento futuro que generará cada inversión, no suelen realizar una planificación y control administrativo de las inversiones, lo que origina que dichas inversiones no generen la rentabilidad esperada; por último, otro de los factores, es que las Mypes no suelen considerar la información contable y financiera para la toma de decisiones, lo cual repercute en la estabilidad económica y financiera de la empresa a la largo plazo. 


\subsubsection{Formulación del Problema.}

\subsubsection{Problema General.}

- ¿Existe relación entre las prácticas de gestión financiera y la rentabilidad de los fabricantes Mypes de calzado de Comas 2020?

\subsubsection{Problemas Específicos.}

- ¿Existe relación entre las prácticas de gestión del capital de trabajo y la rentabilidad de los fabricantes Mypes de calzado de Comas 2020?

- ¿Existe relación entre el sistema de información contable - práctica de análisis de informes financieros y la rentabilidad de los fabricantes Mypes de calzado de Comas $2020 ?$

- ¿Existe relación entre la gestión de estructura de capital - financiamiento y la rentabilidad de los fabricantes Mypes de calzado de Comas 2020?

- ¿Existe relación entre el presupuesto de capital - gestión de activos no corrientes y la rentabilidad de los fabricantes Mypes de calzado de Comas $2020 ?$

\subsubsection{Justificación de la Investigación.}

En la presente investigación se plantea evaluar la relación que existe entre las prácticas de gestión financiera y la rentabilidad de los fabricantes Mypes de calzado del distrito de Comas e identificar si las dimensiones de la variable prácticas de gestión financiera presentan incidencia positiva o negativa sobre la rentabilidad. Se eligió el distrito de Comas, ya que agrupa la mayor cantidad de fabricantes Mypes dedicados al rubro de calzado, esto se logra determinar según la base de datos Sunat (2019); estas empresas se encuentran vulnerables por no implementar estrategias y herramientas que permita gestionar eficientemente el negocio. Por lo general, el inicio de su actividad económica es de manera empírica, si las empresas no cuentan con conocimientos en prácticas de gestión financiera y temas administrativos, podría resultar desfavorable para la rentabilidad y el crecimiento de la empresa. 
De acuerdo al conocimiento obtenido en el proceso de investigación, se podrá recabar información verídica para conocer la situación real de los fabricantes Mypes de calzado del distrito seleccionado. Esta información permitiría establecer medidas correctivas para la toma de decisiones, lo cual contribuiría al crecimiento de la empresa mediante mecanismos que fomenten el buen desempeño. Las variables mostradas en el estudio son factor clave que deben ser consideradas para favorecer la continuidad del negocio, de modo que, es importante que el gerente o administrador de la empresa evalúe los pros y contras antes de tomar una decisión que afecte el futuro de la empresa

El aporte de resultados de la variable prácticas de gestión financiera sería esencial para el correcto manejo de las herramientas financieras, que les permitiría tomar mejores decisiones, donde un riguroso control de dichas prácticas fomentaría la estabilidad económica y financiera de los fabricantes. Con los resultados obtenidos de la variable rentabilidad se logrará determinar si efectivamente las empresas están en la capacidad de generar beneficios utilizando las prácticas de gestión financiera.

Finalmente, con la investigación se beneficiarán directamente las empresas dedicadas a la fabricación de calzado; puesto que, mediante la aplicación de estas prácticas, mejorarán la eficiencia de sus recursos, asimismo reflejándose ganancias que favorezcan al crecimiento sólido de la empresa para así generar más puestos de trabajo que contribuyan en beneficio de los colaboradores y lograr afianzar el compromiso en ambas partes; así mismo se espera que la investigación sirva de referencia para futuras investigaciones que deseen abordar las mismas variables, así como cubrir las brechas académicas existentes en investigaciones que se encuentren relacionadas a las variables propuestas a nivel nacional; ya que después de una extensiva búsqueda no se encuentran muchos estudios que investiguen las variables planteadas con respecto al sector calzado, esto se pudo constatar con la revisión de los antecedentes.

\subsection{Marco Referencial}

\subsubsection{Antecedentes.}

En este apartado, se explica los diversos estudios de autores que se enfocaron en estudiar las variables "prácticas de gestión financiera" y "rentabilidad"; se explican los métodos que se utilizaron para medir el grado de relación entre las variables, los resultados, las 
recomendaciones y/o sugerencias que los autores atribuyeron en cada investigación propuesta. Independientemente del país y sector que los investigadores analizaron, los estudios evidenciaron la importancia de las prácticas de gestión financiera y la rentabilidad de las empresas; para poder respaldar la investigación, se procedió a la búsqueda de antecedentes internacionales y nacionales que contengan o propusieran las variables en cuestión.

\section{Antecedentes Internacionales}

Los estudios internacionales revelaron que la relación entre las variables planteadas y sus respectivas dimensiones que se establecieron de acuerdo a la teoría, presentaban un grado de correlación y significancia; los autores lograron comprobar sus hipótesis planteadas y pudieron demostrar en sus resultados que existían empresas que habían adoptado y desarrollado las prácticas de gestión financiera, pero que dichas prácticas no se realizaban con eficiencia, debido a que las empresas continuaban presentando problemas en su gestión; por lo que, la rentabilidad del negocio no era favorable; en referencia a los estudios internacionales que se identificaron y colocaron en esta investigación, sería conveniente que hubiese investigaciones donde expongan que se realizó un seguimiento a estas empresas estudiadas en su momento, con el fin de conocer si las empresas que adoptaron las prácticas de gestión financiera obtuvieron los beneficios esperados y en qué nivel contribuyó sobre la rentabilidad del negocio; esto permite identificar si la práctica aplicada de acuerdo a la teoría realmente coincide con que la mejora de una variable influye en mejorar la otra variable, además de establecer qué otros problemas actuales enfrentan las empresas, lo cual sería interesante para futuras investigaciones.

En la investigación "Financial Management Practices and Profitability of Small and MediumScale Entities in The Tamale Metropolitan Area", Kwame Nkrumah University of Science and Technology, Ghana (Saah, 2015), menciona que es importante evaluar los constructos de la gestión financiera sobre la rentabilidad de las Pymes, debido a su relevancia en el crecimiento económico. Si bien estas pequeñas empresas favorecen al desarrollo del país, también se observa que no todas sobreviven durante un largo período. La finalidad es determinar si cuentan con las herramientas necesarias y si realmente se produce un efecto en mejora de la empresa. El tipo de investigación es descriptivo y correlacional con diseño no experimental transversal. Asimismo, se analiza los datos mediante el coeficiente de correlación de Pearson. 
La muestra representativa está conformada por 232 Pymes que operan en el Área Metropolitana de Tamale. La técnica utilizada es la encuesta y su instrumento el cuestionario que clasifica las respuestas bajo el método de escala de Likert. Los resultados del informe indican que a pesar de que los sistemas de información contable es uno de los constructos de mayor efecto sobre la rentabilidad, debe de adecuarse correctamente a las prácticas de gestión financiera, por lo que se recomienda que las Pymes evalúen con la seriedad del caso las decisiones de inversión y posterior a ello analizar los informes financieros con el fin de identificar las falencias e implementar o diseñar un plan de acción.

En el artículo científico "Financial Management Practices and Profitability of Modern Rice Milling Firms in Kangayam Cluster, Tamil Nadu", Agricultural Economics Research Review, India (Selvanayaki, Sivakumara, Rohinia, \& Manib, 2016), proponen analizar cómo se relacionan las prácticas de gestión financiera con la rentabilidad de las empresas modernas Moliendas de arroz. El tipo de investigación es correlacional con diseño no experimental; por otro lado, se realiza el análisis de regresión múltiple para establecer la relación entre las variables. La muestra está conformada por 40 empresas situadas en Kangayam de Tamil Nadu-La India; el tipo de muestreo realizado es aleatorio simple para la recolección de datos. Las técnicas utilizadas son la encuesta y su instrumento el cuestionario bajo la escala de Likert, además del análisis documental para recabar información y conocer el estado de las empresas del sector. La investigación concluye que si existe impacto de las prácticas de gestión financiera sobre la rentabilidad; sin embargo, se muestra que el 60\% de empresas dedicadas a este sector están por debajo de la adopción de las prácticas de gestión financiera; por ende, es importante que las empresas evalúen el efecto producido de la Agroindustria Molinera teniendo en cuenta que esta contribuye al crecimiento y desarrollo económico.

En el artículo científico "Financial Management Practices and Profitability of Business Enterprises in Obuasi Municipality, Ghana", Research Journal of Finance and Accounting, Ghana (Yensu, Konadu-Yiadom, \& Awatey, 2016), proponen analizar cómo las prácticas de gestión financiera afectan a la rentabilidad de las empresas comerciales en Ghana. La finalidad es examinar si el presupuesto de capital y la gestión de capital de trabajo presentan relación positiva con la rentabilidad de las empresas situadas en el lugar de estudio. El tipo de investigación es exploratoria y descriptiva con diseño no experimental. La población está conformada por 397 empresas manufactureras y comerciales ubicadas en el Municipio de Obuasi-Ghana del cual se extrajo una muestra representativa de 98 empresas. Las técnicas 
utilizadas son entrevistas y su instrumento el cuestionario. La conclusión de esta investigación evidencia que el presupuesto de capital presenta una relación negativa con la rentabilidad a un nivel de significancia de 0.056, y que el $93 \%$ de las empresas utilizan el periodo de recuperación como método principal para evaluar decisiones de inversión; sin embargo, precisa que existe un porcentaje de empresas que nunca evalúan los proyectos antes de tomar una decisión cuando surge la necesidad de implementar algún equipo para su negocio, compran sin antes evaluar el impacto que generará sobre su empresa. En la investigación se recomienda a los gerentes prestar mayor atención a este tipo de prácticas de gestión financiera para así poder dirigir eficientemente la empresa.

En el artículo científico "Impact of Financial Management Practices on SMEs Profitability with Moderating Role of Agency Cost", Information Management and Business Review, Pakistán (Muneer, Abrar-Ahmad, \& Ali, 2017), proponen examinar el efecto de las prácticas de gestión financiera sobre la rentabilidad de las pequeñas y medianas empresas manufactureras. El propósito de analizar el estudio es para verificar si verdaderamente las prácticas de gestión financiera adoptadas por las Pymes contribuyen a que las empresas sean rentables; cabe señalar que son consideradas empresas generadoras de puestos de trabajo, además de impulsar al desarrollo económico. El tipo de investigación es descriptivo y utiliza el modelo de ecuaciones estructurales con el método de mínimos cuadrados parciales. La muestra está representada por 180 Pymes que operan en la ciudad de Faisalabad ubicado en Pakistán. La técnica para la recolección de datos es la encuesta y el cuestionario como instrumento. La investigación concluye que si existe relación entre las variables porque hay un impacto positivo; sin embargo, también se demuestra que el $64 \%$ de las empresas enfrentan problemas cuando presentan excedente de efectivo, es decir no saben dónde invertir su dinero para obtener ganancias.

En el artículo científico "Effect of Financial Management Practices on Profitability of SmallScale Enterprise: Case Study Hawassa City Administration, Ethiopia", Journal of Business and Management, Ethiopia (Yohanes, Lemie-Debela, \& Shibru, 2018), analizan el efecto de las prácticas de gestión financiera en la rentabilidad de las empresas de pequeña escala. El propósito del estudio es examinar si los aspectos específicos involucrados dentro de las prácticas de gestión financiera inciden significativamente en la rentabilidad de las empresas. Dado que, sin importar el tamaño de la empresa es sumamente importante mantener buenas prácticas de gestión financiera para el desarrollo y éxito de la misma. El tipo de investigación 
es descriptivo y correlacional con un enfoque cualitativo. La población de estudio está conformada por 2316 pequeñas empresas de la ciudad de Awassa de Etiopía, extrayéndose una muestra representativa de 116 empresas de 5 sectores tal como; manufactura, construcción, servicios, comercio y agricultura urbana. Las técnicas utilizadas son entrevistas para recolectar información de cada empresa y la encuesta con su respectivo cuestionario como instrumento. La conclusión de esta investigación demuestra que dentro de la variable independiente "prácticas de gestión financiera", la gestión de estructura de capital repercute de forma negativa sobre la rentabilidad de las empresas de los diversos sectores en estudio, por ende, la formulación de políticas de gestión financiera sería un gran apoyo para las pequeñas empresas.

En el artículo científico "Financial Management Practices, Firm Growth and Profitability of Small and Medium Scale Enterprises (SMEs)", Information Management and Business Review, Ghana (Musah, Dodzi-Gakpetor, \& Pomaa, 2018), proponen analizar el grado de influencia de las prácticas de gestión financiera sobre la rentabilidad de las Pymes. La finalidad es medir las prácticas de gestión financiera mediante 4 indicadores claves que permitan conocer si existe o no una fuerte relación sobre la rentabilidad de las pequeñas y medianas empresas. El tipo de investigación es descriptivo y correlacional con diseño no experimental transversal. Los datos se analizaron mediante la estadística descriptiva y el análisis de correlación de Pearson. El método de selección de la muestra es no probabilístico y está conformada por 100 Pymes de Accra, capital de Ghana. La técnica utilizada es la encuesta y su instrumento el cuestionario en función a la escala de Likert de 5 puntos. La conclusión de esta investigación revela que existen debilidades en los componentes que forman parte de las prácticas de gestión financiera y que los gerentes deben evaluar los proyectos de inversión antes de comprometer los recursos de la empresa, manifestando que se debe mejorar o adoptar técnicas que permitan o generen impacto positivo para la expansión de las Pymes.

\section{Antecedentes Nacionales}

Se recurrieron a investigaciones nacionales, cuyas variables se refieren o vinculan a la presente investigación; en la mayoría de los casos, el problema es el mismo, debido a que las empresas no optan por mecanismos que faciliten el adecuado funcionamiento de la empresa; los autores manifiestan en sus investigaciones que analizar e implementar estrategias contribuye al negocio, además de otras recomendaciones que brindan a las empresas que 
analizaron; en cada investigación propuesta por los autores, se evidenció que las empresas suelen estar de acuerdo con el resultado de las utilidades, pero desconocen qué tan efectivo resultó la adquisición de los activos, siendo esta, solo una de las varias deficiencias en las que incurren las empresas; sin embargo, es necesario indicar que la asesoría continua también es fundamental dentro de una empresa, puesto que permite aplicar no solo estrategias para el logro de sus objetivos, sino también crecer y expandir el negocio, además de poder establecerse como una empresa sólida, lo cual es importante para el acceso a financiamientos.

En la investigación "Manejo Eficiente de Herramientas de Gestión Financiera y su Incidencia en la Rentabilidad de la Empresa Ospina S.A.C.- Huancayo", Universidad Nacional del Centro del Perú, Perú (Bustamante \& Ponce, 2015), mencionan que buscan analizar el manejo eficiente de las herramientas de gestión financiera y cómo estás inciden en la rentabilidad de la empresa. La finalidad es identificar si por medio de ratios financieros la empresa toma buenas decisiones y si el financiamiento de capital tiene relación positiva con la rentabilidad. El tipo de investigación es descriptivo mediante el método deductivo e inductivo. Asimismo, el diseño se define como no experimental transversal - correlacional porque pretende determinar cuál es el grado de relación entre las variables en estudio. Para esta investigación, la muestra estuvo conformada por diez directivos de la empresa. Las técnicas para la recolección de información son la encuesta, entrevista, observación directa y análisis de documentos. La investigación concluye que las herramientas de gestión financiera inciden de manera satisfactoria a pesar que la gestión de la empresa es dada de manera empírica, si bien la empresa se encuentra conforme con las utilidades obtenidas, ello no asegura que esté libre de riesgos por decisiones no acertadas, por ende es preciso tener conocimiento e interés de los instrumentos financieros ya que la empresa tiene necesidad de invertir en activos y contratos de trabajo de considerables montos de dinero.

En la investigación "Evaluación De La Gestión Financiera y su Incidencia en la Rentabilidad de la empresa Zapatería Yuly Período 2013", Universidad Nacional de San Martín, Perú (Ríos, 2015), menciona que el objetivo de la investigación es evaluar la gestión financiera y establecer su incidencia en la rentabilidad de la empresa, asimismo considera que el área de finanzas es el área más importante en una empresa. La finalidad es determinar cómo la gestión financiera incide en la rentabilidad de la empresa Zapatería Yuli - Periodo 2013, dado que la empresa no cuenta con prácticas establecidas sobre su gestión financiera. La investigación es aplicada, tipo descriptivo con diseño no experimental transversal. En el estudio se extrae solo a dos 
personas como muestra representativa, quienes a su vez son responsables directos de la gestión financiera de la empresa. Las técnicas utilizadas son la encuesta y el análisis documental con sus respectivos instrumentos el cuestionario y la guía de análisis documental. La investigación concluye que las deficiencias de la gestión financiera comprenden el 73\% y que solo el $27 \%$ de las actividades se logra cumplir, pero de manera empírica, además de existir inadecuadas políticas de créditos y cobranza como de endeudamiento; también se identifica que la empresa no evalúa en su totalidad si la inversión realmente genera ganancias o pérdidas. Por tanto, establecer estrategias y metas en un determinado tiempo permite reducir el impacto negativo sobre la rentabilidad y maximizar los beneficios en la empresa.

En el artículo científico "Modelo de gestión financiera para mejorar la rentabilidad de las Mypes productoras de calzado en el distrito El Porvenir - Trujillo 2015", Revista Ciencia y Tecnología, Perú (Mendiburu, 2019), tiene como objetivo proponer un modelo de gestión financiera con el fin de mejorar la rentabilidad de las Mypes productoras de calzado, debido a que dichas empresas realizan un inadecuado manejo de sus recursos financieros, lo cual les impide mejorar su rentabilidad. La investigación es aplicada de tipo descriptiva, correlacional y explicativo con un enfoque mixto (cualitativo y cuantitativo) y con un diseño no experimental transaccional. La muestra estuvo compuesta por 132 Mypes que se dedican a la fabricación de calzado ubicadas en el distrito El Porvenir - Trujillo. Las técnicas utilizadas son la encuesta y las fuentes documentales y como instrumento se empleó un cuestionario y una guía de análisis documental. En la investigación se pudo concluir que un modelo de gestión financiera contribuye con el uso adecuado y eficiente de los recursos financieros, permitiendo así lograr una estructura financiera equilibrada y un adecuado nivel de rentabilidad, además se evidenció la ausencia de control sobre la gestión financiera, que no existe una planificación estratégica y financiera, solo el $45 \%$ de las Mypes toman decisiones considerando su información financiera, mientras que el $27 \%$ indicó que nunca utilizan información financiera antes de tomar una decisión; también se pudo concluir que el $47 \%$ de las Mypes estarían dispuestas a implementar un modelo de gestión financiera con el objetivo de mejorar su rentabilidad.

En la investigación "Gestión Financiera y su Influencia en la Rentabilidad de las Empresas Comerciales del Rubro Abarrotes, Adscritas al Régimen General Del Impuesto a La Renta en La Ciudad De Huaraz - 2016", Universidad Nacional Santiago Antúnez de Mayolo, Perú (Castillo \& Rosales, 2017), plantean investigar de qué manera la gestión financiera influye en la rentabilidad de las empresas del Rubro Abarrotes, resaltando que el sector de comercio 
toma protagonismo al generar empleo a nivel nacional. La finalidad es establecer si contribuye de forma eficaz en la mejora gradual de la rentabilidad, dado que en la provincia de Ancash las empresas presentan índices bajos de producción y rentabilidad. El tipo de investigación es correlacional y su diseño es no experimental transversal. En esta investigación, la muestra está conformada por doce empresas comerciales del rubro abarrotes los cuales si cumplen con el requisito establecido para el estudio. Las técnicas utilizadas son la entrevista y el análisis de datos siendo su instrumento la guía de entrevista y la ficha de registros de datos. La conclusión de esta investigación denota que, si existe influencia efectiva y positiva en la rentabilidad económica; sin embargo, debe evaluarse las decisiones que repercuten en la rentabilidad financiera, ya que a pesar de poder hacer frente a sus pagos a corto plazo la empresa presenta un alto nivel de endeudamiento patrimonial.

En la investigación "Aplicación de la Gestión Financiera en la Rentabilidad de la Empresa de Servicios Ronafe S.A.C. En El Distrito De Jesús María, Del Período 2016-2018", Universidad Tecnológica del Perú, Perú (Fernández, Naquiche, \& Rojas, 2018), proponen determinar de qué manera influye la gestión financiera en la rentabilidad de la empresa Ronafe S.A.C, debido a que la gestión que se viene realizando no es la adecuada, lo cual conlleva a reflejarse en las pérdidas de los estados financieros. El tipo de investigación es descriptivo siendo un diseño no experimental longitudinal. La muestra de estudio está conformada por 10 colaboradores que forman parte de las áreas de gerencia general y dirección financiera de la Empresa Ronafe S.A.C. Las técnicas utilizadas son la encuesta y el análisis documental con sus respectivos instrumentos, el cuestionario y la declaración jurada anual junto a libros contables. La conclusión de esta investigación revela que la empresa presenta elevados gastos administrativos y al contar con poca liquidez se ve en la obligación de recibir constantes préstamos de su casa matriz para afrontar sus pagos con los acreedores. Asimismo, en la investigación recomiendan que se deba analizar las remuneraciones de los trabajadores para conocer si realmente existe efecto de contraprestación entre el colaborador y la empresa.

En la investigación "Gestión Financiera y su Influencia en la Rentabilidad de la Empresa Industrias Del Perno S.A.C, Periodo 2017", Universidad Privada del Norte, Perú (Castañeda \& Reyes, 2019), proponen determinar si la gestión financiera influye en la rentabilidad de la empresa, debido a que en los últimos años se suscita una baja rentabilidad en la compañía. Por tanto, siendo indispensable precisar si existen deficiencias en la gestión financiera para así implementar estrategias que mejoren la rentabilidad. El tipo de investigación es descriptivo, 
correlacional y explicativo con un diseño de estudio no experimental transversal debido a la recolección de datos en un momento determinado. La muestra estuvo compuesta por 5 colaboradores de la empresa encargados del área administrativa, contable y gerencial. Las técnicas utilizadas son la encuesta y el análisis de documentos contables y financieros, como instrumento se usó un cuestionario y la guía de análisis financiero, además de la entrevista abierta. La conclusión de la investigación señala que la falta de planificación financiera y la inadecuada gestión financiera influyen de manera negativa en la rentabilidad, el $80 \%$ de los encuestados responde que no utilizan herramientas para evaluar la situación económica, por lo que es indispensable realizar esta acción.

\subsubsection{Marco Teórico.}

\subsubsection{Gestión Financiera.}

\subsection{Definición de gestión financiera.}

Córdova (2012), citado por Fernández, Naquiche y Rojas (2018), indica que la gestión financiera abarca todos los procesos concernientes a los ingresos, egresos y a las actividades económicas de la organización para poder gestionar los recursos, el dinero y la rentabilidad financiera de la empresa, teniendo como principal función el adquirir recursos para invertirlos, buscando métodos de financiamiento y poder administrarlos. También es considerada la administración general una forma de economía aplicada, que tiene como principal función maximizar el patrimonio de la organización por medio de una correcta gestión y aplicación de: recursos financieros por aporte de capital, financiamiento, capital de trabajo e inversiones, permitiendo así que las empresas puedan administrar eficientemente sus recursos y tomar decisiones acertadas a corto y largo plazo.

Meredith (1986), citado por Karadag (2015), indica que la gestión financiera es el centro del éxito de cualquier pequeña o mediana empresa. Esta definición enfatiza el papel central y la posición de la gestión financiera en relación con las otras áreas específicas de la gestión empresarial, refiriéndose a todas las áreas de gestión que implican finanzas, no solo las fuentes y usos de las finanzas de la empresa, sino también las implicaciones financieras de las decisiones de inversión, producción, comercialización y el desempeño total de la empresa. 
Terrazas (2009), citado por Cherres (2016), define a la gestión financiera como la actividad que se encarga de planificar, organizar, dirigir, controlar, monitorear y coordinar la gestión de los recursos financieros con la finalidad de garantizar mayores beneficios para la empresa. El objetivo de la gestión financiera es que, mediante el uso adecuado de los recursos financieros, la empresa se pueda desenvolver con efectividad, apoyar a la toma de decisiones financieras y aprovechar las oportunidades de inversión más rentables para la empresa.

Apaza (2009), citado por Esteba (2016), señala que la gestión financiera puede ser un factor fundamental para las pequeñas y medianas empresas, puesto que les permiten madurar y mantenerse en el mercado. La gestión financiera consiste en efectuar las inversiones correctas en los activos fijos a largo plazo, donde la gestión debe abarcar la planificación y control de dichas inversiones, de forma que se evite la infrautilización de éstas y poder controlar la rentabilidad generada por las mismas e intentando optimizarlas.

Lisovskaya (2006), citado por Khominich, Rybyantseva, Borodacheva, Dik y Afanasev (2016), define a la gestión financiera como la administración eficiente de los recursos que posee una empresa para garantizar que estos sean capaces de cubrir los gastos y que puedan funcionar de manera eficaz, donde su propósito es buscar formas de maximizar la efectividad de los recursos financieros. El concepto de gestión financiera también se define como un sistema de principios y métodos para el desarrollo e implementación de decisiones gerenciales asociadas con la formación, distribución y uso de los recursos para garantizar el tamaño y la estructura necesaria de los activos de acuerdo con las metas y objetivos de la empresa.

\subsection{Componentes de la gestión financiera.}

Según Solomón (1963), citado por Esteba (2016), los componentes de la gestión financiera son:

a) La gestión financiera en relación con los proveedores.

La gestión financiera es la administración de los recursos económicos y los fondos de capital de una empresa abarcando las acciones de planificación y control de la función financiera. Por ello, la gestión financiera refleja la importancia de una eficiente planificación y control de los recursos económicos y los fondos de capital en relación con los proveedores.

b) La gestión financiera en relación con los clientes 
La gestión financiera a largo plazo abarca la elección, diseño y planificación de estrategias, políticas, objetivos, acciones y mecanismos de control, con el fin de efectuar inversiones en los activos que se necesiten para mantener la actividad económica de la empresa rentable, utilizando fuentes de financiamiento que optimicen el costo de capital y generando valor agregado para los inversionistas; con respecto a corto plazo, la gestión financiera abarca las problemáticas que puedan surgir relacionadas al capital de trabajo de la empresa. Por ello, la gestión financiera refleja la importancia de una eficiente planificación y control de los recursos económicos y los fondos de capital en relación con los clientes.

c) La gestión financiera en relación con los entes financieros

La gestión financiera abarca todos los procesos relacionados a adquirir, conservar y utilizar el dinero de la empresa, convirtiendo la visión, misión y objetivos en operaciones monetarias con el fin de mantener una operación eficiente y rentable. Por ello, la gestión financiera refleja la importancia de una eficiente planificación y control de los recursos económicos y los fondos de capital en relación con las entidades financieras.

\subsection{Funciones de la gestión financiera.}

Según Ortiz (2013), citado por Llempen (2018), las funciones de la gestión financiera dentro de una empresa son las siguientes:

- Determina las necesidades de los recursos financieros, realizando un análisis y planteamiento de las necesidades, revisión de los recursos que están disponibles, pronóstico de los recursos liberados y deducir las necesidades de financiación externa.

- Obtener un financiamiento de la fuente más rentable y beneficiosa, teniendo en cuenta los costos y plazos.

- Obtener una estructura financiera eficiente y equilibrada, siendo rentable para la empresa

- Analizar los estados financieros, recolectando información de manera integral de todas las áreas de la empresa.

- Analizar la viabilidad económica y financiera de las inversiones. 


\subsubsection{Prácticas de la gestión financiera.}

\subsection{Definición de las prácticas de la gestión financiera.}

Según Musah, Dodzi-Gakpetor y Pomaa (2018), indican que las prácticas de gestión financiera incluyen todos los aspectos de la gestión que afectan a las finanzas de una empresa y lo que se necesita para lograr el objetivo general de la organización. Esto incluye la gestión del capital de trabajo, la gestión financiera a largo plazo, la gestión de la estructura de capital, la información contable y las prácticas de informes financieros, la elaboración de presupuestos de capital, entre otros.

Moore y Reichert (1989), citado por Macharia (2015), define a las prácticas de gestión financiera como las acciones realizadas por el área contable de una empresa, el director financiero y otros gerentes de las áreas de presupuesto, de gestión de la cadena de suministro, de gestión y control de activos. Las prácticas de gestión financiera utilizadas son: los sistemas de información contable, financieros informes y análisis, gestión del capital de trabajo, gestión de activos fijos y gestión de estructura de capital. Todas estas prácticas son cruciales para una gestión financiera eficiente en las organizaciones.

Chandra (2011), Kilonzo y Ouma (2015) citado por Musah, Dodzi-Gakpetor y Pomaa (2018), indican que el término prácticas de gestión financiera se utiliza para representar la gestión de fondos y cómo se utilizan los fondos para lograr los objetivos de la organización y la maximización del valor de los accionistas.

Lasher (2010), citado por Mwangi (2018), denominan a la práctica de gestión financiera como una disciplina que se ocupa de cómo las organizaciones toman decisiones relacionadas con diversos aspectos financieros y en los instrumentos utilizados para alcanzar un rendimiento óptimo; es decir, es el proceso de adquisición de recursos financieros enfocados en mejorar el rendimiento financiero de las empresas.

Byoun (2010), citado por Mwangi (2018), definen a las prácticas de gestión financiera como todos los aspectos relacionados a los movimientos y control del dinero de todas las transacciones comerciales realizadas por la empresa. Se relaciona con la gestión y el uso óptimo de los recursos financieros para las oportunidades actuales y futuras con el fin de mejorar las operaciones financieras. 


\subsection{Dimensiones de las prácticas de la gestión financiera.}

Según Musah, Dodzi-Gakpetor y Pomaa (2018), detalla que las prácticas de gestión financiera cuentan con 4 principales dimensiones que influyen en la rentabilidad, que son las siguientes:

\section{Prácticas de gestión del capital de trabajo.}

Se define como la inversión de una empresa en activos a corto plazo (efectivo, valores a corto plazo, cuentas por cobrar e inventarios). El excedente de activos corrientes sobre pasivos corrientes se conoce como capital de trabajo neto y muestra la capacidad de la empresa para cumplir con sus obligaciones financieras en corto plazo. La idea del capital de trabajo es considerada como los recursos que necesita la empresa para poder continuar con sus actividades comerciales. El capital de trabajo es esencial para que cualquier empresa tenga éxito, es por ello que mantienen un capital de trabajo adecuado para el buen funcionamiento del negocio. Se cree que cuando el capital de trabajo es inadecuado, los activos fijos no se pueden utilizar de manera eficiente y efectiva.

\section{Sistema de información contable - práctica de análisis de informes financieros.}

El sistema de información contable es un sistema de registros generalmente basado en computadora, que combina los principios y conceptos contables con los beneficios de un sistema de información y que se utiliza para analizar y registrar transacciones de la empresa con el propósito de preparar estados financieros y proporcionar datos contables a sus usuarios. El sistema de información contable ayuda en el análisis de información contable proporcionada por los estados financieros.

En las empresas, los informes financieros se refieren a la utilización de la información financiera, la cual es obtenida regularmente por las empresas en forma de estados financieros tradicionales (balances, estados de ganancias y pérdidas, estados de fondos, entre otros), el resto son conciliación bancaria y resúmenes operativos. La contabilidad sola sin preparar informes contables y financieros probablemente no sea fundamental para ayudar a la toma de decisiones a menos que se preparen y analicen informes adecuados para atribuir un significado que ayude a los responsables a la toma de decisiones en beneficio a la empresa. 


\section{Gestión de estructura de capital - financiamiento.}

La gestión de la estructura de capital se define en cómo una empresa puede financiarse con capital propio o con financiamiento externo. En otras palabras, la estructura de capital está compuesta por la deuda a largo plazo y el capital utilizado para financiar las actividades económicas de la empresa. Para determinar si la estructura de capital de una empresa es óptima, se debe analizar qué porcentaje del flujo de efectivo del negocio corresponde a los accionistas y que porcentaje corresponde a los prestamistas.

La gestión de la estructura de capital es una de las acciones empresariales más críticas, ya que puede influir en gran medida en el crecimiento y la supervivencia de las empresas, dado que todas las decisiones financieras apuntan a maximizar la riqueza, es por ello que se debe evaluar los efectos que puede tener el financiamiento en la estructura de capital de la empresa, y como esta afecta en el desempeño de la empresa.

\section{Presupuesto de capital - gestión de activos no corrientes.}

Las decisiones de presupuesto de capital tienen que ver con disponer capitales o fondos para una empresa por un período de tiempo extendido más allá de un año y puedan tener un efecto en la posición estratégica dentro de su industria. El presupuesto de capital también es definido como la capacidad que tiene una empresa para realizar inversiones de activos no corrientes (activos fijos) con el fin de obtener utilidades a largo plazo por las inversiones realizadas.

Las decisiones de presupuesto de capital son muy cruciales para el crecimiento y la supervivencia de las empresas, es importante que los responsables de la toma de decisiones comprendan cómo evaluar los proyectos de manera apropiada para que puedan tomar decisiones adecuadas sobre qué proyectos tomar y cuáles descartar.

1.2.2.2.3. Teorías relacionadas a las prácticas de la gestión financiera.

Teoría del Ciclo de Crecimiento Financiero de Berger y Udell (1998), citado por Lázaro (2016).

El modelo planteado por Berger y Udell (1998) tuvo como objetivo analizar la relación entre la estructura financiera y el ciclo de vida de una empresa, dicha teoría considera que la estructura de capital va cambiando según la etapa de ciclo de vida en la que se encuentre la 
empresa, puesto que la disponibilidad de financiamiento va a depender de la edad y tamaño de esta.

Los autores indicaron que en la etapa inicial de una empresa nueva o pequeña normalmente recurren al financiamiento interno porque presentan restricciones de financiamiento; el cual va a disminuir con el paso del tiempo; a medida que la empresa crece se va fortaleciendo y aumentando su tamaño y se ven en la necesidad de acudir a fuentes de financiamiento externos (bancarios) o al capital de riesgo. La teoría hace énfasis en la asimetría informativa como un factor determinante ya que las empresas van madurando y ganando experiencia originando una disminución en la carencia de información, lo cual origina cambios en sus necesidades financieras y sus fuentes de financiamiento.

Berger y Udell pudieron concluir con esta teoría, que el ciclo de vida de una empresa es de suma importancia para poder entrar al sistema financiero, ya que conforme va creciendo la empresa, se le va abriendo las fuentes de financiamiento disponibles en el mercado y se van disminuyendo las restricciones financieras, lo cual les ayudará a aumentar su apalancamiento y así ir mejorando su estructura financiera.

\section{Teoría de Modigliani Y Miller (1958), citado por García (2019).}

Esta teoría fue presentada en 2 propuestas por Modigliani, F. \& Miller, M. (1958) sosteniendo lo siguiente: el apalancamiento y la política de dividendos no guarda relación con el valor de la empresa; esto dependerá de la capacidad de la empresa en aumentar su valor sin que tome en consideración la estructura financiera. La otra propuesta fue planteada en (1963) y sostuvo lo contrario a la 1 propuesta: Tuvieron como principal objetivo analizar la estructura financiera de una empresa y como está influía en el valor de la misma, considerando los impuestos y los costos de quiebra, los cuales no habían sido considerados en la primera proposición; siendo factores importantes en la estructura financiera de una empresa, este supuesto indica que la empresa que cuente con deuda tendrá un beneficio tributario, puesto que los pagos de intereses de una deuda son deducibles de los impuestos; bajo este supuesto plantearon el siguiente modelo:

$$
V L=V U+T^{*} D(R D)
$$


Donde:

$\checkmark$ VL: Valor de la empresa apalancada.

$\checkmark$ VU: Valor de la empresa sin apalancamiento

$\checkmark$ T: Impuestos

$\checkmark \quad D(R D)$ : Intereses generados de la deuda (escudo fiscal)

En dicho modelo se puede reflejar que una adecuada estructura financiera puede lograr maximizar el valor de mercado de una empresa y minimizar el costo de capital; considerando que el gasto financiero reduce el pago de impuestos y así disminuye la responsabilidad fiscal de una empresa, de esta manera aumenta el valor de una empresa que tiene deuda en comparación de una sin deuda y esto motiva a las empresas a buscar una deuda óptima y aprovechar el escudo fiscal que se deriva de los pagos de los intereses de una deuda.

\section{Teoría de la Estrategia Corporativa Brander y Lewis (1986) citado por García (2019).}

La presente teoría fue presentada por Brander y Lewis (1986) y nos indica que las estrategias empresariales tienen una influencia sobre la estructura de capital, donde las decisiones financieras y de producción afectan la estructura financiera de la empresa, es decir cuando una empresa tiene más deuda, busca la manera de implementar estrategias dentro de su negocio, para que esté sea más rentable y le genere más retorno a la inversión, en muchos casos las empresas pequeñas utilizan la deuda como un enfoque estratégico, en la cual se comprometen más con su negocio y se enfocan en una producción agresiva para poder afrontar la deuda y generar una buena rentabilidad, en la cual forma un papel determinante: las variaciones de las ventas y la participación en el mercado.

Los autores en su modelo plantearon diferentes estrategias empresariales y como estas influyen en la estructura financiera, por ejemplo: la estrategia de diversificación y diferenciación incentiva a los prestamistas a otorgar créditos a la empresa que lo implementa, ya que incrementa la probabilidad de retorno del crédito y así los prestamistas perciben un bajo riesgo; en el caso de la estrategia de innovación implica un mayor riesgo en comparación con las otras estrategias, puesto que si no se realiza una adecuada investigación de mercado, dicha innovación puede llegar a ser un fracaso, generando así un alto riesgo para el prestatario y el prestamista; esto genera que al tener un alto riesgo se tendrá un menor endeudamiento y las entidades financieras no optarán fácilmente en cederles un crédito por el alto riesgo, ya que el 
retorno esperado por el préstamo no será tan seguro; por otro lado están las estrategias de liderazgo, las cuales reflejan una mejor imagen frente a los prestamistas, ya que suelen tener ventajas competitivas, una mejor gestión empresarial y productiva, esto le abre las puertas para poder aumentar un nivel de endeudamiento, ya que los prestamistas perciben un bajo riesgo y un mayor retorno de la inversión.

Los autores pudieron concluir con esta teoría, que la estructura de financiamiento que tiene una empresa depende mucho de las estrategias que implementen dentro de su negocio, porque de eso depende de si necesitan aumentar su endeudamiento o si se abastecen con sus recursos propios; también depende de ello la percepción que tienen los prestamistas para otorgarles créditos a las empresas.

\subsubsection{Rentabilidad.}

\subsection{Definición de la rentabilidad}

Grayson, Nyamazana y Funjika-Mulenga (2016), definen la rentabilidad como una condición de las empresas para obtener utilidades y ganancias, los autores consideran que adoptar medidas de gestión conduce a garantizar un mejor rendimiento en los resultados de la empresa.

Gitman (1992), citado por Minaya (2019), indica que la rentabilidad permite analizar las ganancias con respecto a los recursos utilizados en un periodo de tiempo, siendo una medida que enlaza los rendimientos obtenidos con las ventas, activos y capital, donde la importancia radica que para que una empresa se mantenga en la industria es necesario producir utilidades, por ende, la rentabilidad se vincula con el riesgo y si una empresa quiere aumentar su rentabilidad debe aumentar el riesgo y al contrario si quiere disminuir el riesgo debe disminuir su rentabilidad.

Sánchez (2002), citado por Castañeda y Reyes (2019), define a la rentabilidad como la relación entre los ingresos y costos generados en la utilización de los recursos que posee la empresa con el fin de obtener resultados positivos, la rentabilidad se conoce también como el rendimiento que producen los capitales en un periodo de tiempo. La rentabilidad también es considerada como uno de los objetivos que se plantea una empresa para conocer el 
rendimiento obtenido por las inversiones realizadas en las acciones económicas de la empresa.

Zamora (2008), citado por Michue (2015), define a la rentabilidad como la relación que existe entre la utilidad y la inversión que se necesitó para obtenerla, la cual permite medir la efectividad del funcionamiento de una empresa siendo reflejada en las utilidades obtenidas por las ventas y la utilización de inversiones. La rentabilidad que se obtiene es debido a una adecuada planeación de costos y gastos y a una administración efectiva.

Guiltinan y Gordon (1984), citado por Rincón (2016), indica que la rentabilidad permite conocer la eficiencia general del manejo de la gerencia en una empresa, lo cual se puede ver reflejado en las utilidades generadas de las ventas y el uso correcto de los recursos; en otras palabras, la rentabilidad se define como la inversión de una empresa.

Baca (1987), citada por Rincón (2016), definen a la rentabilidad como un enfoque en la inversión de capital, es determinada por la tasa mínima esperada del margen de ganancia que tiene una empresa sobre la cantidad de capital que ha sido invertido en una operación o en la empresa.

\subsection{Tipos de rentabilidad.}

Según Sánchez (2002), citado por Castañeda y Reyes (2019), los tipos de rentabilidad son los siguientes:

a) Rentabilidad Financiera (ROE):

El ROE proviene del término Return on Equitty, el cual significa retorno sobre el patrimonio. La rentabilidad financiera mide la posibilidad que tienen los fondos propios para generar beneficios; en otras palabras, es la rentabilidad de los accionistas, ya que se busca conocer el retorno que obtienen los propietarios. Esta ratio permite determinar la rentabilidad obtenida con respecto al patrimonio con el que cuenta una empresa, dando a conocer el rendimiento que se genera por cada sol invertido en el capital de la empresa, donde se refleja la importancia que debe tener el patrimonio dentro de una empresa para generar beneficios. 


$$
R O E=\frac{\text { Resultado del ejercicio }}{\text { Fondos propios }} \times 100
$$

b) Rentabilidad Económica (ROI):

El ROI proviene del término Return on Investment. La rentabilidad económica mide la posibilidad de los activos totales en generar beneficios sin considerar la manera y el costo del financiamiento; es decir, relaciona el activo total con el beneficio antes de intereses e impuestos. Esta ratio permite determinar la rentabilidad generada producto de una inversión y analizar cuáles inversiones están generando beneficio y cuáles no; el ROI permite a las empresas poder determinar qué inversiones deben realizarse y cuál es el retorno de cada una.

$$
R O I=\frac{\text { Resultado de explotación }}{\text { Total Activo }} \times 100
$$

\subsection{Teorías relacionadas a la rentabilidad.}

Teoría de la rentabilidad y del riesgo en el modelo de Markowitz (1952), citado por Serrano (2015).

Según Markowitz (1952), sostiene que el inversor debe diversificar su inversión entre diferentes opciones; es decir, deben invertir en varios activos y no solo uno, con el fin de detectar cual ofrece el menor riesgo mientras se mantiene la rentabilidad esperada; esta teoría se basa en que el rendimiento real de una cartera refleja un valor aproximado a la rentabilidad media esperada, donde la cartera con una máxima rentabilidad tiene un nivel de riesgo bajo; es por ello que esta teoría enfatiza que el inversor puede aumentar su rentabilidad esperada con una cartera con el nivel de riesgo alto o puede disminuir su riesgo asumiendo una rentabilidad esperada baja.

La teoría de Markowitz se basa en el grado de aversión al riesgo y el grado de maximización de rentabilidad que espera un inversor y se pueden agrupar en los siguientes grupos:

-Adversos al riesgo: Elección de la inversión con el menor riesgo frente a dos opciones con el mismo nivel de rentabilidad. 
-Propensos al riesgo: Elección de la inversión con el mayor riesgo frente a dos opciones con el mismo nivel de rentabilidad.

-Neutrales al riesgo: El inversor no toma en consideración el riesgo de las inversiones, se mantiene indiferente en la elección entre dos opciones con el mismo nivel de rentabilidad.

Markowitz sostiene que el factor clave para contar con un portafolio óptimo es la diversificación, donde se busca la mejor relación entre el riesgo y rendimiento esperado; es por ello la importancia de invertir en más de un activo, lo cual ayuda a reducir el nivel de riesgo; cabe mencionar que el riesgo nunca se elimina por completo, puesto que hay factores macroeconómicos que influyen en las empresas originando que siempre haya riesgo para las inversionistas. Pero, se debe tener en consideración que la inversión en el número de activos no debe ser excesiva, ya que puede resultar difícil de gestionar, produciendo un mayor riesgo para las inversiones realizadas.

El modelo manifiesta que el riesgo que se mantiene a pesar de la diversificación, es conocido como riesgo sistemático (aplicable a las fuentes de riesgo de todo el mercado); mientras que el riesgo no sistemático se puede eliminar mediante la diversificación.

Teoría de la Rentabilidad y del Riesgo en el Modelo de Mercado de Sharpe (1963), citado por Serrano (2015).

Sharpe manifiesta que el modelo de Markowitz era dificultoso para el cálculo de todas las covarianzas existentes entre cada pareja de títulos; por dicho motivo, Sharpe buscaba simplificar el modelo de Markowitz, para lo cual estableció un modelo donde se debe relacionar el desarrollo de la rentabilidad de cada activo financiero con un determinado índice bursátil.

El modelo de Sharpe establece una relación entre el rendimiento de cada activo financiero con un determinado índice, donde el comportamiento del índice afecta dicho rendimiento, lo cual origina el modelo de regresión simple. Mediante este modelo Sharpe establece una fijación de precios de los activos financieros, donde un inversionista puede elegir el nivel de riesgo a través de una combinación de una cartera de renta variable y los valores de renta fija.

La presente teoría tiene como objetivo principal determinar la rentabilidad y el riesgo de cada activo financiero, así como determinar un indicador que permita medir dicho riesgo donde el modelo establece que el rendimiento del activo financiero es una función lineal del 
rendimiento de la cartera de mercado, también establece una descomposición del riesgo total del activo y de la cartera, así como una clasificación de los títulos y carteras en relación con su rendimiento esperado.

En este modelo no se toma en consideración el riesgo no sistemático, ya que este se reduce por medio de la diversificación, solo se toma en consideración el riesgo sistemático, lo que quiere decir que debe existir una relación creciente entre el riesgo y el rendimiento esperado de los activos, donde a mayor riesgo mayor rendimiento.

\subsubsection{Empresas fabricantes de calzado en Perú.}

El Instituto de Comercio Exterior (2019), indica que Perú es el cuarto mayor productor de calzado de América del Sur, por detrás de Brasil, Argentina y Colombia. El consumidor peruano compra alrededor de 2.5 pares de calzado al año, un promedio bajo en comparación a otros países; sin embargo, se prevé que las ventas de calzado aumenten para los próximos años, se espera que las ventas de moda y calzado llegue a los 4.024 millones de soles.

Según la Sociedad Nacional de Industrias (SNI), citado por el Instituto de Comercio Exterior (2019), sostiene que existen 3,669 empresas del rubro de fabricantes de calzado en Perú al 2018, las cuales están divididas de la siguiente manera:

$\checkmark$ Microempresas: Su fabricación promedio es inferior a 40 pares por día y representan el $88 \%$ de las empresas existentes de calzado y su producción representa el $24 \%$

$\checkmark$ Empresas pequeñas: Su fabricación promedio son 250 pares por día y representan el $36 \%$ de producción.

$\checkmark$ Empresas medianas: Su fabricación promedio son 700 pares por día y representan el 40\% de la producción.

Con respecto a la distribución geográfica del sector de calzado, está compuesto por 3 principales ciudades: Lima, Trujillo y Arequipa, donde Lima tiene una participación del 60\%, Trujillo el 20\% y Arequipa con el 15\%.

El ministerio de producción detalla los tipos de calzado fabricados en Perú, la producción del 2017 - 2018 y como ha sido su evolución: 


\begin{tabular}{|lrrr|}
\hline $\begin{array}{l}\text { PRODUCCIÓN DE CALZADO EN PERÚ } \\
\text { En número de pares } \\
\text { Tipo de calzado }\end{array}$ & 2017 & 2018 & Evolución \\
\hline Zapatos & 1.228 .583 & 1.181 .265 & $-3,9 \%$ \\
\hline Zapatillas & 8.238 .266 & 2.482 .259 & $-69,9 \%$ \\
\hline Botas, botines & 3.129 .530 & 2.932 .785 & $-6,3 \%$ \\
\hline Sandalias & 1.140 .564 & 957.748 & $-16,0 \%$ \\
\hline Total & 13.736 .942 & 7.554 .057 & $-45,0 \%$ \\
\hline
\end{tabular}

Figura 1. Producción del Calzado en Perú

Fuente: El Instituto de Comercio Exterior (2019)

Por otro lado, el Instituto Nacional de Estadística e Informática (2018), citado por El Instituto de Comercio Exterior (2019), indica que la fabricación de calzado en Perú se destina al consumo final, donde el mayor consumo de calzado radica en la demanda interna como se puede visualizar en la figura de líneas abajo:

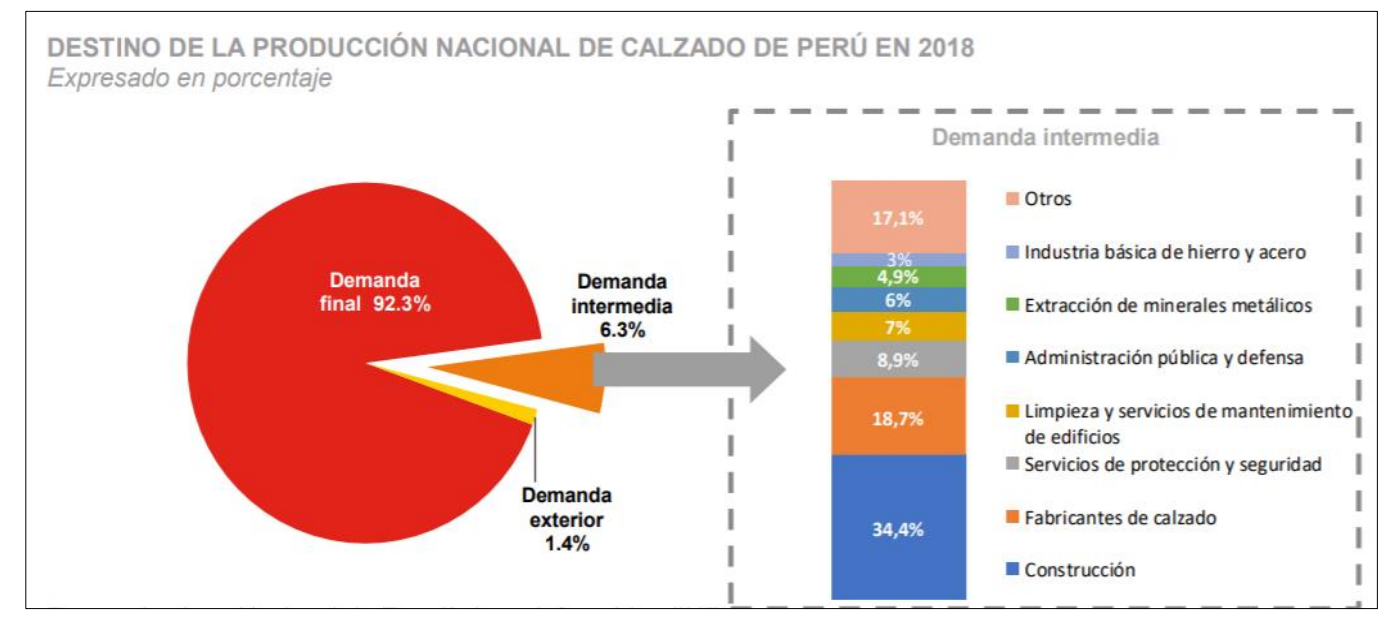

Figura 2. Destino de la producción nacional de calzado de Perú en 2018 Fuente: El Instituto de Comercio Exterior (2019)

Según un estudio del portal de ventas online Linio, citado por el Instituto de Comercio Exterior (2019), señala que el precio promedio por un par de zapatos en los países de Latinoamérica es de 48.76 dólares y en el Perú el precio promedio es de 46.15 dólares, levemente por debajo del precio promedio de Latinoamérica. 


\begin{tabular}{|c|c|c|c|c|c|c|c|c|}
\hline $\begin{array}{l}\text { PRECIO MEDIO } \\
\text { Expresado en US }\end{array}$ & EL CALZAD & N PAI & SES DE LAT & NOAMÉRIC & & & & \\
\hline Tipo de calzado & Argentina & Chile & Colombia & Ecuador & México & Perú & Panamá & Promedio \\
\hline Zapatillas blancas & 71,57 & 34,68 & 33,24 & 44,98 & 55,22 & 63,40 & 38,62 & 48,82 \\
\hline Bailarinas negras & 49,46 & 49,96 & 19,96 & 43,98 & 33,51 & 37,44 & 35,28 & 38,51 \\
\hline Sandalias altas & 52,11 & 34,20 & 19,53 & 60,98 & 46,28 & 26,17 & 48,62 & 41,13 \\
\hline Botines & 129,75 & 57,82 & 34,64 & 84,98 & 44,09 & 57,58 & 57,28 & 66,59 \\
\hline Promedio & 75,72 & 44,16 & 26,84 & 58,73 & 44,78 & 46,15 & 44,95 & 48,76 \\
\hline
\end{tabular}

Figura 3. Precio medio del calzado en Países de Latinoamérica 2018 Fuente: El Instituto de Comercio Exterior (2019)

Según la Superintendencia Nacional de Aduanas y de Administración Tributaria (2019), señala que los 3 principales distritos que concentran la mayor cantidad de fabricantes de calzado son: Comas, San Juan de Lurigancho y San Martín de Porres.

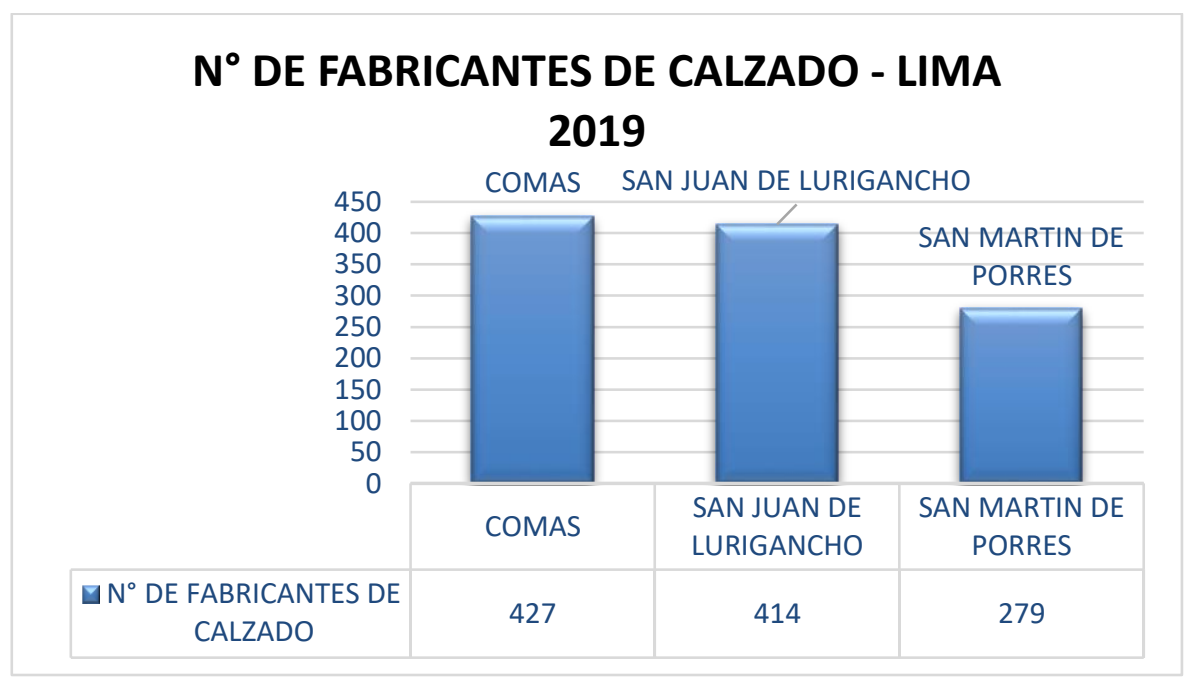

Figura 4. Número de fabricantes de calzado en los 3 principales distritos Fuente: SUNAT (2019) Elaboración propia 


\subsubsection{Mypes.}

\subsection{Definición de Mypes.}

Según La Superintendencia Nacional de Aduanas y de Administración Tributaria (2019), define a la Mype como una unidad económica que puede estar constituida por una persona natural o persona jurídica con el fin de desarrollar diversas actividades comerciales.

A continuación, se muestra las características de las micro y pequeñas empresas según SUNAT (2019).

\section{Tabla 1 \\ Características de la Microempresa}

\begin{tabular}{cc}
\hline \multicolumn{3}{c}{ MICROEMPRESA } \\
\hline $\begin{array}{c}\text { Número de trabajadores } \\
\text { Ventas Anuales }\end{array}$ & De 1 a 10 máx. \\
& $\begin{array}{c}\text { Monto máximo de 150 Unidades } \\
\text { Impositivas Tributarias (UIT) }\end{array}$ \\
\hline
\end{tabular}

Fuente: SUNAT (2019)

Elaboración propia

Tabla 2

Características de la Pequeña empresa

PEQUEÑA EMPRESA

\begin{tabular}{cc}
\hline Número de trabajadores & De 1 a 100 máx. \\
Ventas Anuales & Monto máximo de 1700 Unidades \\
& Impositivas Tributarias (UIT)
\end{tabular}

Fuente: SUNAT (2019)

Elaboración propia

\subsection{Régimen laboral de la Micro y Pequeña Empresa.}

El desarrollo de la actividad empresarial contrae obligaciones laborales con aquellos trabajadores que presten sus servicios a las Mypes; por esta razón existen beneficios que se otorgan a los colaboradores de las empresas.

A continuación, se muestra el régimen laboral de la Mype según SUNAT (2019) . 
Tabla 3

Beneficios otorgados por las Mypes.

\begin{tabular}{|c|c|c|}
\hline BENEFICIOS & MICROEMPRESA & PEQUEÑA EMPRESA \\
\hline $\begin{array}{l}\text { Remuneración } \\
\text { (RMV) }\end{array}$ & Remuneración Mínima Vital & Remuneración Mínima Vital \\
\hline Jornada de trabajo & $\begin{array}{l}8 \text { horas diarias o } 48 \text { horas } \\
\text { semanales }\end{array}$ & $\begin{array}{l}8 \text { horas diarias o } 48 \text { horas } \\
\text { semanales }\end{array}$ \\
\hline Descanso & $\begin{array}{l}\text { Descanso semanal y en } \\
\text { días feriados }\end{array}$ & $\begin{array}{l}\text { Descanso semanal y en días } \\
\text { feriados }\end{array}$ \\
\hline Vacaciones & $\begin{array}{l}\text { Descanso vacacional de } 15 \\
\text { días calendarios }\end{array}$ & $\begin{array}{l}\text { Descanso vacacional de } 15 \\
\text { días calendarios }\end{array}$ \\
\hline $\begin{array}{l}\text { Seguro Social de } \\
\text { Salud }\end{array}$ & $\begin{array}{l}\text { Cobertura de seguridad } \\
\text { social en salud a través del } \\
\text { SIS (Seguro Integral de } \\
\text { Salud) }\end{array}$ & $\begin{array}{l}\text { Cobertura de seguridad } \\
\text { social en salud a través del } \\
\text { ESSALUD }\end{array}$ \\
\hline $\begin{array}{l}\text { Indemnización por } \\
\text { despido injustificado }\end{array}$ & $\begin{array}{l}\text { Indemnización equivalente } \\
\text { a } 10 \text { días de remuneración } \\
\text { por año de servicios (con un } \\
\text { tope de } 90 \text { días de } \\
\text { remuneración) }\end{array}$ & $\begin{array}{l}\text { Indemnización equivalente a } \\
20 \text { días de remuneración por } \\
\text { año de servicios (con un tope } \\
\text { de } 120 \text { días de } \\
\text { remuneración) }\end{array}$ \\
\hline $\begin{array}{l}\text { Compensación por } \\
\text { Tiempo de Servicios }\end{array}$ & No & $\begin{array}{l}\text { Derecho a la Compensación } \\
\text { por Tiempo de Servicios } \\
\text { (CTS) equivalente a } 15 \text { días } \\
\text { de remuneración por año de } \\
\text { servicio con tope de } 90 \text { días } \\
\text { de remuneración. }\end{array}$ \\
\hline Gratificaciones & No & $\begin{array}{l}\text { Derecho a percibir } 2 \\
\text { gratificaciones al año de } \\
\text { medio sueldo cada una } \\
\text { (Fiestas Patrias y Navidad) }\end{array}$ \\
\hline $\begin{array}{l}\text { Seguro } \\
\text { Complementario de } \\
\text { Trabajo de Riesgo }\end{array}$ & No & $\begin{array}{l}\text { Cobertura de Seguro de Vida } \\
\text { y Seguro Complementario de } \\
\text { trabajo de Riesgo (SCTR) }\end{array}$ \\
\hline Utilidades & No & $\begin{array}{l}\text { Derecho a participar en las } \\
\text { utilidades de la empresa. }\end{array}$ \\
\hline
\end{tabular}

Fuente: SUNAT (2019)

Elaboración propia

\subsection{Objetivos e Hipótesis}

\subsubsection{Objetivos.}

- Objetivo General.

Determinar cómo se relacionan las prácticas de gestión financiera y la rentabilidad de los fabricantes Mypes de calzado de Comas 2020. 


\section{- Objetivos Específicos.}

- Determinar cómo se relacionan las prácticas de gestión del capital de trabajo y la rentabilidad de los fabricantes Mypes de calzado de Comas 2020.

- Determinar cómo se relaciona el sistema de información contable - práctica de análisis de informes financieros y la rentabilidad de los fabricantes Mypes de calzado de Comas 2020.

- Determinar cómo se relaciona la gestión de estructura de capital - financiamiento y la rentabilidad de los fabricantes Mypes de calzado de Comas 2020.

- Determinar cómo se relaciona el presupuesto de capital - gestión de activos no corrientes y la rentabilidad de los fabricantes Mypes de calzado de Comas 2020.

\subsubsection{Hipótesis.}

- Hipótesis General.

Las prácticas de gestión financiera se relacionan positivamente con la rentabilidad de los fabricantes Mypes de calzado de Comas 2020.

\section{- Hipótesis Específicas.}

- Las prácticas de gestión del capital de trabajo se relacionan positivamente con la rentabilidad de los fabricantes Mypes de calzado de Comas 2020.

- El sistema de información contable - práctica de análisis de informes financieros se relaciona positivamente con la rentabilidad de los fabricantes Mypes de calzado de Comas 2020.

- La gestión de estructura de capital - financiamiento se relaciona positivamente con la rentabilidad de los fabricantes Mypes de calzado de Comas 2020.

- El presupuesto de capital - gestión de activos no corrientes se relaciona positivamente con la rentabilidad de los fabricantes Mypes de calzado de Comas 2020. 


\section{Capítulo II}

\subsection{Método}

Para la presente investigación se utilizó el método cuantitativo; donde se empleó el cuestionario para la recolección de datos, las preguntas se relacionan con las variables que se plantearon en la investigación. De acuerdo con Hernández, Fernández y Baptista, señalan que el método cuantitativo "utiliza la recolección de datos para probar hipótesis con base en la medición numérica y el análisis estadístico, con el fin establecer pautas de comportamiento y probar teorías" (2014, p. 4), los autores sostienen que este método implica el uso del cuestionario y que las preguntas deben ser específicas con posibilidad de respuesta 0 categorías predeterminadas para poder ser analizadas estadísticamente.

Según Cadena-Iñiguez et al. (2017), mencionan que elegir el tipo de método es parte fundamental dentro del proceso de investigación; puesto que el método cuantitativo es aquel en donde se recopilan y analizan los datos cuantitativos para determinar el grado de asociación entre las variables.

\subsubsection{Tipo de Investigación}

El tipo de investigación es de alcance correlacional, debido al método de análisis cuantitativo. La finalidad del estudio es determinar el grado de relación que existe entre las variables planteadas (prácticas de gestión financiera y rentabilidad) e identificar si la correlación es positiva o negativa. Según Hernández et al. (2014), mencionan que este tipo de investigación tiene como objetivo conocer el grado de asociación o relación que hay entre dos o más variables en un determinado grupo o población.

\subsubsection{Diseño de Investigación}

El diseño de investigación que se emplea es no experimental de corte transversal, debido a que las variables no son manipuladas en beneficio de la investigación; la recolección de datos se realiza en un momento determinado y único para poder analizar la incidencia que ejerce entre una y otra variable. Acorde con Hernández, Fernández y Baptista explica que "EI diseño transversal tiene como propósito describir a las variables y analizar su incidencia e interrelación en un momento dado" (2014, p. 154). Por tanto, el diseño es adecuado para el análisis de la interrelación entre las variables de la investigación en un momento determinado. 


\subsubsection{Variables}

\section{Variable 1: Prácticas de gestión financiera}

Según Musah, Dodzi-Gakpetor y Pomaa (2018), indican que las prácticas de gestión financiera incluyen todos los aspectos de la gestión que afectan las finanzas de una empresa y lo que se necesita para lograr el objetivo general de la organización.

Dimensiones de las prácticas de gestión financiera: Según Musah, Dodzi-Gakpetor y Pomaa (2018), sostienen que la variable comprende 4 dimensiones:

$\checkmark$ Prácticas de gestión del capital de trabajo.

$\checkmark$ Sistema de información contable - práctica de análisis de informes financieros

$\checkmark$ Gestión de estructura de capital - financiamiento

$\checkmark$ Presupuesto de capital - gestión de activos no corrientes

Variable 2: Rentabilidad

Según Grayson, Nyamazana y Funjika-Mulenga (2016), definen la rentabilidad como una condición de las empresas para obtener utilidades y ganancias, los autores consideran que adoptar medidas de gestión conduce a garantizar un mejor rendimiento en los resultados de la empresa.

Dimensiones de la rentabilidad: Según los autores Grayson, Nyamazana, y FunjikaMulenga (2016) la variable rentabilidad se representa como unidimensional.

\subsubsection{Población}

Según los datos sustraídos de SUNAT (2019), Comas es el distrito que comprende la mayor cantidad de empresas dedicadas a la fabricación de calzado; por tanto, la población estuvo compuesta por 427 empresas.

A continuación, se describen los criterios de inclusión y exclusión que se consideraron para delimitar la población de acuerdo con el planteamiento de la investigación; como referencia se revisó el libro de Metodología de la Investigación, donde los autores Hernández et al. (2014), señalan que delimitar el universo o población es uno de los primeros pasos para evitar errores, sobre todo que los criterios establecidos cumplan con los objetivos del estudio. 
Criterios de inclusión:

$\checkmark$ Son incluidos las microempresas y pequeñas empresas que se encuentren inscritas y activas en Sunat con el código de Clasificación Industrial Internacionalmente Uniforme (CIIU) 1920, el cual describe la actividad económica de fabricación de calzado.

$\checkmark$ Son incluidos las Mypes fabricantes de calzado ubicados en el distrito de Comas Lima.

$\checkmark$ Son incluidos las Mypes fabricantes de calzado que aceptaron ser encuestadas como representantes de la empresa.

$\checkmark$ Son incluidos las Mypes fabricantes de calzado que tienen como representante de la empresa a gerentes o administradores con al menos 2 años en el cargo.

Criterios de exclusión

$\checkmark$ Son excluidos las empresas informales que realizan como actividad económica la fabricación de calzado y empresas que no estén registradas con el código de Clasificación Industrial Internacionalmente Uniforme (CIIU) 1920.

$\checkmark$ Son excluidas las medianas y grandes empresas fabricantes de calzado que se encuentran consignadas con el código de Clasificación Industrial Internacionalmente Uniforme (CIIU) 1920 que figuran en The Top 10,000 companies (2019)

$\checkmark$ Son excluidos las Mypes fabricantes de calzado que pertenecen a otros distritos de Lima.

$\checkmark$ Son excluidos los trabajadores que no tienen relación con la función de gerente o administrador dentro de las Mypes fabricantes de calzado. 
A continuación, se detalla la cantidad de contribuyentes registrados en Sunat según el distrito y actividad económica:

Tabla 4

Cantidad de contribuyentes registrados según Distrito y Actividad Económica.

\begin{tabular}{cccccc}
\hline Año & Provincia & Distrito & $\begin{array}{c}\text { Actividad } \\
\text { Económica }\end{array}$ & $\begin{array}{c}\text { Cod. } \\
\text { CllU }\end{array}$ & $\begin{array}{c}\text { Cantidad de } \\
\text { contribuyentes }\end{array}$ \\
\hline 2019 & Lima & Comas & $\begin{array}{c}\text { Fab. de } \\
\text { calzado }\end{array}$ & 1920 & 427 \\
\hline
\end{tabular}

Fuente: SUNAT (2019)

Elaboración propia

Como se mencionó anteriormente, en SUNAT (2019) se logró obtener el número de empresas formales, pero mediante la página The top 10,000 companies (2019) se determinó excluir a grandes y medianas empresas fabricantes de calzado, por lo que en este caso se encontró solo una mediana empresa dedicada a esta actividad en el distrito de Comas, en consecuencia, la población se conformó por 426 Mypes fabricantes de calzado.

\subsubsection{Muestra}

Para la presente investigación, se utilizó la muestra no probabilística por conveniencia. Según Hernández et al. (2014), refieren que una muestra no probabilística es el procedimiento de selección que está orientado a características de la investigación. De acuerdo con Kinnear y Taylor (1998), señalan que para el muestreo por conveniencia, la unidad o elemento de muestreo se autoselecciona o se procede a seleccionar con base a la libre disponibilidad de los mismos elementos, por tal razón se determinó seleccionar a 203 Mypes fabricantes de calzado en Comas con la finalidad de que respondieran el cuestionario, teniendo en consideración la recomendación que formula Hair, Anderson, Tatham y Black (1999), que para obtener una información confiable se requiere como mínimo 200 encuestas para que sea considerada como muestra representativa.

\subsubsection{Instrumentos de la Investigación}

El instrumento de investigación que se empleó fue el cuestionario; se aplicó a 203 fabricantes Mypes de calzado del distrito de Comas. El cuestionario se divide en dos partes para la recopilación de información; la variable "prácticas de gestión financiera" está 
compuesto por 24 preguntas (Anexo 2) y en la variable "rentabilidad" se establecieron 6 preguntas (Anexo 3).

$>$ Prácticas de gestión financiera

El cuestionario de la variable prácticas de gestión financiera comprende 24 ítems e incluye 4 dimensiones; la primera dimensión es prácticas de gestión del capital de trabajo (ítem 1 al 6), la segunda dimensión es sistema de información contable - práctica de análisis de informes financieros (ítem 7 al 12), la tercera dimensión es gestión de estructura de capital financiamiento (ítem 13 al 19) y la cuarta dimensión es presupuesto de capital - gestión de activos no corrientes (ítem 20 al 24). Las preguntas se distribuyeron adecuadamente con la escala de Likert; debido a que al sumar las puntuaciones de cada ítem se logra obtener la calificación final; las puntuaciones de la escala de Likert que se presentan en las preguntas corresponden de la siguiente manera: 1 "Muy en desacuerdo", 2 "En desacuerdo", 3 "Ni de acuerdo, ni en desacuerdo", 4 "De acuerdo" y 5 "Muy de acuerdo".

Tabla 5

Ficha técnica Cuestionario Prácticas de gestión financiera.

\begin{tabular}{ll}
\hline Nombre & Cuestionario de Prácticas de gestión financiera \\
Autor & Musah, Dodzi-Gakpetor y Pomaa \\
Procedencia & Republica de Ghana \\
Año & 2018 \\
Forma de Aplicación & Individual \\
Duración & 13 a 15 minutos \\
Versión & Original en inglés \\
Validadores & Dr. Braggi Bamberger Vargas \\
& Mag. Pedro Calderón Culque \\
& Mag. Farah Yzquieta Naveda
\end{tabular}

Elaboración propia

$>$ Rentabilidad

El segundo cuestionario corresponde a la variable rentabilidad y comprende de 6 ítems. Las preguntas se distribuyeron adecuadamente con la escala de Likert; debido a que al sumar las puntuaciones de cada ítem se logra obtener la calificación final; las puntuaciones de la escala 
de Likert que se establecieron en las preguntas corresponden de la siguiente manera: 1 "Muy en desacuerdo", 2 "En desacuerdo", 3 “Ni de acuerdo, ni en desacuerdo", 4 "De acuerdo" y 5 "Muy de acuerdo".

Tabla 6

Ficha técnica Cuestionario Rentabilidad. Nombre

Cuestionario de Rentabilidad

Autor Grayson, Nyamazana y Funjika-Mulenga

Procedencia Inglaterra

Año 2016

Forma de Aplicación Individual

Duración 8 a 10 minutos

Versión Original en inglés

Validadores

Dr. Braggi Bamberger Vargas

Mag. Pedro Calderón Culque

Mag. Farah Yzquieta Naveda

Elaboración propia

Los instrumentos que corresponden a las dos variables planteadas en esta investigación fueron validados mediante el juicio de 3 expertos, en este proceso de validación los jueces calificaron cada pregunta concerniente a las variables; las calificaciones fueron medidas por medio del coeficiente $V$ de Aiken, obteniendo como resultado un valor de 0.87 para la variable prácticas de gestión financiera (Anexo 4) y un valor de 0.91 para la variable rentabilidad (Anexo $5)$.

Por otro lado, se procedió a realizar el análisis de confiabilidad del instrumento con el Software SPSS 25, mediante el coeficiente Alfa de Cronbach se consiguieron resultados correspondientes para cada dimensión comprendidas dentro de la variable prácticas de gestión financiera, la dimensión prácticas de gestión del capital de trabajo fue de 0.871 (Anexo 6), para la dimensión sistema de información contable - práctica de análisis de informes financieros fue de 0.730 (Anexo 7), para la dimensión gestión de estructura de capital financiamiento fue de 0.836 (Anexo 8), para la dimensión presupuesto de capital - gestión de activos no corrientes fue de 0.902 (Anexo 9) y para la variable rentabilidad el Alfa de Cronbach fue de 0.872 (Anexo 10). 


\subsubsection{Procedimiento de recolección de datos}

Para la recolección de datos se utilizó un cuestionario por cada variable; el primero fue el cuestionario para la variable "Prácticas de gestión financiera" (Anexo 2) y el segundo cuestionario fue para la variable "Rentabilidad" (Anexo 3). Para determinar la muestra se utilizó el tipo de muestreo no probabilístico por conveniencia; los cuestionarios fueron respondidos por el gerente o administrador de las empresas fabricantes de calzado del distrito de Comas, cabe resaltar que solo una persona respondía el cuestionario para así obtener precisión en los datos.

Para lograr encuestar a 203 Mypes fabricantes de calzado en el distrito de Comas, primero se realizó una búsqueda en el directorio de empresas de la página de Citeccal y Datos Perú, asimismo se usó la página The top 10,000 companies (2019) para excluir a las medianas y grandes empresas, posterior a ello se realizó una base de datos para poder contactarlos vía telefónica, sin embargo no todas las empresas contestaron las llamadas y con las que se pudo contactar, se consultó la disponibilidad para responder el cuestionario, logrando así coordinar la visita en sus respectivas empresas, pero no todas accedieron a participar en la investigación, por lo que también se realizó trabajo de campo considerando la ubicación de las empresas que figuraban en la base de datos (Av. Víctor Andrés Belaunde y Av. Túpac Amaru del distrito de Comas), cada cuestionario tenía una duración siendo de 13 a 15 minutos aproximadamente para el cuestionario "Prácticas de gestión financiera" y de 8 a 10 minutos aproximadamente para el cuestionario "Rentabilidad" por cada empresa, por ende los cuestionarios se llevaron a cabo durante aproximadamente 2 meses, iniciando el 11 de Enero y finalizando el 06 de Marzo del 2020.

Después de concluir con la recolección de datos por medio de los cuestionarios, se prosiguió a tabular los cuestionarios en Excel, para luego procesar los datos en el Software SPSS 25 , se realizaron las pruebas estadísticas necesarias para poder contrastar con las hipótesis que se plantearon al inicio de la investigación

\subsubsection{Plan de Análisis}

Para la presente investigación se realizó un análisis descriptivo de cada variable: "Prácticas de gestión financiera" y "Rentabilidad". 
Para la validación del instrumento se utilizó el coeficiente de Aiken, donde se obtuvo como resultado un valor de 0.87 para la variable prácticas de gestión financiera (Anexo 4) y para la variable rentabilidad se obtuvo un valor de 0.91 (Anexo 5), donde se determinó que ambas variables tuvieron un puntaje óptimo para la validación.

Es importante mencionar que, en la investigación los resultados de las siguientes preguntas no fueron consideradas para las pruebas estadísticas.

- Pregunta codificada PGF8: Los estados financieros se preparan de acuerdo con los principios contables generalmente aceptados.

Motivo: En el Perú los Principios de Contabilidad Generalmente Aceptados están constituidos por las Normas Internacionales de Información Financiera.

- Pregunta codificada PGF9: Los estados financieros se publican regularmente.

Motivo: Las Mypes no tienen la obligación de publicar información de sus estados financieros.

- Pregunta codificada PGF17: La empresa tiene propiedad extranjera.

Motivo: Debido al tamaño de empresas (Mypes) no reciben inversión extranjera.

Con respecto a la confiabilidad de los instrumentos, se realizó un análisis del coeficiente de Alfa de Cronbach, el cual fue elaborado por cada variable, esta medición se realizó por cada dimensión de la variable "Prácticas de gestión financiera", ya que está compuesta por 4 dimensiones: Prácticas de gestión del capital de trabajo, Sistema de información contable práctica de análisis de informes financieros, Gestión de estructura de capital - financiamiento y Presupuesto de capital - gestión de activos no corrientes, se obtuvieron los siguientes resultados: 0.871 (Anexo 6), 0.730 (Anexo 7), 0.836 (Anexo 8) y 0.902 (Anexo 9) respectivamente; mientras que la variable "Rentabilidad" es unidimensional y se obtuvo como resultado 0.872 (Anexo 10). El análisis factorial se realizó mediante el estadístico de KaiserMeyer- Olkin (KMO), con el fin de reducir la dimensionalidad de los datos, identificando el número mínimo de dimensiones aptos para expresar toda la información obtenida. 
Se realizó la prueba de normalidad de Kolmogorov - Smirnov (Anexo 11 y 12) con el objetivo de determinar el tipo de distribución que posee cada una de las preguntas empleadas en los cuestionarios, donde los resultados demostraron contar con una distribución no paramétrica, para lo cual los autores Hernández et al. (2014) sugieren para la distribución no paramétrica, utilizar el coeficiente de correlación de Spearman cuando la investigación es correlacional y las variables son ordinales. Es por ello que se llevó acabo el análisis de las correlaciones de Rho de Spearman utilizando el Software estadístico SPSS 25 donde se obtuvo una matriz de correlaciones, en la cual se confirmó la existencia de relaciones entre las variables y dimensiones para después corroborar las hipótesis planteadas en la presente investigación. 


\section{Capítulo III}

\subsection{Análisis de resultados del cuestionario}

A continuación, se muestra los resultados obtenidos de los 203 cuestionarios realizados a los fabricantes Mypes de calzado del distrito de Comas, dichos resultados corresponden a la primera variable "Prácticas de gestión financiera".

Los resultados del cuestionario estuvieron definidos por un total de 21 preguntas, que están dividas de la siguiente manera: Prácticas de gestión del capital de trabajo (ítem 1 al 6), Sistema de información contable - práctica de análisis de informes financieros (ítem 7 al 12, excluyéndose el ítem 8 y 9), Gestión de estructura de capital - financiamiento (ítem 13 al 19, excluyéndose el ítem 17) y Presupuesto de capital - gestión de activos no corrientes (ítem 20 al 24).

Tabla 7

PGF1. La empresa cuenta con un sistema de gestión de capital de trabajo.

\begin{tabular}{lcc}
\hline \multicolumn{1}{c}{ Alternativa } & Frecuencia & Porcentaje Válido \\
\hline Muy en desacuerdo & 35 & $17.24 \%$ \\
En desacuerdo & 34 & $16.75 \%$ \\
Ni de acuerdo, ni en desacuerdo & 65 & $32.02 \%$ \\
& & $20.69 \%$ \\
De acuerdo & 42 & $13.30 \%$ \\
Muy de acuerdo & 27 & $100.00 \%$ \\
\hline Total & 203 &
\end{tabular}

Elaboración Propia - Extraído del SPSS 25

Interpretación: Se observa que el 33.99\% de las respuestas indicaron estar de acuerdo en que la empresa cuenta con un sistema de gestión de capital de trabajo, mientras que el 33.99\% señalaron estar en desacuerdo y el $32.02 \%$ se encuentran en una postura de ni de acuerdo, ni en desacuerdo. 


\section{Tabla 8}

PGF2. Mantiene registros de inventario que se actualizan regularmente.

\begin{tabular}{lcc}
\hline \multicolumn{1}{c}{ Alternativa } & Frecuencia & Porcentaje Válido \\
\hline Muy en desacuerdo & 17 & $8.37 \%$ \\
En desacuerdo & 25 & $12.32 \%$ \\
Ni de acuerdo, ni en desacuerdo & 49 & $24.14 \%$ \\
De acuerdo & 72 & $35.47 \%$ \\
Muy de acuerdo & 40 & $19.70 \%$ \\
\hline Total & 203 & $100.00 \%$ \\
\hline
\end{tabular}

Elaboración Propia - Extraído del SPSS 25

Interpretación: Se observa que el 55.17\% señalaron estar de acuerdo en que la empresa mantiene registros de inventario que se actualizan regularmente, el $24.14 \%$ indicaron estar en una posición de ni de acuerdo, ni en desacuerdo y por el último, el 20.69\% respondieron estar en desacuerdo.

Tabla 9

PGF3. La empresa mantiene saldos de efectivo óptimos en todo momento.

\begin{tabular}{lcc}
\hline \multicolumn{1}{c}{ Alternativa } & Frecuencia & Porcentaje Válido \\
\hline Muy en desacuerdo & 35 & $17.24 \%$ \\
En desacuerdo & 48 & $23.65 \%$ \\
Ni de acuerdo, ni en desacuerdo & 58 & $28.57 \%$ \\
De acuerdo & 36 & $17.73 \%$ \\
Muy de acuerdo & 26 & $12.81 \%$ \\
\hline Total & 203 & $100.00 \%$ \\
\hline
\end{tabular}

Elaboración Propia - Extraído del SPSS 25

Interpretación: Se observa que el $40.89 \%$ expresaron estar en desacuerdo en que la empresa mantiene saldos de efectivo óptimos en todo momento, en tanto el $30.54 \%$ denotaron estar de acuerdo y el $28.57 \%$ sostuvieron una postura de ni de acuerdo, ni en desacuerdo. 


\section{Tabla 10}

PGF4. Mantiene registros adecuados y oportunos para todas las cuentas por pagar, catalogando a sus acreedores según sus condiciones de pago.

\begin{tabular}{lcc}
\hline \multicolumn{1}{c}{ Alternativa } & Frecuencia & Porcentaje Válido \\
\hline Muy en desacuerdo & 12 & $5.90 \%$ \\
En desacuerdo & 33 & $16.26 \%$ \\
Ni de acuerdo, ni en desacuerdo & 45 & $22.17 \%$ \\
De acuerdo & 76 & $37.44 \%$ \\
Muy de acuerdo & 37 & $18.23 \%$ \\
\hline Total & 203 & $100.00 \%$ \\
\hline
\end{tabular}

Elaboración Propia - Extraído del SPSS 25

Interpretación: Se observa que el 55.67\% comunicaron estar de acuerdo en que la empresa mantiene registros adecuados y oportunos para todas las cuentas por pagar, catalogando a sus acreedores según sus condiciones de pago, mientras que el $22.17 \%$ se encuentra en una postura de ni de acuerdo, ni en desacuerdo y por último el $22.16 \%$ denotaron estar en desacuerdo.

Tabla 11

PGF5. Asegura que haya suficiente flujo de efectivo para satisfacer las necesidades diarias.

\begin{tabular}{lcc}
\hline \multicolumn{1}{c}{ Alternativa } & Frecuencia & Porcentaje Válido \\
\hline Muy en desacuerdo & 15 & $7.39 \%$ \\
En desacuerdo & 35 & $17.24 \%$ \\
Ni de acuerdo, ni en desacuerdo & 67 & $33.00 \%$ \\
De acuerdo & 61 & $30.05 \%$ \\
Muy de acuerdo & 25 & $12.32 \%$ \\
\hline Total & 203 & $100.00 \%$ \\
\hline
\end{tabular}

Elaboración Propia - Extraído del SPSS 25

Interpretación: Se observa que el $42.37 \%$ demostraron estar de acuerdo en que la empresa asegura que haya suficiente flujo de efectivo para satisfacer las necesidades diarias, en tanto el $33.00 \%$ sostuvieron una posición de ni de acuerdo, ni en desacuerdo y el $24.63 \%$ expresaron estar en desacuerdo. 


\section{Tabla 12}

PGF6. Prepara pronósticos de flujo de efectivo para identificar futuros excedentes y déficits.

\begin{tabular}{lcc}
\hline \multicolumn{1}{c}{ Alternativa } & Frecuencia & Porcentaje Válido \\
\hline Muy en desacuerdo & 42 & $20.69 \%$ \\
En desacuerdo & 71 & $34.98 \%$ \\
Ni de acuerdo, ni en desacuerdo & 37 & $18.23 \%$ \\
De acuerdo & 35 & $17.24 \%$ \\
Muy de acuerdo & 18 & $8.86 \%$ \\
\hline Total & 203 & $100.00 \%$ \\
\hline
\end{tabular}

Elaboración Propia - Extraído del SPSS 25

Interpretación: Se observa que el $55.67 \%$ de las respuestas expresaron estar en desacuerdo en que la empresa prepara pronósticos de flujo de efectivo para identificar futuros excedentes y déficits, el $26.10 \%$ indicaron estar de acuerdo, mientras que el $18.23 \%$ se encuentran en una posición de ni de acuerdo, ni es desacuerdo.

Tabla 13

PGF7. Los estados financieros de la empresa se preparan de acuerdo con los estándares de contabilidad financiera.

\begin{tabular}{lcc}
\hline \multicolumn{1}{c}{ Alternativa } & Frecuencia & Porcentaje Válido \\
\hline Muy en desacuerdo & 15 & $7.39 \%$ \\
En desacuerdo & 44 & $21.67 \%$ \\
Ni de acuerdo, ni en desacuerdo & 85 & $41.87 \%$ \\
De acuerdo & 46 & $22.67 \%$ \\
Muy de acuerdo & 13 & $6.40 \%$ \\
\hline \multicolumn{1}{c}{ Total } & 203 & $100.00 \%$ \\
\hline
\end{tabular}

Elaboración Propia - Extraído del SPSS 25

Interpretación: Se observa que el $41.87 \%$ sostuvieron una postura de ni de acuerdo, ni en desacuerdo en que los estados financieros de la empresa se preparan de acuerdo con los estándares de contabilidad financiera, en tanto el $29.06 \%$ señalaron estar de acuerdo y por último el $29.07 \%$ comunicaron estar en desacuerdo. 


\section{Tabla 14}

PGF10. El estado financiero está preparado de acuerdo con las Normas Internacionales de Información Financiera para las MYPES.

\begin{tabular}{lcc}
\hline \multicolumn{1}{c}{ Alternativa } & Frecuencia & Porcentaje Válido \\
\hline Muy en desacuerdo & 15 & $7.38 \%$ \\
En desacuerdo & 48 & $23.65 \%$ \\
Ni de acuerdo, ni en desacuerdo & 79 & $38.92 \%$ \\
De acuerdo & 41 & $20.20 \%$ \\
Muy de acuerdo & 20 & $9.85 \%$ \\
\hline Total & 203 & $100.00 \%$ \\
\hline
\end{tabular}

Elaboración Propia - Extraído del SPSS 25

Interpretación: Se observa que el 38.92\% se encuentran en una postura de ni de acuerdo, ni en desacuerdo en que el estado financiero está preparado de acuerdo con las Normas Internacionales de Información Financiera para las MYPES, mientras que el 31.03\% expresaron estar en desacuerdo y el $30.05 \%$ comunicaron estar de acuerdo.

Tabla 15

PGF11. La empresa utiliza información contable para la toma de decisiones.

\begin{tabular}{lcc}
\hline \multicolumn{1}{c}{ Alternativa } & Frecuencia & Porcentaje Válido \\
\hline Muy en desacuerdo & 6 & $2.96 \%$ \\
En desacuerdo & 23 & $11.33 \%$ \\
Ni de acuerdo, ni en desacuerdo & 44 & $21.67 \%$ \\
De acuerdo & 71 & $34.98 \%$ \\
Muy de acuerdo & 59 & $29.06 \%$ \\
\hline Total & 203 & $100.00 \%$
\end{tabular}

Elaboración Propia - Extraído del SPSS 25

Interpretación: Se observa que el 64.04\% denotaron estar de acuerdo en que la empresa utiliza información contable para la toma de decisiones, en tanto el $21.67 \%$ sostuvieron una postura de ni de acuerdo, ni en desacuerdo, mientras que el $14.29 \%$ expresaron estar en desacuerdo. 


\section{Tabla 16}

PGF12. Genera informes periódicos para la toma de decisiones.

\begin{tabular}{lcc}
\hline \multicolumn{1}{c}{ Alternativa } & Frecuencia & Porcentaje Válido \\
\hline Muy en desacuerdo & 15 & $7.39 \%$ \\
En desacuerdo & 48 & $23.65 \%$ \\
Ni de acuerdo, ni en desacuerdo & 66 & $32.51 \%$ \\
De acuerdo & 50 & $24.63 \%$ \\
Muy de acuerdo & 24 & $11.82 \%$ \\
\hline Total & 203 & $100.00 \%$ \\
\hline
\end{tabular}

Elaboración Propia - Extraído del SPSS 25

Interpretación: Se observa que el 36.45\% de las respuestas denotaron estar de acuerdo de que la empresa genera informes periódicos para la toma de decisiones, mientras que el $32.51 \%$ se encuentran en una posición de ni de acuerdo, ni en desacuerdo y el $31.04 \%$ manifestaron estar en desacuerdo.

Tabla 17

PGF13. La empresa tiene conocimiento de su estructura de capital.

\begin{tabular}{lcc}
\hline \multicolumn{1}{c}{ Alternativa } & Frecuencia & Porcentaje Válido \\
\hline En desacuerdo & 21 & $10.34 \%$ \\
Ni de acuerdo, ni en desacuerdo & 52 & $25.62 \%$ \\
De acuerdo & 81 & $39.90 \%$ \\
Muy de acuerdo & 49 & $24.14 \%$ \\
\hline Total & 203 & $100.00 \%$ \\
\hline
\end{tabular}

Elaboración Propia - Extraído del SPSS 25

Interpretación: Se observa que el 64.04\% manifestaron estar de acuerdo en que la empresa tiene conocimiento de su estructura de capital, en tanto el $25.62 \%$ se encuentran en una posición de ni de acuerdo, ni en desacuerdo y el 10.34\% señalaron estar en desacuerdo. 


\section{Tabla 18}

PGF14. La estructura de capital de la empresa es adecuada.

\begin{tabular}{lcc}
\hline \multicolumn{1}{c}{ Alternativa } & Frecuencia & Porcentaje Válido \\
\hline Muy en desacuerdo & 3 & $1.48 \%$ \\
En desacuerdo & 33 & $16.26 \%$ \\
Ni de acuerdo, ni en desacuerdo & 77 & $37.93 \%$ \\
De acuerdo & 53 & $26.10 \%$ \\
Muy de acuerdo & 37 & $18.23 \%$ \\
\hline Total & 203 & $100.00 \%$ \\
\hline
\end{tabular}

Elaboración Propia - Extraído del SPSS 25

Interpretación: Se observa que el $44.33 \%$ expresaron estar de acuerdo en que la estructura de capital de la empresa es adecuada, en tanto el 37.93\% sostuvieron una posición de ni de acuerdo, ni en desacuerdo y por último el $17.74 \%$ comunicaron estar en desacuerdo.

\section{Tabla 19}

PGF15. La empresa ha utilizado eficientemente la línea de crédito de acuerdo con sus capacidades.

\begin{tabular}{lcc}
\hline \multicolumn{1}{c}{ Alternativa } & Frecuencia & Porcentaje Válido \\
\hline Muy en desacuerdo & 5 & $2.46 \%$ \\
En desacuerdo & 37 & $18.23 \%$ \\
Ni de acuerdo, ni en desacuerdo & 50 & $24.63 \%$ \\
De acuerdo & 65 & $32.02 \%$ \\
Muy de acuerdo & 46 & $22.66 \%$ \\
\hline Total & 203 & $100.00 \%$ \\
\hline
\end{tabular}

Elaboración Propia - Extraído del SPSS 25

Interpretación: Se observa que el $54.68 \%$ sostuvieron estar de acuerdo en que la empresa ha utilizado eficientemente la línea de crédito de acuerdo con sus capacidades, mientras que el $24.63 \%$ se encuentran en una posición de ni de acuerdo, ni en desacuerdo, en tanto el $20.69 \%$ señalaron estar en desacuerdo. 
Tabla 20

PGF16. La empresa depende únicamente del capital social.

\begin{tabular}{lcc}
\hline \multicolumn{1}{c}{ Alternativa } & Frecuencia & Porcentaje Válido \\
\hline Muy en desacuerdo & 61 & $30.06 \%$ \\
En desacuerdo & 82 & $40.39 \%$ \\
Ni de acuerdo, ni en desacuerdo & 55 & $27.09 \%$ \\
De acuerdo & 5 & $2.46 \%$ \\
\hline Total & 203 & $100.00 \%$ \\
\hline
\end{tabular}

Elaboración Propia - Extraído del SPSS 25

Interpretación: Se observa que el $70.45 \%$ respondieron estar en desacuerdo en que la empresa depende únicamente del capital social, mientras que el $27.09 \%$ se encuentran en una posición de ni de acuerdo, ni en desacuerdo y el 2.46\% indicaron estar de acuerdo.

\section{Tabla 21}

PGF18. La empresa no tiene ninguna dificultad en aumentar el capital social en comparación con la deuda.

\begin{tabular}{lcc}
\hline \multicolumn{1}{c}{ Alternativa } & Frecuencia & Porcentaje Válido \\
\hline Muy en desacuerdo & 26 & $12.81 \%$ \\
En desacuerdo & 114 & $56.16 \%$ \\
Ni de acuerdo, ni en desacuerdo & 63 & $31.03 \%$ \\
\hline Total & 203 & $100.00 \%$ \\
\hline
\end{tabular}

Elaboración Propia - Extraído del SPSS 25

Interpretación: Se observa que el 68.97\% respondieron estar en desacuerdo en que la empresa no tiene dificultad en aumentar el capital social en comparación con la deuda, en tanto el $31.03 \%$ se situaron en una posición de ni de acuerdo, ni desacuerdo. 


\section{Tabla 22}

PGF19. La empresa puede aumentar el capital de deuda fácilmente en comparación con el capital social.

\begin{tabular}{lcc}
\multicolumn{1}{c}{ Alternativa } & Frecuencia & Porcentaje Válido \\
\hline En desacuerdo & 15 & $7.39 \%$ \\
Ni de acuerdo, ni en desacuerdo & 63 & $31.03 \%$ \\
De acuerdo & 81 & $39.90 \%$ \\
Muy de acuerdo & 44 & $21.68 \%$ \\
\hline Total & 203 & $100.00 \%$ \\
\hline
\end{tabular}

Elaboración Propia - Extraído del SPSS 25

Interpretación: Se observa que el 61.58\% manifestaron estar de acuerdo en que la empresa puede aumentar el capital de deuda fácilmente en comparación con el capital social, en tanto el $31.03 \%$ se encuentra en una postura de ni de acuerdo, ni en desacuerdo y el $7.39 \%$ indicaron estar en desacuerdo.

Tabla 23

PGF20. La empresa cuenta con asesoramiento profesional en inversiones de capital.

\begin{tabular}{lcc}
\hline \multicolumn{1}{c}{ Alternativa } & Frecuencia & Porcentaje Válido \\
\hline Muy en desacuerdo & 20 & $9.85 \%$ \\
En desacuerdo & 46 & $22.66 \%$ \\
Ni de acuerdo, ni en desacuerdo & 62 & $30.54 \%$ \\
De acuerdo & 42 & $20.69 \%$ \\
Muy de acuerdo & 33 & $16.26 \%$ \\
\hline Total & 203 & $100.00 \%$
\end{tabular}

Elaboración Propia - Extraído del SPSS 25

Interpretación: Se observa que el 36.95\% respondieron estar de acuerdo en que la empresa cuenta con asesoramiento profesional en inversiones de capital, en tanto el $32.51 \%$ indicaron estar en desacuerdo y el 30.54\% mostraron una postura de ni de acuerdo, ni en desacuerdo. 
Tabla 24

PGF21. La empresa utiliza la técnica de presupuesto de capital como recuperación de la inversión.

\begin{tabular}{lcc}
\hline \multicolumn{1}{c}{ Alternativa } & Frecuencia & Porcentaje Válido \\
\hline Muy en desacuerdo & 27 & $13.30 \%$ \\
En desacuerdo & 48 & $23.65 \%$ \\
Ni de acuerdo, ni en desacuerdo & 58 & $28.57 \%$ \\
De acuerdo & 42 & $20.69 \%$ \\
Muy de acuerdo & 28 & $13.79 \%$ \\
\hline Total & 203 & $100.00 \%$ \\
\hline
\end{tabular}

Elaboración Propia - Extraído del SPSS 25

Interpretación: Se observa que el $36.95 \%$ expresaron estar en desacuerdo en que la empresa utiliza la técnica de presupuesto de capital como recuperación de la inversión, mientras que el $34.48 \%$ mencionaron estar de acuerdo y el $28.57 \%$ se encuentran en una postura de ni de acuerdo, ni en desacuerdo.

Tabla 25

PGF22. La empresa utiliza técnicas de presupuesto de capital como flujo de caja descontado.

\begin{tabular}{lcc}
\hline \multicolumn{1}{c}{ Alternativa } & Frecuencia & Porcentaje Válido \\
\hline Muy en desacuerdo & 41 & $20.20 \%$ \\
En desacuerdo & 81 & $39.90 \%$ \\
Ni de acuerdo, ni en desacuerdo & 33 & $16.26 \%$ \\
De acuerdo & 28 & $13.79 \%$ \\
Muy de acuerdo & 20 & $9.85 \%$ \\
\hline Total & 203 & $100.00 \%$ \\
\hline
\end{tabular}

Elaboración Propia - Extraído del SPSS 25

Interpretación: Se observa que el $60.10 \%$ indicaron estar en desacuerdo en que la empresa utiliza técnicas de presupuesto de capital como flujo de caja descontado, en tanto el $23.64 \%$ expresaron estar de acuerdo y el 16.26\% encontrándose en una posición de ni de acuerdo, ni en desacuerdo. 


\section{Tabla 26}

PGF23. La empresa aplica técnicas de presupuesto de capital en la toma de decisiones.

\begin{tabular}{lcc}
\multicolumn{1}{c}{ Alternativa } & Frecuencia & Porcentaje Válido \\
\hline Muy en desacuerdo & 27 & $13.30 \%$ \\
En desacuerdo & 40 & $19.70 \%$ \\
Ni de acuerdo, ni en desacuerdo & 56 & $27.59 \%$ \\
De acuerdo & 46 & $22.66 \%$ \\
Muy de acuerdo & 34 & $16.75 \%$ \\
\hline Total & 203 & $100.00 \%$ \\
\hline
\end{tabular}

Elaboración Propia - Extraído del SPSS 25

Interpretación: Se observa que el 39.41\% señalaron estar de acuerdo en que la empresa aplica técnicas de presupuesto de capital en la toma de decisiones, en tanto el $33.00 \%$ indicaron estar en desacuerdo y el $27.59 \%$ adoptaron una posición de ni de acuerdo, ni en desacuerdo.

Tabla 27

PGF24. La empresa mantiene un registro adecuado de activos no corrientes.

\begin{tabular}{lcc}
\hline \multicolumn{1}{c}{ Alternativa } & Frecuencia & Porcentaje Válido \\
\hline Muy en desacuerdo & 41 & $20.20 \%$ \\
En desacuerdo & 75 & $36.95 \%$ \\
Ni de acuerdo, ni en desacuerdo & 42 & $20.69 \%$ \\
De acuerdo & 28 & $13.79 \%$ \\
Muy de acuerdo & 17 & $8.37 \%$ \\
\hline Total & 203 & $100.00 \%$ \\
\hline
\end{tabular}

Elaboración Propia - Extraído del SPSS 25

Interpretación: Se observa que el 57.15\% respondieron estar en desacuerdo en que la empresa mantiene un registro de activos no corrientes, mientras que el $22.16 \%$ indicaron estar de acuerdo y el $20.69 \%$ evidenciaron una postura de ni de acuerdo, ni en desacuerdo. 
A continuación, se muestra los resultados obtenidos de los 203 cuestionarios realizados a los fabricantes Mypes de calzado del distrito de Comas, dichos resultados corresponden a la segunda variable "Rentabilidad".

El cuestionario estuvo definido por un total de 6 preguntas:

Tabla 28

R1. Las ventas de la empresa han crecido.

\begin{tabular}{lcc}
\hline \multicolumn{1}{c}{ Alternativa } & Frecuencia & Porcentaje Válido \\
\hline Muy en desacuerdo & 19 & $9.35 \%$ \\
En desacuerdo & 29 & $14.29 \%$ \\
Ni de acuerdo, ni en desacuerdo & 37 & $18.23 \%$ \\
De acuerdo & 72 & $35.47 \%$ \\
Muy de acuerdo & 46 & $22.66 \%$ \\
\hline Total & 203 & $100.00 \%$ \\
\hline
\end{tabular}

Elaboración Propia - Extraído del SPSS 25

Interpretación: Se observa que el $58.13 \%$ señalaron estar de acuerdo en que las ventas de la empresa han crecido, mientras que el $23.64 \%$ respondieron estar en desacuerdo y el $18.23 \%$ se encuentran en una postura de ni de acuerdo, ni en desacuerdo.

Tabla 29

R2. El retorno de los activos de la empresa ha aumentado.

\begin{tabular}{lcc}
\hline \multicolumn{1}{c}{ Alternativa } & Frecuencia & Porcentaje Válido \\
\hline Muy en desacuerdo & 25 & $12.31 \%$ \\
En desacuerdo & 29 & $14.29 \%$ \\
Ni de acuerdo, ni en desacuerdo & 37 & $18.23 \%$ \\
De acuerdo & 66 & $32.51 \%$ \\
Muy de acuerdo & 46 & $22.66 \%$ \\
\hline Total & 203 & $100.00 \%$ \\
\hline
\end{tabular}

Elaboración Propia - Extraído del SPSS 25 
Interpretación: Se observa que el 55.17\% respondieron estar de acuerdo en que el retorno de la empresa ha aumentado, en tanto el $26.60 \%$ expresaron estar en desacuerdo y el $18.23 \%$ ratificaron una postura de ni de acuerdo, ni en desacuerdo.

\section{Tabla 30}

R3. El rendimiento del capital de la empresa ha aumentado.

\begin{tabular}{lcc}
\hline \multicolumn{1}{c}{ Alternativa } & Frecuencia & Porcentaje Válido \\
\hline Muy en desacuerdo & 23 & $11.32 \%$ \\
En desacuerdo & 29 & $14.29 \%$ \\
Ni de acuerdo, ni en desacuerdo & 37 & $18.23 \%$ \\
De acuerdo & 68 & $33.50 \%$ \\
Muy de acuerdo & 46 & $22.66 \%$ \\
\hline Total & 203 & $100.00 \%$ \\
\hline
\end{tabular}

Elaboración Propia - Extraído del SPSS 25

Interpretación: Se observa que el 56.16\% respondieron estar de acuerdo en que el rendimiento del capital de la empresa ha aumentado, mientras que el $25.61 \%$ revelaron estar en desacuerdo y el $18.23 \%$ se encuentran en una posición de ni de acuerdo, ni en desacuerdo.

Tabla 31

R4. El retorno de la inversión de la empresa ha aumentado.

\begin{tabular}{lcc}
\hline \multicolumn{1}{c}{ Alternativa } & Frecuencia & Porcentaje Válido \\
\hline Muy en desacuerdo & 7 & $3.45 \%$ \\
En desacuerdo & 15 & $7.39 \%$ \\
Ni de acuerdo, ni en desacuerdo & 29 & $14.29 \%$ \\
De acuerdo & 37 & $18.22 \%$ \\
Muy de acuerdo & 115 & $56.65 \%$ \\
\hline Total & 203 & $100.00 \%$ \\
\hline
\end{tabular}

Elaboración Propia - Extraído del SPSS 25

Interpretación: Se observa que el $74.87 \%$ respondieron estar de acuerdo en que el retorno de la inversión de la empresa ha aumentado, mientras que el 14.29\% expresaron una postura de ni de acuerdo, ni en desacuerdo y el $10.84 \%$ sostuvieron estar en desacuerdo. 


\section{Tabla 32}

R5. Las ganancias de la empresa han crecido.

\begin{tabular}{lcc}
\hline \multicolumn{1}{c}{ Alternativa } & Frecuencia & Porcentaje Válido \\
\hline Muy en desacuerdo & 12 & $5.91 \%$ \\
En desacuerdo & 17 & $8.37 \%$ \\
Ni de acuerdo, ni en desacuerdo & 29 & $14.29 \%$ \\
De acuerdo & 37 & $18.23 \%$ \\
Muy de acuerdo & 108 & $53.20 \%$ \\
\hline Total & 203 & $100.00 \%$ \\
\hline
\end{tabular}

Elaboración Propia - Extraído del SPSS 25

Interpretación: Se observa que el $71.43 \%$ expresaron estar de acuerdo en que las ganancias de la empresa han crecido, en tanto el 14.29\% evidenciaron una postura de ni de acuerdo, ni en desacuerdo y el $14.28 \%$ mostraron estar en desacuerdo.

Tabla 33

R6. La cuota de mercado de la empresa ha mejorado.

\begin{tabular}{lcc}
\hline \multicolumn{1}{c}{ Alternativa } & Frecuencia & Porcentaje Válido \\
\hline Muy en desacuerdo & 19 & $9.36 \%$ \\
En desacuerdo & 33 & $16.26 \%$ \\
Ni de acuerdo, ni en desacuerdo & 39 & $19.21 \%$ \\
De acuerdo & 59 & $29.06 \%$ \\
Muy de acuerdo & 53 & $26.11 \%$ \\
\hline Total & 203 & $100.00 \%$ \\
\hline
\end{tabular}

Elaboración Propia - Extraído del SPSS 25

Interpretación: Se observa que el 55.17\% manifestaron estar de acuerdo en que la cuota de mercado de la empresa ha mejorado, mientras que el 25.62\% mostraron estar en desacuerdo y el $19.21 \%$ encontrándose en una posición de ni de acuerdo, ni en desacuerdo. 


\subsection{Contrastación de hipótesis}

\subsubsection{Prueba de normalidad}

En la presente investigación, se realizó la prueba de normalidad de Kolmogorov-Smirnov para determinar si los datos referían a una distribución paramétrica o no paramétrica, se encontraron que los datos no se ajustaban a una distribución normal, es decir era una distribución no paramétrica. En el (Anexo 11) se evidencia que la variable prácticas de gestión financiera presenta un nivel de significancia de $(p=0.000<0.05)$, lo mismo surge para la variable rentabilidad (Anexo 12) donde se muestra que su nivel de significancia es $(p=0.000<0.05)$ deduciendo así que ambas variables no son normales; por lo tanto, se rechaza la hipótesis nula $\left(\mathrm{H}_{0}\right)$ y se acepta la hipótesis alterna $\left(\mathrm{H}_{1}\right)$; se emplea el coeficiente de correlación de Rho Spearman, según lo indicado por los autores Hernández et al. (2014), este coeficiente permite medir el grado de asociación que ocurre en las variables ordinales, con el propósito de demostrar las hipótesis planteadas en el estudio.

\subsubsection{Análisis factorial exploratorio}

Según López-Aguado y Gutiérrez-Provecho (2019), mencionan que el análisis factorial es una técnica de reducción de dimensiones cuyo objetivo es identificar factores latentes no observables en un conjunto de variables cuantitativas y que tienen lógica dentro del marco de la teoría. Se denomina factor latente a variables ocultas que no se observan directamente sino a través de la medición de las variables observadas.

El análisis factorial es importante por ser una técnica por excelencia utilizada para comprobar la validación del constructo, los autores Hernández et al. (2014) refieren que el constructo es la variable medida dentro del modelo teórico y que la validez del constructo es posiblemente el más importante para validar un instrumento, debido a que implica identificar cómo las mediciones de la variable se vinculan con los conceptos teóricos además de manifestar si el tipo de validez responde a preguntas como ¿El concepto teórico está realmente reflejado en el instrumento?, ¿El instrumento mide el constructo y sus dimensiones?, gracias a este análisis se exhibe la cantidad de dimensiones que integra la variable planteada y también se identifica los ítems incluidos en cada dimensión. 
Para este tipo de análisis se utilizó el método de extracción de factores que implica componentes principales, para lo cual se realizó el procedimiento de rotación y método Varimax, consiguiendo como resultado en la variable prácticas de gestión financiera un estadístico de Kaiser-Meyer-Olkin (KMO) de 0.804 con un Chi-cuadrado aproximado de 2046.859 y un nivel de significancia de 0.000 (Anexo 13), lo que conlleva a comprobar la eficacia del KMO por tener un valor mayor o superior a 0.80 y afirmar un buen ajuste factorial. En base a los análisis realizados, se obtuvo 4 factores que demuestran el $61.821 \%$ de la matriz de componente y la varianza total explicada, mediante el análisis factorial los porcentajes de varianza de la primera variable prácticas de gestión financiera se explican de la siguiente manera.

El factor 1 "Prácticas de gestión del capital de trabajo" explica un importante porcentaje en su varianza de $17.615 \%$, el factor 2 "Presupuesto de capital - gestión de activos no corrientes" muestra un porcentaje de $17.140 \%$ en la varianza, el factor 3 "Gestión de estructura de capital - financiamiento" indica un porcentaje de $16.159 \%$ en su varianza y por último, el factor 4 "Sistema de información contable - práctica de análisis de informes financieros" señala el porcentaje de $10.906 \%$ en su varianza. (Anexo 13).

Con el método Varimax con Normalización Kaiser, la matriz de componente rotado muestra la existencia de 4 factores que agrupan cada dimensión (Anexo 13), el primer factor comprende la dimensión "Prácticas de gestión del capital de trabajo" e incluye preguntas (1 al 6), el segundo factor contiene la dimensión "Presupuesto de capital - gestión de activos no corrientes" con intervalo de preguntas (20 al 24), el tercer factor comprende la dimensión "Gestión de estructura de capital - financiamiento" con preguntas (13 al 19) y el cuarto factor evidencia la dimensión "Sistema de información contable - práctica de análisis de informes financieros" con preguntas (7 al 12).

En referencia a la variable rentabilidad, se obtuvo un estadístico de Kaiser-Meyer-Olkin (KMO) de 0.861 con un Chi-cuadrado aproximado de 685.894 y se reflejó un nivel de significancia de 0.000 (Anexo 14) por tanto, se valida un óptimo ajuste factorial. Al proceder con el análisis se consiguió como resultado la existencia de 1 factor que agrupa a la variable "rentabilidad", el cual explica el $62.174 \%$ de la varianza total. 


\subsubsection{Correlación de Rho Spearman}

En el (Anexo 15) se muestra la relación que existe entre la variable prácticas de gestión financiera y la rentabilidad de las empresas en estudio, esta información se logró obtener por medio de cuestionarios que fueron realizados a los fabricantes Mypes de calzado ubicados en el distrito de Comas, comprobándose la existencia de correlación positiva; se expone que la variable rentabilidad mantiene relación significativa con las Prácticas de gestión del capital de trabajo (sig=0.019), Sistemas de información contable - práctica de informes financieros (sig=0.019), Gestión de estructura de capital - financiamiento ( $\mathrm{sig}=0.011)$ y Presupuesto de capital - gestión de activos no corrientes (sig=0.000).

\subsubsection{Contrastación de Hipótesis}

Para demostrar la contrastación de las hipótesis se utilizó el nivel de significancia, el cual es definido por Babbie (2012) y Mertens (2010), citado por Hernández et al. (2014), como la probabilidad de rechazar la hipótesis nula cuando es verdadera, es decir que existe $5 \%$ de posibilidad de error al aceptar la hipótesis, correlación o valor obtenido al aplicar una prueba estadística; o 5\% de riesgo de que se rechace una hipótesis nula cuando era verdadera. Además, se evaluó el Coeficiente de correlación de Spearman, el cual es definido por Akoglu (2018) , como una prueba no paramétrica cuando se requiere medir la relación entre dos variables y no se cumple el supuesto de normalidad en la distribución de tales valores y es cuantificado con un número, que varía de -1.0 (correlación negativa perfecta) a +1.0 (correlación positiva perfecta), considerando el 0 como ausencia de correlación entre las variables jerarquizadas, donde el signo del coeficiente de correlación muestra la dirección de la correlación.

En la tabla de coeficiente de correlación Rho de Spearman del artículo científico "User's guide to correlation coefficients", el autor Akoglu (2018) indica que, el intervalo de 0.1 a 0.2 se considera "débil", de 0.2 a 0.3 se considera "moderado", de 0.3 a 0.6 se considera "fuerte", de 0.6 a 0.9 se interpreta "muy fuerte" y de 0.9 a 1.0 se considera "perfecto".

\section{Hipótesis General}

Las prácticas de gestión financiera se relacionan positivamente con la rentabilidad de los fabricantes Mypes de calzado de Comas 2020. 


\section{a. Hipótesis Nula ( $\left.\mathrm{H}_{0}\right)$}

Las prácticas de gestión financiera NO se relacionan positivamente con la rentabilidad de los fabricantes Mypes de calzado de Comas 2020.

\section{b. Hipótesis Alterna $\left(\mathbf{H}_{1}\right)$}

Las prácticas de gestión financiera SI se relacionan positivamente con la rentabilidad de los fabricantes Mypes de calzado de Comas 2020.

\section{c. Nivel de Significancia ( $\alpha)$}

Para la presente investigación se consideró un nivel de significancia de: $\alpha=5 \%$.

\section{d. Prueba estadística}

\section{Tabla 34}

Resultado de Rho de Spearman - Hipótesis General.

\begin{tabular}{|c|c|c|c|c|}
\hline \multicolumn{5}{|c|}{ Correlaciones } \\
\hline & & & Pract_gest_financ & Rentabilidad \\
\hline \multirow{6}{*}{ Rho de Spearman } & Pract_gest_financ & $\begin{array}{c}\text { Coeficiente de } \\
\text { correlación }\end{array}$ & 1.000 & $.353^{* *}$ \\
\hline & & Sig. (bilateral) & . & .000 \\
\hline & & $\mathrm{N}$ & 203 & 203 \\
\hline & Rentabilidad & $\begin{array}{c}\text { Coeficiente de } \\
\text { correlación }\end{array}$ & $.353^{* *}$ & 1.000 \\
\hline & & Sig. (bilateral) & .000 & . \\
\hline & & $\mathrm{N}$ & 203 & 203 \\
\hline
\end{tabular}

**. La correlación es significativa en el nivel 0,01 (bilateral).

Elaboración Propia - Extraído del SPSS 25

\section{e. Toma de decisiones}

Considerando los resultados presentados con un nivel de significancia del $5 \%$, se deduce que se rechaza la hipótesis nula y se acepta la hipótesis Alterna, $(r=0.353 ; p<0.05)$, concluyendo que "Las prácticas de gestión financiera SI se relacionan positivamente con la rentabilidad de los fabricantes Mypes de calzado de Comas 2020", donde se demuestra un 
grado de relación fuerte entre las dos variables, el cual se comprobó por la prueba no paramétrica ejecutado por el software SPSS 25.

\section{Primera hipótesis específica}

Las prácticas de gestión del capital de trabajo se relacionan positivamente con la rentabilidad de los fabricantes Mypes de calzado de Comas 2020.

\section{a. Hipótesis Nula $\left(\mathrm{H}_{0}\right)$}

Las prácticas de gestión del capital de trabajo NO se relacionan positivamente con la rentabilidad de los fabricantes Mypes de calzado de Comas 2020.

\section{b. Hipótesis Alterna $\left(\mathbf{H}_{1}\right)$}

Las prácticas de gestión del capital de trabajo SI se relacionan positivamente con la rentabilidad de los fabricantes Mypes de calzado de Comas 2020

\section{c. Nivel de significancia ( $\alpha)$}

Para el caso del problema se ha estimado un nivel de significación de: $\alpha=5 \%$.

\section{d. Prueba estadística}

\section{Tabla 35}

Resultado de Rho Spearman - Primera Hipótesis específica

\begin{tabular}{lc}
\hline Prueba estadística & Rho Spearman \\
Significancia & 0.019 \\
Coeficiente de correlación & 0.164 \\
Nivel de significancia & 0.05 \\
Conclusión & $<5 \%$ Se rechaza la hipótesis nula \\
\hline
\end{tabular}

Elaboración Propia - Extraído del SPSS 25

\section{e. Toma de decisiones}

Con un nivel de significancia del $5 \%$, se infiere que se rechaza la hipótesis nula y se acepta la hipótesis Alterna, $(r=0.164 ; p<0.05)$, concluyendo que "Las prácticas de gestión del capital de trabajo SI se relacionan positivamente con la rentabilidad de los fabricantes Mypes de calzado de Comas 2020", donde se demuestra un grado de relación débil entre las dos variables, el cual se verificó por la prueba no paramétrica ejecutado por el software SPSS 25. 


\section{Segunda Hipótesis Específica}

El sistema de información contable - práctica de análisis de informes financieros se relaciona positivamente con la rentabilidad de los fabricantes Mypes de calzado de Comas 2020.

\section{a. Hipótesis nula $\left(\mathrm{H}_{0}\right)$}

El sistema de información contable - práctica de análisis de informes financieros NO se relaciona positivamente con la rentabilidad de los fabricantes Mypes de calzado de Comas 2020.

\section{b. Hipótesis Alterna $\left(\mathbf{H}_{1}\right)$}

El sistema de información contable - práctica de análisis de informes financieros SI se relaciona positivamente con la rentabilidad de los fabricantes Mypes de calzado de Comas 2020.

\section{c. Nivel de significancia ( $\alpha)$}

Para el caso del problema se ha estimado un nivel de significación de: $\alpha=5 \%$.

\section{d. Prueba estadística}

\section{Tabla 36}

Resultado de Rho de Spearman - Segunda Hipótesis específica

\begin{tabular}{lc}
\hline Prueba estadística & Rho Spearman \\
Significancia & 0.019 \\
Coeficiente de correlación & 0.164 \\
Nivel de significancia & 0.05 \\
Conclusión & $<5 \%$ Se rechaza la hipótesis nula \\
\hline
\end{tabular}

\section{Elaboración Propia - Extraído del SPSS 25}

\section{e. Toma de decisiones}

Con un nivel de significancia del $5 \%$, se deduce que se rechaza la hipótesis nula y se acepta la hipótesis Alterna, $(r=0.164 ; p<0.05)$, concluyendo que "El sistema de información contable práctica de análisis de informes financieros SI se relaciona positivamente con la rentabilidad de los fabricantes Mypes de calzado de Comas 2020", donde se demuestra un grado de relación débil entre las dos variables, el cual fue confirmado por la prueba no paramétrica ejecutado por el software SPSS 25. 


\section{Tercera Hipótesis Específica}

La gestión de estructura de capital - financiamiento se relaciona positivamente con la rentabilidad de los fabricantes Mypes de calzado de Comas 2020.

\section{a. Hipótesis nula (Ho)}

La gestión de estructura de capital - financiamiento NO se relaciona positivamente con la rentabilidad de los fabricantes Mypes de calzado de Comas 2020.

\section{b. Hipótesis Alterna $\left(\mathbf{H}_{1}\right)$}

La gestión de estructura de capital - financiamiento SI se relaciona positivamente con la rentabilidad de los fabricantes Mypes de calzado de Comas 2020.

\section{c. Nivel de significancia ( $\alpha)$ :}

Para el caso del problema se ha estimado un nivel de significación de: $\alpha=5 \%$.

\section{d. Prueba estadística}

\section{Tabla 37}

Resultado de Rho de Spearman - Tercera Hipótesis Específica.

\begin{tabular}{lc}
\hline Prueba estadística & Rho Spearman \\
Significancia & 0.011 \\
Coeficiente de correlación & 0.179 \\
Nivel de significancia & 0.05 \\
Conclusión & $<5 \%$ Se rechaza la hipótesis nula \\
\hline
\end{tabular}

Elaboración Propia - Extraído del SPSS 25

\section{e. Toma de decisiones}

Con un nivel de significancia del $5 \%$, se deduce que se rechaza la hipótesis nula y se acepta la hipótesis Alterna, $(r=0.179 ; p<0.05)$, concluyendo que "La gestión de estructura de capital financiamiento $\mathrm{SI}$ se relaciona positivamente con la rentabilidad de los fabricantes Mypes de calzado de Comas 2020", donde se demuestra un grado de relación débil entre las dos variables, el cual se corroboró por la prueba no paramétrica ejecutado por el software SPSS 25. 


\section{Cuarta Hipótesis Específica}

El presupuesto de capital - gestión de activos no corrientes se relaciona positivamente con la rentabilidad de los fabricantes Mypes de calzado de Comas 2020.

\section{a. Hipótesis nula $\left(\mathrm{H}_{\mathrm{o}}\right)$ :}

El presupuesto de capital - gestión de activos no corrientes NO se relaciona positivamente con la rentabilidad de los fabricantes Mypes de calzado de Comas 2020.

\section{b. Hipótesis Alterna $\left(\mathrm{H}_{1}\right)$ :}

El presupuesto de capital - gestión de activos no corrientes SI se relaciona positivamente con la rentabilidad de los fabricantes Mypes de calzado de Comas 2020.

\section{c. Nivel de significancia ( $\alpha$ ):}

Para el caso del problema se ha estimado un nivel de significación de: $\alpha=5 \%$.

\section{d. Prueba estadística}

\section{Tabla 38}

Resultado de Rho de Spearman - Cuarta Hipótesis Específica

\begin{tabular}{lc}
\hline Prueba estadística & Rho Spearman \\
Significancia & 0.000 \\
Coeficiente de correlación & 0.314 \\
Nivel de significancia & 0.05 \\
Conclusión & $<5 \%$ Se rechaza la hipótesis nula \\
\hline
\end{tabular}

\section{Elaboración Propia - Extraído del SPSS 25}

\section{e. Toma de decisiones}

Con un nivel de significancia del $5 \%$, se deduce que se rechaza la hipótesis nula y se acepta la hipótesis Alterna, $(r=0.314 ; p<0.05)$, concluyendo que "El presupuesto de capital - gestión de activos no corrientes SI se relaciona positivamente con la rentabilidad de los fabricantes Mypes de calzado de Comas 2020", donde se demuestra un grado de relación fuerte entre las 
dos variables, el cual se corroboró por la prueba no paramétrica ejecutado por el software SPSS 25.

\subsection{Discusión}

En la presente investigación titulada "Las prácticas de gestión financiera y la rentabilidad de los fabricantes Mypes de calzado de Comas 2020" se realizaron dos cuestionarios dirigidos a las empresas Mypes fabricantes de calzado del distrito en mención, dichos cuestionarios corresponden a cada una de las variables: "Prácticas de gestión financiera" y "Rentabilidad". A continuación, se indicarán otras investigaciones que tienen relación con los resultados obtenidos en la presente investigación.

\subsubsection{Hipótesis general.}

En la hipótesis general se observa que "Las prácticas de gestión financiera se relacionan positivamente con la rentabilidad de los fabricantes Mypes de calzado de Comas", los resultados muestran un coeficiente de correlación $(r=0.353)$ y nivel de significancia (sig=0.000), se acepta la hipótesis planteada y se rechaza la hipótesis nula. El estudio concuerda con la investigación de los autores Musah, A., Dodzi-Gakpetor, E., \& Pomaa, P. (2018) al indicar la existencia de correlación positiva entre las prácticas de gestión financiera y la rentabilidad.

\subsubsection{Primera Hipótesis Específica.}

La primera hipótesis específica "Las prácticas de gestión del capital de trabajo se relacionan positivamente con la rentabilidad de los fabricantes Mypes de calzado de Comas 2020", cuenta con un coeficiente de correlación $r=0.164$, sig $=0.019, p<0.05$, por ello se rechaza la hipótesis nula y se acepta la hipótesis alternante, confirmando que existe una relación positiva entre las prácticas de gestión del capital de trabajo y la rentabilidad de las fabricantes Mypes de calzado de Comas. Para poder respaldar los resultados obtenidos en relación de la presente hipótesis, se mencionará una de las investigaciones donde demuestran dicha relación, en la investigación de Yohanes, D., Lemie-Debela, K., \& Shibru, W. (2018) se demuestra que existe una relación positiva entre las prácticas de gestión del capital de trabajo y la rentabilidad. 


\subsubsection{Segunda Hipótesis Específica.}

La segunda hipótesis específica "El sistema de información contable - práctica de análisis de informes financieros se relaciona positivamente con la rentabilidad de los fabricantes Mypes de calzado de Comas 2020" cuenta con un coeficiente de correlación $r=0.164$, sig $=0.019$, $p<0.05$, por ello se rechaza la hipótesis nula y se acepta la hipótesis alternante, confirmando que existe una relación positiva entre el sistema de información contable - prácticas de análisis de informes financieros de los fabricantes Mypes de calzado de Comas. Para poder respaldar los resultados obtenidos en relación de la presente hipótesis, se mencionará una de las investigaciones donde demuestran dicha relación, en la investigación de Saah, P. (2015) concluyen que existe una relación positiva entre el sistema de información contable - práctica de análisis de informes financieros y la rentabilidad.

\subsubsection{Tercera Hipótesis Específica.}

En la tercera hipótesis específica, "Gestión de estructura de capital - financiamiento se relaciona positivamente con la rentabilidad de los fabricantes Mypes de calzado de Comas 2020", por lo que se rechaza la hipótesis nula y se acepta la hipótesis alternante, se explica un coeficiente de correlación $r=0.179$, sig $=0.011, p<0.05$, lo que significa que si la gestión de estructura de capital - financiamiento mejora, lo mismo sucederá con la rentabilidad. Este resultado está respaldado por la investigación de los autores Musah, A., Dodzi-Gakpetor, E., \& Pomaa, P. (2018), quienes confirmaron que la estructura de capital afecta a la rentabilidad de la empresa por estar muy relacionadas, los autores precisaron la importancia de determinar la combinación apropiada entre deuda y capital para poder minimizar el riesgo, además indicaron que la buena gestión de este componente contribuye al crecimiento de la empresa.

\subsubsection{Cuarta Hipótesis Específica.}

En la cuarta hipótesis específica, "El presupuesto de capital - gestión de activos no corrientes se relaciona positivamente con la rentabilidad de los fabricantes Mypes de calzado de Comas 2020", por lo que se rechaza la hipótesis nula y se acepta la hipótesis alternante, se obtuvo como resultado un coeficiente de correlación $r=0.314$, sig $=0.000, p<0.05$, por lo que se afirma que si existe relación directa, esta afirmación indica que si las decisiones son idóneas en cuanto adquisiciones de equipo, ello contribuirá en favor de la rentabilidad de la empresa. Para poder respaldar los resultados obtenidos en la cuarta hipótesis específica, se 
menciona a los investigadores Yohanes, D., Lemie-Debela, K., \& Shibru, W. (2018) quienes concluyeron que el coeficiente estimado si presentaba asociación positiva con la rentabilidad de las pequeñas empresas.

\subsection{Conclusiones}

1. En base a los resultados obtenidos por medio del coeficiente de correlación de Spearman $r=0.353$; sig=0.000, $p<0.05$, se permitió comprobar que existe relación positiva entre las prácticas de gestión financiera y la rentabilidad de los fabricantes Mypes de calzado de Comas 2020, cuyo grado de intensidad entre las variables es fuerte. Por ende, en la presente investigación se afirma que el aporte de estas prácticas contribuye a generar una mejor rentabilidad de las empresas investigadas. Con la implementación de las prácticas de gestión financiera dentro de las Mypes de calzado, se logra la eficiencia en el manejo de los recursos para que de esta manera la empresa sea rentable, la gran mayoría de estas empresas que se desempeñan en este rubro, no prestan la debida atención a los beneficios que pueden obtener, no gestionan adecuadamente sus finanzas porque lo realizan de manera empírica; cabe recalcar que solo se logrará siempre y cuando sepan adoptar las prácticas de manera efectiva.

2. En base a los resultados obtenidos por medio del coeficiente de correlación de Spearman $r=0.164$; sig=0.019, $p<0.05$, se permitió comprobar que existe relación positiva entre las prácticas de gestión del capital de trabajo y la rentabilidad de los fabricantes Mypes de calzado de Comas 2020, cuyo grado de intensidad es débil. Por ende, en la presente investigación se afirma que las prácticas de gestión del capital de trabajo contribuyen a mejorar la rentabilidad de las empresas investigadas, este tipo de prácticas es fundamental para obtener eficiencia en el corto-mediano y largo plazo; ciertamente para estas Mypes les resulta difícil prever las entradas y salidas de efectivo de la caja de la empresa, ya que no cuentan con un flujo que les permita identificar el equilibrio entre sus activos y pasivos, en la mayoría de casos, estas Mypes no consideran que la gestión del capital de trabajo tiene como propósito disminuir los riesgos y lograr la rentabilidad.

3. En base a los resultados obtenidos por medio del coeficiente de correlación de Spearman $r=0.164$; sig $=0.019, p<0.05$, se permitió comprobar que existe relación positiva entre el sistema de información contable - práctica de análisis de informes financieros y la rentabilidad de los fabricantes Mypes de calzado de Comas 2020, cuyo grado de intensidad es débil. Por ende, 
en la presente investigación se afirma que el sistema de información contable - práctica de análisis de informes financieros contribuye a mejorar la rentabilidad de las empresas investigadas. Esta práctica referida al sistema contable y análisis financieros juega un rol muy importante en la rentabilidad de los fabricantes Mypes de calzado de Comas 2020, ya que mantener actualizados los registros de sus operaciones les permite obtener información relevante y confiable de la empresa para la toma de decisiones que contribuyan a la rentabilidad de la misma; las Mypes del sector calzado no aplican esta práctica porque desconocen de temas contables y/o manejo de la tecnología de la información; algunas empresas suelen llevar su información contable y financiera en hojas o cuadernos, lo que origina que no puedan contar con información ordenada y precisa para la toma de decisiones, donde se les dificulta realizar una adecuada elaboración y análisis de sus informes contables y financieros; por otro lado, la falta de conocimiento y capacitación por parte del gerente o administrador en el manejo de la información contable y financiera afecta la estabilidad de la empresa; estas empresas no comprenden que mediante un sistema de información contable pueden analizar sus informes financieros además de contrarrestar sus debilidades para así monitorear eficientemente su empresa, con la finalidad de conseguir la rentabilidad esperada.

4. En base a los resultados obtenidos por medio del coeficiente de correlación de Spearman $r=0.179$; sig=0.011, $p<0.05$, se permitió comprobar que existe relación positiva entre la gestión de estructura de capital -financiamiento y la rentabilidad de los fabricantes Mypes de calzado de Comas 2020, cuyo grado de intensidad es débil. Por ende, en la presente investigación se afirma que lograr una adecuada estructura de capital contribuye a mejorar la rentabilidad de las empresas investigadas. La gestión de estructura de capital -financiamiento es primordial para la rentabilidad de las Mypes investigadas; estas empresas tienen proyectos para crecer o expandir el negocio, por lo que buscan a entidades financieras que faciliten su acceso al crédito, sin embargo, estas Mypes suelen realizar sencillos cálculos que no les permite tomar en consideración que la deuda adquirida puede estar fuera de sus posibilidades de pago y además aumentar el riesgo de endeudamiento, más aún si optan por continuar financiándose para lograr competir con otras empresas, trayendo como consecuencia una deficiencia en la combinación de deuda y capital que afecte a la rentabilidad de la empresa. 
5. En base a los resultados obtenidos por medio del coeficiente de correlación de Spearman $r=0.314$; sig=0.000, $p<0.05$, se permitió comprobar que existe relación positiva entre el presupuesto de capital - gestión de activos no corrientes y la rentabilidad de los fabricantes Mypes de calzado de Comas 2020, cuyo grado de intensidad es fuerte. Por ende, en la presente investigación se afirma que la implementación de esta práctica contribuye a mejorar la rentabilidad de las empresas investigadas. El presupuesto de capital - gestión de activos no corrientes es un componente importante para la rentabilidad de los fabricantes Mypes de calzado de Comas 2020, más aun si las Mypes del sector no suelen evaluar la inversión por la adquisición del activo fijo, cuando surge la necesidad de comprar la maquinaria ya sea por innovación o competitividad, no consideran los futuros problemas financieros que podrían ocasionarse en la empresa, debido a que no evalúan el retorno de las inversiones que realizan.

\subsection{Recomendaciones}

1. Se recomienda que las Mypes fabricantes de calzado implementen las prácticas de gestión financiera, utilizando las técnicas y herramientas de diagnóstico financiero de manera periódica para que les permita conocer la situación económica y financiera de la empresa, con la finalidad de controlar los indicadores claves de rentabilidad, sobre todo en donde se han identificado debilidades como la falta de liquidez, el uso efectivo de los activos, las inversiones, los niveles de endeudamiento, para que puedan tomar decisiones fundamentadas con el fin de cumplir los objetivos de rentabilidad de la empresa. Por otro lado, las Mypes fabricantes de calzado deben de tomar en consideración que para lograr una adecuada administración de las prácticas de gestión financiera, el administrador o gerente debe contar con los conocimientos necesarios sobre contabilidad y finanzas para poder llevar un adecuada gestión financiera, como lo menciona Esteba, L. (2016), en su investigación "Influencia de la gestión financiera en la rentabilidad de las Mypes, en el sector hotelero - Tacna, año 2014", indica que el administrador o gerente de una empresa debe conocer los temas concernientes a la gestión financiera para lograr un buen manejo del negocio y así lograr un desarrollo financiero y económico; es por ello que recomienda que las empresas promuevan un plan de capacitación sobre temas contables y financieros para los administradores o gerentes, además recomienda promover un plan de acción de seguimiento y supervisión a las prácticas y acciones de la gestión financiera. 
2. Con respecto a las prácticas de gestión del capital de trabajo y su relación con la rentabilidad, se recomienda que las Mypes fabricantes de calzado implementen procedimientos internos para mejorar el control del capital de trabajo, como el uso del presupuesto de efectivo, la cual ayudará a pronosticar los ingresos y egresos que pueda tener la empresa en un periodo dado; efectuar un seguimiento a las necesidades del efectivo y a las fuentes requeridas para financiar un déficit y aplicar políticas de control respecto a las salidas de efectivo, con el objetivo de resguardar el dinero y que la empresa no se quede sin capital de trabajo para sus operaciones diarias. Gonzales, E. (2018), en su investigación "La administración del capital de trabajo y su influencia en la rentabilidad de la agencia de viajes expediciones las balsas S.R.L. - Puno, periodos 2015 - 2016" recomienda analizar regularmente la conducta del patrimonio, inversiones, ventas netas y total de activos con respecto a la rentabilidad mediante ratios de rentabilidad financiera y económica, además sugiere evaluar regularmente el capital de trabajo para que así la empresa pueda conocer si las decisiones tomadas son acertadas y si están favoreciendo a la rentabilidad de la empresa.

3. Contar con un sistema de información contable contribuye favorablemente al análisis de informes financieros, por ello se recomienda que las Mypes fabricantes de calzado, desarrollen un plan de capacitación permanente al gerente o administrador sobre el manejo efectivo de la información financiera y contable, prepararlos de manera completa para que puedan hacer un uso correcto de su sistema de información contable, con la finalidad de aprovechar dicha información para la toma de decisiones; también se recomienda que las empresas obtengan los servicios de un Contador Público para que pueda dar revisión y efectuar la veracidad de los libros contables obligados a llevar de acuerdo a sus ingresos anuales y que de tal manera se pueda brindar las observaciones y gestionar de una manera más eficaz las oportunidades de mejora para la empresa; en el caso de los libros contables obligados a llevar, el Régimen Mype Tributario donde están acogidas la mayoría de Mypes, están obligadas a llevar ciertos libros contables correspondientes a sus ingresos anuales: hasta 300 UIT, están obligadas a llevar Registro de Ventas, Registro de Compras y Libro Diario de Formato Simplificado; mayores 300 UIT hasta los 500 UIT, están obligados a llevar Registro de Ventas, Registro de Compras, Libro Diario y Libro Mayor; mayores a 500 UIT hasta 1700 UIT, están obligadas a llevar Registro de Compras, Registro de Ventas, Libro Diario, Libro Mayor, Libro de Inventarios y Balances; considerando las Mypes que cuenten con ingresos iguales o mayores a 75 UIT en el periodo comprendido entre el mes de mayo del año precedente al anterior y abril del año anterior, están obligadas a llevar su Registro de Ventas e Ingresos y del Registro de Compras 
de manera electrónica desde los sistemas del contribuyente, mediante el Programa de Libros Electrónicos - PLE, o desde los sistemas de la SUNAT, denominado PORTAL. Reyes, D. \& Salina, A. (2015), en su investigación "Implementación de un sistema de información contable y su influencia en la gestión de la contabilidad en la empresa de transportes Turismo Días S.A. año 2015", indica que es de suma importancia que la empresa cuente con personal con conocimientos para el uso del sistema de información contable, ya que de nada servirá contar con un sistema contable sino se cuenta con personal capacitado para su uso y análisis, lo que origina que el sistema no funcione adecuadamente en toda su capacidad.

4. Se recomienda a las Mypes fabricantes de calzado evaluar cada inversión que realicen, así sea la inversión de capital propio o financiamiento externo, los fabricantes de calzado deben de establecer una política de endeudamiento, donde se considere la rentabilidad que se espera de cada inversión y el riesgo que pueda asumir la empresa. Por otro lado, las Mypes deben de evaluar y analizar minuciosamente su estructura de capital y hasta qué punto son capaces de afrontar sus deudas externas, ya que, si no cuentan con capacidad de pago frente a las instituciones financieras, esto afectará negativamente su historial crediticio, lo cual perjudicaría a la empresa. Como lo comenta Apaza, F. (2017), en su investigación "Determinación de la estructura óptima de capital y la rentabilidad (ROIC) para maximizar el valor de una empresa caso: Lanera Sur L \& G S.R.L. años 2011 al 2015", señala que las empresas deben realizar análisis financieros periódicamente con el uso de ratios financieros, esto les permitirá conocer su situación actual y podrán establecer un plan financiero proyectado a largo plazo, con el fin de evaluar y analizar la rentabilidad y el riesgo de cada inversión, con ello las empresas podrán tomar mejores decisiones con respecto a las fuentes de financiamiento (capital propio o financiamiento externo).

5. Se pudo observar un grado de relación fuerte entre el presupuesto de capital de gestión de activos no corrientes y la rentabilidad, a diferencia de las otras dimensiones, donde el grado de relación fue débil; cabe señalar que para las Mypes fabricantes de calzado invertir en activos fijos representa salidas significativas de dinero, lo cual puede impactar fuertemente su situación económica y financiera, por ello se recomienda que deben de analizar y decidir en qué activos deben invertir considerando cuales son los más rentables y que representen el mínimo costo de las fuentes de financiamiento, por ello las Mypes deben enfocarse en establecer un presupuesto de capital óptimo, planificando los gastos y riesgos a asumir concernientes a los activos que generarán flujos de efectivo a más de un año y analizando si 
dicha inversión le generará el rendimiento esperado a largo plazo. Alarcón, A.; Ullua, E. \& Carretero, Y. (2018) en su investigación "Las decisiones de presupuesto de capital: Criterios financieros fundamentales", señalan que las empresas deberían de elaborar un presupuesto de venta, puesto que invertirán en activos para periodos largos y al significar salidas significativas de dinero, es recomendable que las empresas realicen pronósticos de ventas por ese mismo periodo, con el fin de conocer si la inversión realizada será rentable. 


\section{Referencias Bibliográficas}

Akoglu, H. (2018). User's guide to correlation coefficients. Turkish Journal of Emergency Medicine, 18(2018), 91-93.

Alarcón, A., Ullua, E., \& Carretero, Y. (2018). Las decisiones de presupuesto de capital: Criterios financieros fundamentales. Universidad de Ciego de Ávila. Obtenido de https://www.researchgate.net/publication/325066760

Apaza, F. (2017). Determinación de la estructura óptima de capital y la rentabilidad (ROIC) para maximizar el valor de una empresa caso: Lanera Sur L \& G S.R.L. años 2011 al 2015. (Tesis de Pregrado). Obtenido de http://repositorio.unsa.edu.pe/handle/UNSA/5787

Barrios, R. (26 de diciembre de 2019). Produce: Más de 2 mil mipymes de calzado recibirán asistencia técnica. La República. Obtenido de https://larepublica.pe/economia/2019/12/26/produce-mas-de-2-mil-mipymes-decalzado-recibiran-asistencia-tecnica/

Bustamante, L., \& Ponce, J. (2015). Manejo eficiente de herramientas de gestión financiera y su incidencia en la rentabilidad de la empresa Ospina S.A.C.- Huancayo. (Tesis de Pregrado). Obtenido de http://repositorio.uncp.edu.pe/handle/UNCP/3281

Cadena-Iñiguez et al. (2017). Métodos cuantitativos, métodos cualitativos o su combinación en la investigación: un acercamiento en las ciencias sociales. Revista Mexicana de Ciencias Agrícolas, 8(7), 1603-1617.

Castañeda, Z., \& Reyes, I. (2019). Gestión financiera y su influencia en la rentabilidad de la empresa Industrias del Perno S.A.C., periodo 2017. (Tesis de Pregrado). Obtenido de https://repositorio.upn.edu.pe/handle/11537/15119

Castillo, M., \& Rosales, S. (2017). Gestión financiera y su influencia en la rentabilidad de las empresas comerciales del rubro abarrotes, adscritas al régimen general del impuesto a la renta en la ciudad de Huaraz - 2016. (Tesis de Pregrado). Obtenido de http://repositorio.unasam.edu.pe/handle/UNASAM/2173

Chávez, M. (11 de diciembre de 2019). Perú importó 43 millones de pares de calzado por US\$ 410 millones a octubre. Gestión. Obtenido de https://gestion.pe/economia/peru- 
importo-43-millones-de-pares-de-calzado-por-us-410-millones-a-octubre-nndc-

noticia/?ref=gesr

Cherres, Y. (2016). La gestión financiera y su impacto en la rentabilidad de la empresa "FABITEX" de la ciudad de Ambato año 2015. (Tesis de Pregrado). Obtenido de https://repositorio.uta.edu.ec/handle/123456789/24073

Citeccal Lima. (2017). Boletín oficial de Citeccal Informa. Obtenido de http://citeccal.itp.gob.pe/wp-content/uploads/2016/11/BOLETIN-OFICIAL-CITECCALLIMA-JULIO.pdf

Dávalos, S. (2018). Procesos contables e información financiera en empresas de fabricación de calzado, Distrito de San Juan de Lurigancho, 2018. (Tesis de Pregrado). Obtenido de

http://repositorio.ucv.edu.pe/bitstream/handle/20.500.12692/34138/DAVALOS_HS.pdf ?sequence $=1$

El Instituto de Comercio Exterior. (2019). Calzado en Perú. Obtenido de https://www.icex.es/icex/wcm/idc/groups/public/documents/documento/mde5/ode5/ e disp/doc2019819676.pdf?utm_source=RSS\&utm_medium=ICEX.es\&utm_content=26 $-04-$

2019\&utm_campaign=Ficha\%20sector.\%20Calzado\%20en\%20Per\%C3\%BA\%20201 9

Esteba, L. (2016). Influencia de la gestión financiera en la rentabilidad de las Mypes, en el sector hotelero - Tacna, año 2014. (Tesis de Pregrado). Obtenido de http://repositorio.unjbg.edu.pe/handle/UNJBG/2702

Fernández, C., Naquiche, R., \& Rojas, A. M. (2018). Aplicación de la gestión financiera en la rentabilidad de la empresa de servicios Ronafe S.A.C. en el distrito de Jesús María, del período 2016-2018. (Tesis de Pregrado). Obtenido de http://repositorio.utp.edu.pe/handle/UTP/1875

García, J. (2019). Estructura de capital y competitividad del mercado. (Tesis de Posgrado). Obtenido de https://repositorio.ufmg.br/bitstream/1843/30956/1/Disserta\%C3\%A7\%C3\%A3o_Joice _VF.pdf 
Gonzales, E. (2018). La administración del capital de trabajo y su influencia en la rentabilidad de la agencia de viajes Expediciones las Balsas S.R.L. - Puno, periodos 2015- 2016. (Tesis de Pregrado). Obtenido de http://repositorio.unap.edu.pe/handle/UNAP/9960

Grayson, K., Nyamazana, M., \& Funjika-Mulenga, P. (2016). Management quality, productivity, and profitability in Zambia. Working Paper. International Growth Centre.

Hair, J., Anderson, R., Tatham, R., \& Black, W. (1999). Análisis Multivariante (5ta ed.). España: Prentice Hall Iberia S.R.L.

Hernández, R., Fernández, C., \& Baptista, M. (2014). Metodología de la Investigación (6ta ed.). México D.F: McGraw-Hill.

Karadag, H. (2015). Financial Management Challenges In Small and Medium-Sized Enterprises: A Strategic Management Approach. Emerging Markets Journal, 5(1), 2640. doi:10.5195/emaj.2015.67

Khominich, I., Rybyantseva, M., Borodacheva, L., Dik, E., \& Afanasev, E. (2016). Financial Management as a System of Relations of the Enterprise for Highly Efficient Management of its Finances. International Journal of Economics and Financial Issues, 6(8S), 96-101, ISSN: 2146-4138.

Kinnear, T., \& Taylor, J. (1998). Investigación de mercados (5ta ed.). México D.F: McGraw-Hill. La Superintendencia Nacional de Aduana y de Administración Tributaria. (2019). Definición de la Micro y Pequeña empresa. Obtenido de http://www.sunat.gob.pe/orientacion/mypes/define-microPequenaEmpresa.html

La Superintendencia Nacional de Aduanas y Administración Tributaria. (2019). Régimen Laboral de la Micro y Pequeña empresa. Obtenido de http://www.sunat.gob.pe/orientacion/mypes/regimenLaboral.html\#: :text=MYPES,a\% 20sus\%20conductores\%20y\%20empleadores.

La Superintendencia Nacional de Aduanas y de Administración Tributaria. (2019). Características de la Micro y Pequeña empresa. Obtenido de http://www.sunat.gob.pe/orientacion/mypes/caracteristicas-

microPequenaEmpresa.html 
La Superintendencia Nacional de Aduanas y de Administración Tributaria. (2019). Información Tributaria - Registro y Base Tributaria. Obtenido de http://www.sunat.gob.pe/estadisticasestudios/registro-baseTributaria.html

Lázaro, M. (2016). Análisis del proceso de financiamiento de las Startups en el Perú desde la perspectiva de los emprendedores. (Tesis de Posgrado). Obtenido de http://repositorio.concytec.gob.pe/bitstream/20.500.12390/237/3/2016_Lazaro_An\%C 3\%A1lisis-del-proceso-de-financiamiento-de-las-startups.pdf

Llempen, A. (2018). Gestión financiera y su incidencia en la rentabilidad de la empresa Inversiones Aquario's S.A.C., Chiclayo - 2018. (Tesis de Pregrado). Obtenido de http://repositorio.uss.edu.pe/handle/uss/5688

Lopéz-Aguado, M. \& Gutiérrez-Provecho, L. (2019). Cómo realizar e interpretar un análisis factorial exploratorio utilizando SPSS. REIRE Revista d'Innovació i Recerca en Educació, 12(2), 1-14.

Macharia, K. (2015). The relationship between financial management practices and financial performance in the dairy industry in Kenya. (Master's thesis). Obtenido de http://erepository.uonbi.ac.ke/bitstream/handle/11295/94484/Kamande\%2C\%20Kelvin \%20M_The\%20relationship\%20between\%20financial\%20management\%20practices \%20and\%20financial\%20performance\%20in\%20the\%20dairy\%20industry\%20in\%20 Kenya. pdf? sequence $=1$ \&isAllowed $=y$

Mendiburu, J. (2019). Modelo de gestión financiera para mejorar la rentabilidad de las Mypes productoras de calzado en el distrito El Porvenir - Trujillo 2015. Revista ciencia y tecnología, 15(1), 49-58, ISSN: 1810-6781.

Mendoza, M. (2017). Gestión Financiera y su relación con el capital de trabajo en las microempresas comercializadoras de calzado en el distrito de Independencia 2017. (Tesis de Pregrado). Obtenido de http://repositorio.ucv.edu.pe/handle/UCV/15606?show=full\&locale-attribute=en

Michue, E. (2015). Gestión de personas y su impacto en la rentabilidad de la empresa FAMACIN S.A.C. (Tesis de Pregrado). Obtenido de http://repositorio.uncp.edu.pe/handle/UNCP/1625 
Minaya, C. (2019). Factores que inciden en la rentabilidad de la central de Cooperativas Agrarias Cafetaleras COCLA LTDA. 281 periodo 2007 - 2017. (Tesis de Pregrado). Obtenido http://repositorio.unas.edu.pe/bitstream/handle/UNAS/1578/CMC_2019.pdf?sequence =1\&amp;isAllowed=y

Muneer, S., Abrar-Ahmad, R., \& Ali, A. (2017). Impact of Financial Management Practices on SMEs Profitability with Moderating Role of Agency Cost. Information Management and Business Review, 9(1), 23-30, ISSN: 2220-3796.

Musah, A., Dodzi-Gakpetor, E., \& Pomaa, P. (2018). Financial Management Practices, Firm Growth and Profitability of Small and Medium Scale Enterprises (SMEs). Information Management and Business Review, 10(3), 25-37, ISSN: 2220-3796.

Mwangi, M. (2018). The effect of financial management practices on the financial performance of the companies listed at Nairobi securities exchange. (Master's thesis). Obtenido de https://www.semanticscholar.org/paper/The-Effect-Of-Financial-ManagementPractices-On-The-Muguchia/a8ae4950950cc1e1a6342755622b8174942ae4d1

Onton, S.,Pérez, G., \& Santana, F. (2019). Gestión Financiera y su efecto en la liquidez de la empresa de calzados Torito E.I.R.L. para el periodo 2018. (Tesis de pregrado). Obtenido de http://repositorio.utp.edu.pe/handle/UTP/2169

Peru Top Publications. (2019). Información de mercados: Calzados. Obtenido de https://ptp.pe/informacion-de-mercados-calzados/

Reyes, D., \& Salina, A. (2015). Implementación de un sistema de información contable y su influencia en la gestión de la contabilidad en la empresa de transportes Turismo Días S.A. año 2015. (Tesis de Pregrado). Obtenido de http://repositorio.upao.edu.pe/bitstream/upaorep/1487/1/Salinas_Jara_Implementacio n_Contable_Gestion.pdf

Rincón, F. (2016). La gestión de calidad y la rentabilidad en las empresas del sector textil en el distrito de La Victoria, año 2015. (Tesis de Pregrado). Obtenido de http://www.repositorioacademico.usmp.edu.pe/bitstream/handle/usmp/2758/rincon_rfy .pdf;jsessionid=A0BAC36A92EDA4BE18E00D8DA046AA8E? sequence $=1$ 
Ríos, J. (2015). Evaluación de la gestión financiera y su incidencia en la rentabilidad, de la empresa zapatería Yuly, periodo 2013. (Tesis de Pregrado). Obtenido de http://repositorio.unsm.edu.pe/handle/11458/1898

Saah, P. (2015). Financial management practices and profitability of small and medium-scale entities in the Tamale metropolitan Area. (Master's thesis), Ghana. Obtenido de http://ir.knust.edu.gh/xmlui/handle/123456789/8587

Selvanayaki, S., Sivakumara, S., Rohinia, A., \& Manib, K. (2016). Financial Management Practices and Profitability of Modern Rice Milling Firms in Kangayam Cluster, Tamil Nadu. Agricultural Economics Research Review, 29(2), 297-306. doi:10.5958/09740279.2016.00057.4

Serrano, T. (2015). Estrategia de inversión: Factor Momentum en IGBM. (Trabajo de Fin de Grado). Obtenido de http://zaguan.unizar.es/record/32571/files/TAZ-TFG-20153500.pdf

The top 10,000 companies. (2019). The top 10,000 companies. Obtenido de http://www.ptp.pe/top10000/

Yensu, J., Konadu-Yiadom, E., \& Awatey, S. (2016). Financial Management Practices and Profitability of Business Enterprises in Obuasi Municipality, Ghana. Research Journal of Finance and Accounting, 7(16), 66-76, ISSN: 2222-1697.

Yohanes, D., Lemie-Debela, K., \& Shibru, W. (2018). Effect of Financial Management Practices on Profitability of Small-Scale Enterprise: Case Study Hawassa City Administration, Ethiopia. IOSR Journal of Business and Management, 20(6), 39-45. 


\section{ANEXOS}

Anexo 1. Matriz de consistencia.

\begin{tabular}{|c|c|c|c|c|}
\hline $\begin{array}{c}\text { FORMULACIÓN DE } \\
\text { PROBLEMA }\end{array}$ & OBJETIVOS & HIPÓTESIS & VARIABLES & METODOLOGÍA \\
\hline Problema General & Objetivo General & Hipótesis General & \multirow{7}{*}{$\begin{array}{l}\text { Variable 1: } \\
\text { X: Prácticas de } \\
\text { la gestión } \\
\text { financiera } \\
\text { X1: Prácticas de } \\
\text { gestión del } \\
\text { capital de } \\
\text { trabajo. } \\
\text { X2: Sistema de } \\
\text { información } \\
\text { contable - } \\
\text { práctica de } \\
\text { análisis de } \\
\text { informes } \\
\text { financieros. } \\
\text { X3: Gestión de } \\
\text { estructura de } \\
\text { capital - } \\
\text { financiamiento } \\
\text { X4: Presupuesto } \\
\text { de capital - } \\
\text { gestión de } \\
\text { activos no } \\
\text { corrientes }\end{array}$} & \multirow{7}{*}{$\begin{array}{l}\text { Método de investigación: } \\
\text { Enfoque cuantitativo. } \\
\text { Tipo de investigación: } \\
\text { Esta investigación de basa } \\
\text { en un tipo cuantitativo } \\
\text { correlacional. } \\
\text { Diseño de investigación: } \\
\text { No experimental de corte } \\
\text { transversal. } \\
\quad \text { Muestra: } \\
\text { 203 fabricantes Mypes de } \\
\text { calzado de Comas } 2020 \\
\text { Instrumentos de la } \\
\text { investigación: } \\
\text { - Cuestionario de prácticas } \\
\text { de gestión financiera: } 24 \\
\text { ítems } \\
\text { Autores: } \\
\text { - Alhassan Musah } \\
\text { - Erasmus Dodzi Gakpetor } \\
\text { - Portia Pomaa } \\
\text { Año: } 2018 \\
\text { País: Republica de Ghana } \\
\text { - Cuestionario de } \\
\text { rentabilidad: } 6 \text { ítems } \\
\text { Autores: } \\
\text { - Koyi Grayson } \\
\text { - Mushiba Nyamazana } \\
\text { - Patricia Funjika-Mulenga } \\
\text { Año: } 2016 \\
\text { País: Inglaterra }\end{array}$} \\
\hline $\begin{array}{c}\text { ¿Existe relación entre las } \\
\text { prácticas de gestión financiera y } \\
\text { la rentabilidad de los fabricantes } \\
\text { Mypes de calzado de Comas } \\
2020 ?\end{array}$ & $\begin{array}{l}\text { Determinar cómo se relacionan las } \\
\text { prácticas de gestión financiera y la } \\
\text { rentabilidad de los fabricantes Mypes } \\
\text { de calzado de Comas } 2020 \text {. }\end{array}$ & $\begin{array}{l}\text { Las prácticas de gestión } \\
\text { financiera se relacionan } \\
\text { positivamente con la rentabilidad } \\
\text { de los fabricantes Mypes de } \\
\text { calzado de Comas } 2020 .\end{array}$ & & \\
\hline Problemas Específicos & Objetivos Específicos & Hipótesis Específicos & & \\
\hline $\begin{array}{c}\text { ¿Existe relación entre las } \\
\text { prácticas de gestión del capital } \\
\text { de trabajo y la rentabilidad de los } \\
\text { fabricantes Mypes de calzado de } \\
\text { Comas 2020? }\end{array}$ & $\begin{array}{l}\text { Determinar cómo se relacionan las } \\
\text { prácticas de gestión del capital de } \\
\text { trabajo y la rentabilidad de los } \\
\text { fabricantes Mypes de calzado de } \\
\text { Comas } 2020 .\end{array}$ & $\begin{array}{l}\text { Las prácticas de gestión del } \\
\text { capital de trabajo se relacionan } \\
\text { positivamente con la rentabilidad } \\
\text { de los fabricantes Mypes de } \\
\text { calzado de Comas } 2020 .\end{array}$ & & \\
\hline $\begin{array}{c}\text { ¿Existe relación entre el sistema } \\
\text { de información contable - práctica } \\
\text { de análisis de informes } \\
\text { financieros y la rentabilidad de } \\
\text { los fabricantes Mypes de calzado } \\
\text { de Comas 2020? }\end{array}$ & $\begin{array}{l}\text { Determinar cómo se relaciona el } \\
\text { sistema de información contable - } \\
\text { práctica de análisis de informes } \\
\text { financieros y la rentabilidad de los } \\
\text { fabricantes Mypes de calzado de } \\
\text { Comas } 2020\end{array}$ & $\begin{array}{l}\text { El sistema de información } \\
\text { contable - práctica de análisis de } \\
\text { informes financieros se relaciona } \\
\text { positivamente con la rentabilidad } \\
\text { de los fabricantes Mypes de } \\
\text { calzado de Comas } 2020 .\end{array}$ & & \\
\hline $\begin{array}{l}\text { ¿Existe relación entre la gestión } \\
\text { de la estructura de capital - } \\
\text { financiamiento y la rentabilidad } \\
\text { de los fabricantes Mypes de } \\
\text { calzado de Comas 2020? }\end{array}$ & $\begin{array}{l}\text { Determinar cómo se relaciona la } \\
\text { gestión de estructura de capital - } \\
\text { financiamiento y la rentabilidad de los } \\
\text { fabricantes Mypes de calzado de } \\
\text { Comas } 2020 \text {. }\end{array}$ & $\begin{array}{l}\text { La gestión de estructura de } \\
\text { capital - financiamiento se } \\
\text { relaciona positivamente con la } \\
\text { rentabilidad de los fabricantes } \\
\text { Mypes de calzado de Comas } \\
2020 \text {. }\end{array}$ & & \\
\hline $\begin{array}{l}\text { ¿Existe relación entre el } \\
\text { presupuesto de capital - gestión } \\
\text { de activos no corrientes y la } \\
\text { rentabilidad de los fabricantes } \\
\text { Mypes de calzado de Comas } \\
2020 ?\end{array}$ & $\begin{array}{c}\text { Determinar cómo se relaciona el } \\
\text { presupuesto de capital - gestión de } \\
\text { activos no corrientes y la rentabilidad } \\
\text { de los fabricantes Mypes de calzado } \\
\text { de Comas } 2020 .\end{array}$ & $\begin{array}{l}\text { El presupuesto de capital - } \\
\text { gestión de activos no corrientes } \\
\text { se relaciona positivamente con la } \\
\text { rentabilidad de los fabricantes } \\
\text { Mypes de calzado de Comas } \\
2020 \text {. }\end{array}$ & & \\
\hline
\end{tabular}




\section{Anexo 2. Cuestionario de Prácticas de Gestión Financiera}

\section{Tema: "LAS PRÁCTICAS DE GESTIÓN FINANCIERA Y LA RENTABILIDAD DE LOS FABRICANTES MYPES DE CALZADO DE COMAS 2020"}

A continuación, se presenta una serie de ítems para que sean respondidos por usted. Lea detenidamente cada enunciado, marque una sola alternativa con un $\mathrm{X}$ en la casilla correspondiente al enunciado elegido. Es fundamental su absoluta sinceridad dentro de las respuestas, pues de ellas depende el éxito de la presente investigación.

NOTA: Para cada pregunta se considera la escala de 1 a 5 donde:

\section{Prácticas de Gestión Financiera}

\begin{tabular}{|c|c|c|c|c|}
\hline 1 & 2 & 3 & 4 & 5 \\
\hline $\begin{array}{c}\text { Muy en } \\
\text { desacuerdo }\end{array}$ & $\begin{array}{c}\text { En } \\
\text { desacuerdo }\end{array}$ & $\begin{array}{c}\text { Ni de acuerdo, } \\
\text { ni en } \\
\text { desacuerdo }\end{array}$ & De acuerdo & Muy de acuerdo \\
\hline
\end{tabular}

\begin{tabular}{|c|c|c|c|c|c|c|}
\hline Número & ITEM & 1 & 2 & 3 & 4 & 5 \\
\hline 1 & $\begin{array}{l}\text { La empresa cuenta con un sistema de gestión de } \\
\text { capital de trabajo. }\end{array}$ & & & & & \\
\hline 2 & $\begin{array}{l}\text { Mantiene registros de inventario que se actualizan } \\
\text { regularmente. }\end{array}$ & & & & & \\
\hline 3 & $\begin{array}{l}\text { La empresa mantiene saldos de efectivo óptimos } \\
\text { en todo momento }\end{array}$ & & & & & \\
\hline 4 & $\begin{array}{l}\text { Mantiene registros adecuados y oportunos para } \\
\text { todas las cuentas por pagar, catalogando a sus } \\
\text { acreedores según sus condiciones de pago. }\end{array}$ & & & & & \\
\hline 5 & $\begin{array}{l}\text { Asegura que haya suficiente flujo de efectivo para } \\
\text { satisfacer las necesidades diarias. }\end{array}$ & & & & & \\
\hline 6 & $\begin{array}{l}\text { Prepara pronósticos de flujo de efectivo para } \\
\text { identificar futuros excedentes y déficits. }\end{array}$ & & & & & \\
\hline 7 & $\begin{array}{l}\text { Lo estados financieros de la empresa se preparan } \\
\text { de acuerdo con los estándares de contabilidad } \\
\text { financiera. }\end{array}$ & & & & & \\
\hline 8 & $\begin{array}{l}\text { Los estados financieros se preparan de acuerdo } \\
\text { con los principios contables generalmente } \\
\text { aceptados. }\end{array}$ & & & & & \\
\hline 9 & Los estados financieros se publican regularmente. & & & & & \\
\hline
\end{tabular}




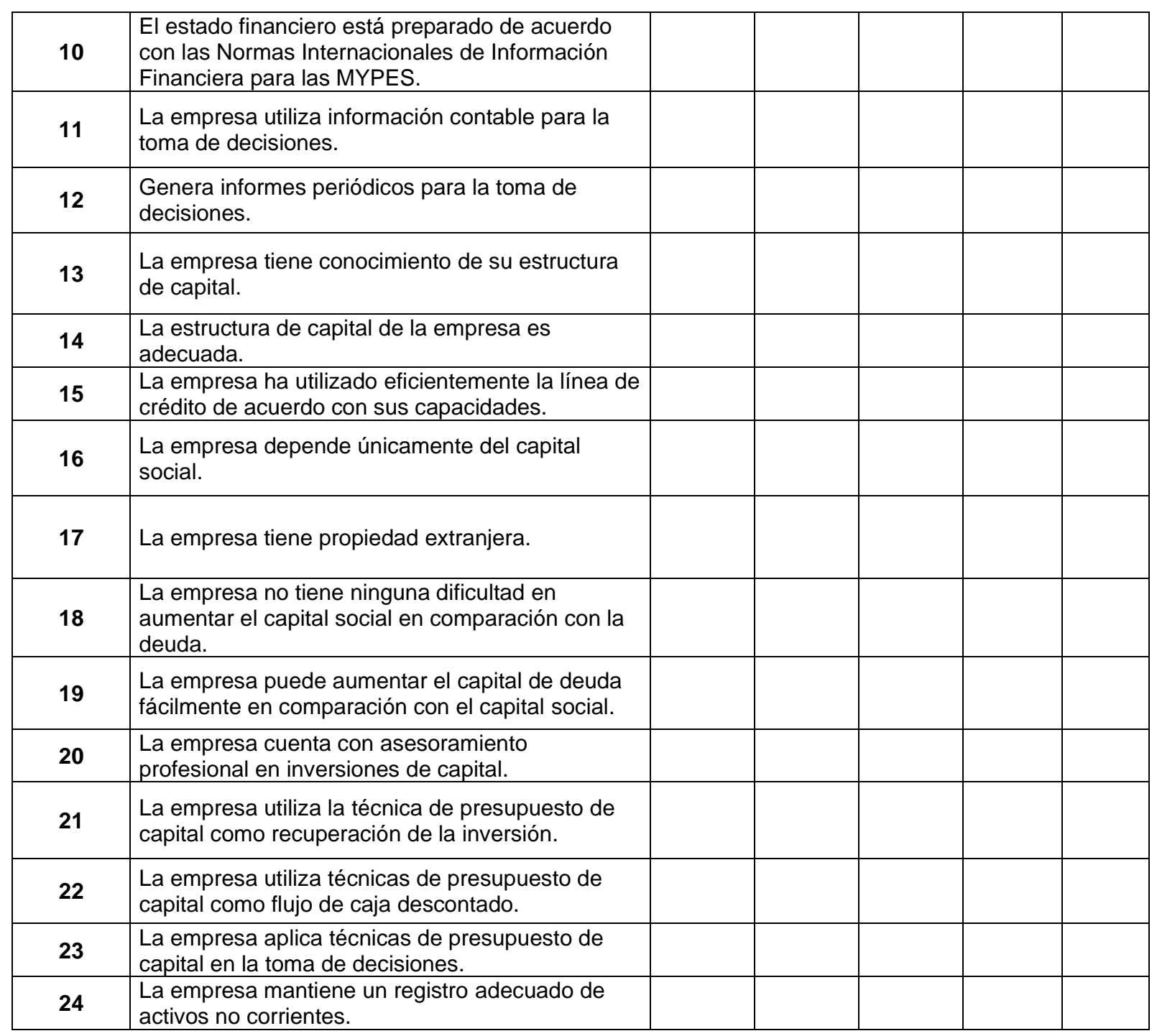




\section{Anexo 3. Cuestionario de Rentabilidad}

\section{Tema: "LAS PRÁCTICAS DE GESTIÓN FINANCIERA Y LA RENTABILIDAD DE LOS FABRICANTES MYPES DE CALZADO DE COMAS 2020"}

A continuación, se presenta una serie de ítems para que sean respondidos por usted. Lea detenidamente cada enunciado, marque una sola alternativa con un $\mathrm{X}$ en la casilla correspondiente al enunciado elegido. Es fundamental su absoluta sinceridad dentro de las respuestas, pues de ellas depende el éxito de la presente investigación.

\section{Rentabilidad}

NOTA: Para cada pregunta se considera la escala de 1 a 5 donde:

\begin{tabular}{|c|c|c|c|c|}
\hline 1 & 2 & 3 & 4 & 5 \\
\hline $\begin{array}{c}\text { Muy en } \\
\text { desacuerdo }\end{array}$ & $\begin{array}{c}\text { En } \\
\text { desacuerdo }\end{array}$ & $\begin{array}{c}\text { Ni de acuerdo, } \\
\text { ni en } \\
\text { desacuerdo }\end{array}$ & De acuerdo & Muy de acuerdo \\
\hline
\end{tabular}

\begin{tabular}{|c|c|c|c|c|c|c|}
\hline Número & ITEM & 1 & 2 & 3 & 4 & 5 \\
\hline 1 & Las ventas de la empresa han crecido. & & & & & \\
\hline 2 & $\begin{array}{l}\text { El retorno de los activos de la empresa ha } \\
\text { aumentado. }\end{array}$ & & & & & \\
\hline 3 & $\begin{array}{l}\text { El rendimiento del capital de la empresa ha } \\
\text { aumentado. }\end{array}$ & & & & & \\
\hline 4 & $\begin{array}{l}\text { El retorno de la inversión de la empresa ha } \\
\text { aumentado. }\end{array}$ & & & & & \\
\hline 5 & Las ganancias de la empresa han crecido. & & & & & \\
\hline 6 & $\begin{array}{l}\text { La cuota de mercado de la empresa ha } \\
\text { mejorado. }\end{array}$ & & & & & \\
\hline
\end{tabular}


Anexo 4. Coeficiente V de Aiken - Prácticas de gestión financiera

\begin{tabular}{|c|c|c|c|c|c|c|c|c|c|c|c|c|c|c|}
\hline JUECES & & & Z 1 & & & JU & $Z 2$ & & & JU & Z3 & & SUMA & AIKEN \\
\hline ITEM & $\begin{array}{c}\text { CLARI } \\
\text { DAD }\end{array}$ & $\begin{array}{c}\text { CONG } \\
\text { RUENC } \\
\text { IA }\end{array}$ & $\begin{array}{c}\text { CONTE } \\
\text { XTO }\end{array}$ & $\begin{array}{l}\text { DOMINI } \\
\text { O DEL } \\
\text { CONST } \\
\text { RUCTO }\end{array}$ & $\begin{array}{c}\text { CLARID } \\
\text { AD }\end{array}$ & $\begin{array}{c}\text { CONG } \\
\text { RUENC } \\
\text { IA }\end{array}$ & $\begin{array}{c}\text { CONTE } \\
\text { XTO }\end{array}$ & $\begin{array}{l}\text { DOMINI } \\
\text { O DEL } \\
\text { CONST } \\
\text { RUCTO }\end{array}$ & $\begin{array}{c}\text { CLARID } \\
\text { AD }\end{array}$ & $\begin{array}{c}\text { CONG } \\
\text { RUENC } \\
\text { IA }\end{array}$ & $\begin{array}{c}\text { CONTE } \\
\text { XTO }\end{array}$ & $\begin{array}{l}\text { DOMINI } \\
\text { O DEL } \\
\text { CONST } \\
\text { RUCTO }\end{array}$ & & \\
\hline PGF1 & 5 & 5 & 5 & 5 & 4 & 4 & 4 & 4 & 4 & 4 & 4 & 4 & 52.00 & 0.87 \\
\hline PGF2 & 5 & 5 & 4 & 4 & 5 & 5 & 5 & 4 & 4 & 4 & 4 & 4 & 53.00 & 0.88 \\
\hline PGF3 & 5 & 5 & 5 & 5 & 4 & 4 & 4 & 4 & 4 & 4 & 4 & 4 & 52.00 & 0.87 \\
\hline PGF4 & 5 & 5 & 4 & 4 & 3 & 3 & 3 & 3 & 4 & 4 & 4 & 4 & 46.00 & 0.77 \\
\hline PGF5 & 5 & 5 & 5 & 5 & 4 & 4 & 4 & 3 & 4 & 4 & 4 & 4 & 51.00 & 0.85 \\
\hline PGF6 & 5 & 5 & 4 & 4 & 5 & 5 & 5 & 4 & 4 & 4 & 4 & 4 & 53.00 & 0.88 \\
\hline PGF7 & 5 & 5 & 5 & 5 & 5 & 5 & 5 & 5 & 4 & 4 & 4 & 4 & 56.00 & 0.93 \\
\hline PGF8 & 5 & 5 & 5 & 5 & 5 & 5 & 5 & 5 & 4 & 4 & 4 & 4 & 56.00 & 0.93 \\
\hline PGF9 & 5 & 5 & 5 & 5 & 5 & 5 & 5 & 5 & 4 & 4 & 4 & 4 & 56.00 & 0.93 \\
\hline PGF10 & 5 & 5 & 5 & 5 & 5 & 5 & 5 & 5 & 4 & 4 & 4 & 4 & 56.00 & 0.93 \\
\hline PGF11 & 5 & 5 & 4 & 4 & 5 & 5 & 5 & 5 & 4 & 4 & 4 & 4 & 54.00 & 0.90 \\
\hline PGF12 & 5 & 5 & 4 & 4 & 5 & 5 & 5 & 4 & 4 & 4 & 4 & 4 & 53.00 & 0.88 \\
\hline
\end{tabular}




\begin{tabular}{|c|c|c|c|c|c|c|c|c|c|c|c|c|c|c|}
\hline PGF13 & 5 & 5 & 4 & 4 & 4 & 4 & 4 & 4 & 4 & 4 & 4 & 4 & 50.00 & 0.83 \\
\hline PGF14 & 5 & 5 & 4 & 4 & 4 & 4 & 4 & 4 & 4 & 4 & 4 & 4 & 50.00 & 0.83 \\
\hline PGF15 & 5 & 5 & 4 & 4 & 4 & 4 & 4 & 4 & 4 & 4 & 4 & 4 & 50.00 & 0.83 \\
\hline PGF16 & 5 & 5 & 5 & 5 & 4 & 4 & 4 & 4 & 4 & 4 & 4 & 4 & 52.00 & 0.87 \\
\hline PGF17 & 5 & 5 & 5 & 5 & 5 & 5 & 5 & 1 & 3 & 3 & 3 & 3 & 48.00 & 0.80 \\
\hline PGF18 & 5 & 5 & 5 & 5 & 5 & 5 & 5 & 3 & 4 & 4 & 4 & 4 & 54.00 & 0.90 \\
\hline PGF19 & 5 & 5 & 5 & 5 & 4 & 4 & 4 & 3 & 4 & 4 & 4 & 4 & 51.00 & 0.85 \\
\hline PGF20 & 5 & 5 & 5 & 5 & 4 & 4 & 4 & 4 & 4 & 4 & 4 & 4 & 52.00 & 0.87 \\
\hline PGF21 & 5 & 5 & 5 & 5 & 4 & 4 & 4 & 4 & 4 & 4 & 4 & 4 & 52.00 & 0.87 \\
\hline PGF22 & 5 & 5 & 5 & 5 & 4 & 4 & 4 & 4 & 4 & 4 & 4 & 4 & 52.00 & 0.87 \\
\hline PGF23 & 5 & 5 & 5 & 5 & 4 & 4 & 4 & 5 & 4 & 4 & 4 & 4 & 53.00 & 0.88 \\
\hline PGF24 & 5 & 5 & 5 & 5 & 4 & 4 & 4 & 4 & 4 & 4 & 4 & 4 & 52.00 & 0.87 \\
\hline
\end{tabular}


Anexo 5. Coeficiente V de Aiken - Rentabilidad

\begin{tabular}{|c|c|c|c|c|c|c|c|c|c|c|c|c|c|c|}
\hline JUECES & \multicolumn{4}{|c|}{ JUEZ 1} & \multicolumn{4}{|c|}{ JUEZ 2} & \multicolumn{4}{|c|}{ JUEZ 3} & \multirow[t]{2}{*}{ SUMA } & \multirow[t]{2}{*}{ AIKEN } \\
\hline ITEM & $\begin{array}{c}\text { CLARID } \\
\text { AD }\end{array}$ & $\begin{array}{c}\text { CONGRU } \\
\text { ENCIA }\end{array}$ & $\begin{array}{c}\text { CONTEXT } \\
\mathrm{O}\end{array}$ & $\begin{array}{l}\text { DOMINIO } \\
\text { DEL } \\
\text { CONSTR } \\
\text { UCTO }\end{array}$ & $\begin{array}{c}\text { CLARIDA } \\
\text { D }\end{array}$ & $\begin{array}{c}\text { CONGRU } \\
\text { ENCIA }\end{array}$ & $\begin{array}{c}\text { CONTEXT } \\
\mathrm{O}\end{array}$ & $\begin{array}{l}\text { DOMINIO } \\
\text { DEL } \\
\text { CONSTR } \\
\text { UCTO }\end{array}$ & $\begin{array}{c}\text { CLARIDA } \\
\text { D }\end{array}$ & $\begin{array}{c}\text { CONGRU } \\
\text { ENCIA }\end{array}$ & $\begin{array}{c}\text { CONTEXT } \\
\text { O }\end{array}$ & $\begin{array}{c}\text { DOMINIO } \\
\text { DEL } \\
\text { CONSTR } \\
\text { UCTO }\end{array}$ & & \\
\hline R1 & 5 & 4 & 5 & 5 & 5 & 5 & 5 & 5 & 4 & 4 & 4 & 4 & 55.00 & 0.92 \\
\hline R2 & 4 & 5 & 5 & 5 & 5 & 5 & 5 & 5 & 4 & 4 & 4 & 4 & 55.00 & 0.92 \\
\hline R3 & 5 & 5 & 4 & 5 & 5 & 5 & 5 & 5 & 4 & 4 & 4 & 4 & 55.00 & 0.92 \\
\hline R4 & 5 & 4 & 4 & 4 & 5 & 5 & 5 & 5 & 4 & 4 & 4 & 4 & 53.00 & 0.88 \\
\hline R5 & 5 & 5 & 4 & 5 & 5 & 5 & 5 & 5 & 4 & 4 & 4 & 4 & 55.00 & 0.92 \\
\hline R6 & 5 & 5 & 4 & 5 & 5 & 5 & 5 & 5 & 4 & 4 & 4 & 4 & 55.00 & 0.92 \\
\hline & & & & & & & & & & & & KEN & 0.91 & \\
\hline
\end{tabular}




\section{Anexo 6. Alpha de Cronbach de Prácticas de gestión del capital de trabajo}

Estadísticas de confiabilidad

\begin{tabular}{|r|r|}
\hline $\begin{array}{c}\text { Alfa de } \\
\text { Cronbach }\end{array}$ & N de ítems \\
\hline .871 & 6 \\
\hline
\end{tabular}

Ítem-Estadísticas totales

\begin{tabular}{|c|c|c|c|c|}
\hline & $\begin{array}{l}\text { Media de escala } \\
\text { si el elemento } \\
\text { se ha suprimido }\end{array}$ & $\begin{array}{c}\text { Varianza de } \\
\text { escala si el } \\
\text { elemento se ha } \\
\text { suprimido }\end{array}$ & $\begin{array}{c}\text { Correlación total } \\
\text { de elementos } \\
\text { corregida }\end{array}$ & $\begin{array}{c}\text { Alfa de } \\
\text { Cronbach si el } \\
\text { elemento se ha } \\
\text { suprimido }\end{array}$ \\
\hline $\begin{array}{l}\text { PGF1. La empresa cuenta } \\
\text { con un sistema de gestión } \\
\text { de capital de trabajo. } \\
\text { PGF2. Mantiene registros } \\
\text { de inventario que se } \\
\text { actualizan regularmente. } \\
\text { PGF3. La empresa } \\
\text { mantiene saldos de efectivo } \\
\text { óptimos en todo momento. } \\
\text { PGF4. Mantiene registros } \\
\text { adecuados y oportunos para } \\
\text { todas las cuentas por pagar, } \\
\text { catalogando a sus } \\
\text { acreedores según sus } \\
\text { condiciones de pago. } \\
\text { PGF5. Asegura que haya } \\
\text { suficiente flujo de efectivo } \\
\text { para satisfacer las } \\
\text { necesidades diarias. } \\
\text { PGF6. Prepara pronósticos } \\
\text { de flujo de efectivo para } \\
\text { identificar futuros } \\
\text { excedentes y déficits. }\end{array}$ & $\begin{array}{l}15.58 \\
15.08 \\
15.69 \\
15.08 \\
15.96\end{array}$ & $\begin{array}{l}20.878 \\
22.820 \\
20.502 \\
24.414 \\
22.557\end{array}$ & $\begin{array}{l}.791 \\
.656 \\
.831 \\
.525 \\
.638\end{array}$ & $\begin{array}{l}.852 \\
.820 \\
.873\end{array}$ \\
\hline
\end{tabular}


Anexo 7. Alpha de Cronbach de Sistema de información contable - práctica de análisis de informes financieros

Estadísticas de confiabilidad

\begin{tabular}{|r|r|}
\hline $\begin{array}{c}\text { Alfa de } \\
\text { Cronbach }\end{array}$ & N de ítems \\
\hline .730 & 4 \\
\hline
\end{tabular}

Ítem-Estadísticas totales

\begin{tabular}{|c|c|c|c|c|}
\hline & $\begin{array}{c}\text { Media de escala } \\
\text { si el elemento } \\
\text { se ha suprimido }\end{array}$ & $\begin{array}{c}\text { Varianza de } \\
\text { escala si el } \\
\text { elemento se ha } \\
\text { suprimido }\end{array}$ & $\begin{array}{c}\text { Correlación total } \\
\text { de elementos } \\
\text { corregida }\end{array}$ & $\begin{array}{c}\text { Alfa de } \\
\text { Cronbach si el } \\
\text { elemento se ha } \\
\text { suprimido }\end{array}$ \\
\hline $\begin{array}{l}\text { PGF7. Los estados } \\
\text { financieros de la empresa } \\
\text { se preparan de acuerdo con } \\
\text { los estándares de } \\
\text { contabilidad financiera. } \\
\text { PGF10. El estado financiero } \\
\text { está preparado de acuerdo } \\
\text { con las Normas } \\
\text { Internacionales de } \\
\text { Información Financiera para } \\
\text { las MYPES. } \\
\text { PGF11. La empresa utiliza } \\
\text { información contable para la } \\
\text { toma de decisiones. } \\
\text { PGF12. Genera informes } \\
\text { periódicos para la toma de } \\
\text { decisiones. }\end{array}$ & $\begin{array}{l}9.87 \\
9.85 \\
9.10 \\
9.76\end{array}$ & $\begin{array}{l}5.825 \\
6.100 \\
6.539 \\
6.231\end{array}$ & $\begin{array}{r}.425 \\
.465\end{array}$ & $\begin{array}{l}.724 \\
.704\end{array}$ \\
\hline
\end{tabular}




\section{Anexo 8. Alpha de Cronbach de Gestión de estructura de capital-financiamiento.}

Estadísticas de confiabilidad

\begin{tabular}{|r|r|}
\hline $\begin{array}{c}\text { Alfa de } \\
\text { Cronbach }\end{array}$ & N de ítems \\
\hline .836 & 6 \\
\hline
\end{tabular}

Ítem-Estadísticas totales

\begin{tabular}{|c|c|c|c|c|}
\hline & $\begin{array}{c}\text { Media de escala } \\
\text { si el elemento } \\
\text { se ha suprimido }\end{array}$ & $\begin{array}{c}\text { Varianza de } \\
\text { escala si el } \\
\text { elemento se ha } \\
\text { suprimido }\end{array}$ & $\begin{array}{c}\text { Correlación total } \\
\text { de elementos } \\
\text { corregida }\end{array}$ & $\begin{array}{c}\text { Alfa de } \\
\text { Cronbach si el } \\
\text { elemento se ha } \\
\text { suprimido }\end{array}$ \\
\hline $\begin{array}{l}\text { PGF13. La empresa tiene } \\
\text { conocimiento de su } \\
\text { estructura de capital. } \\
\text { PGF14. La estructura de } \\
\text { capital de la empresa es } \\
\text { adecuada. } \\
\text { PGF15. La empresa ha } \\
\text { utilizado eficientemente la } \\
\text { línea de crédito de acuerdo } \\
\text { con sus capacidades. } \\
\text { PGF16. La empresa } \\
\text { depende únicamente del } \\
\text { capital social. } \\
\text { PGF18. La empresa no } \\
\text { tiene ninguna dificultad en } \\
\text { aumentar el capital social en } \\
\text { comparación con la deuda. } \\
\text { PGF19. La empresa puede } \\
\text { aumentar el capital de } \\
\text { deuda fácilmente en } \\
\text { comparación con el capital } \\
\text { social. }\end{array}$ & $\begin{array}{l}14.94 \\
15.28 \\
15.17 \\
16.69 \\
16.53 \\
14.96\end{array}$ & $\begin{array}{l}11.634 \\
11.213 \\
10.223 \\
12.916 \\
13.646\end{array}$ & $\begin{array}{l}.608 \\
.607 \\
.697 \\
.471 \\
.490 \\
.836\end{array}$ & $\begin{array}{l}.833 \\
.764\end{array}$ \\
\hline
\end{tabular}


Anexo 9. Alpha de Cronbach de Presupuesto de capital - gestión de activos no corrientes.

Estadísticas de confiabilidad

\begin{tabular}{|r|r|}
\hline $\begin{array}{c}\text { Alfa de } \\
\text { Cronbach }\end{array}$ & N de ítems \\
\hline .902 & 5 \\
\hline
\end{tabular}

Ítem-Estadísticas totales

\begin{tabular}{|c|c|c|c|c|}
\hline & $\begin{array}{l}\text { Media de escala } \\
\text { si el elemento } \\
\text { se ha suprimido }\end{array}$ & $\begin{array}{c}\text { Varianza de } \\
\text { escala si el } \\
\text { elemento se ha } \\
\text { suprimido }\end{array}$ & $\begin{array}{l}\text { Correlación total } \\
\text { de elementos } \\
\text { corregida }\end{array}$ & $\begin{array}{c}\text { Alfa de } \\
\text { Cronbach si el } \\
\text { elemento se ha } \\
\text { suprimido }\end{array}$ \\
\hline $\begin{array}{l}\text { PGF20. La empresa cuenta } \\
\text { con asesoramiento } \\
\text { profesional en inversiones } \\
\text { de capital. } \\
\text { PGF21. La empresa utiliza } \\
\text { la técnica de presupuesto } \\
\text { de capital como } \\
\text { recuperación de la } \\
\text { inversión. } \\
\text { PGF22. La empresa utiliza } \\
\text { técnicas de presupuesto de } \\
\text { capital como flujo de caja } \\
\text { descontado. } \\
\text { PGF23. La empresa aplica } \\
\text { técnicas de presupuesto de } \\
\text { capital en la toma de } \\
\text { decisiones. } \\
\text { PGF24. La empresa } \\
\text { mantiene un registro } \\
\text { adecuado de activos no } \\
\text { corrientes. }\end{array}$ & $\begin{array}{l}11.14 \\
11.27 \\
11.72 \\
11.15 \\
11.72\end{array}$ & $\begin{array}{l}17.885 \\
17.228 \\
18.698 \\
17.100 \\
18.490\end{array}$ & $\begin{array}{l}.827 \\
.659 \\
.811 \\
.712\end{array}$ & $\begin{array}{l}.900 \\
.868 \\
.889\end{array}$ \\
\hline
\end{tabular}




\section{Anexo 10. Alpha de Cronbach de Rentabilidad}

Estadísticas de confiabilidad

\begin{tabular}{|r|r|}
\hline $\begin{array}{c}\text { Alfa de } \\
\text { Cronbach }\end{array}$ & N de ítems \\
\hline .872 & 6 \\
\hline
\end{tabular}

Ítem-Estadísticas totales

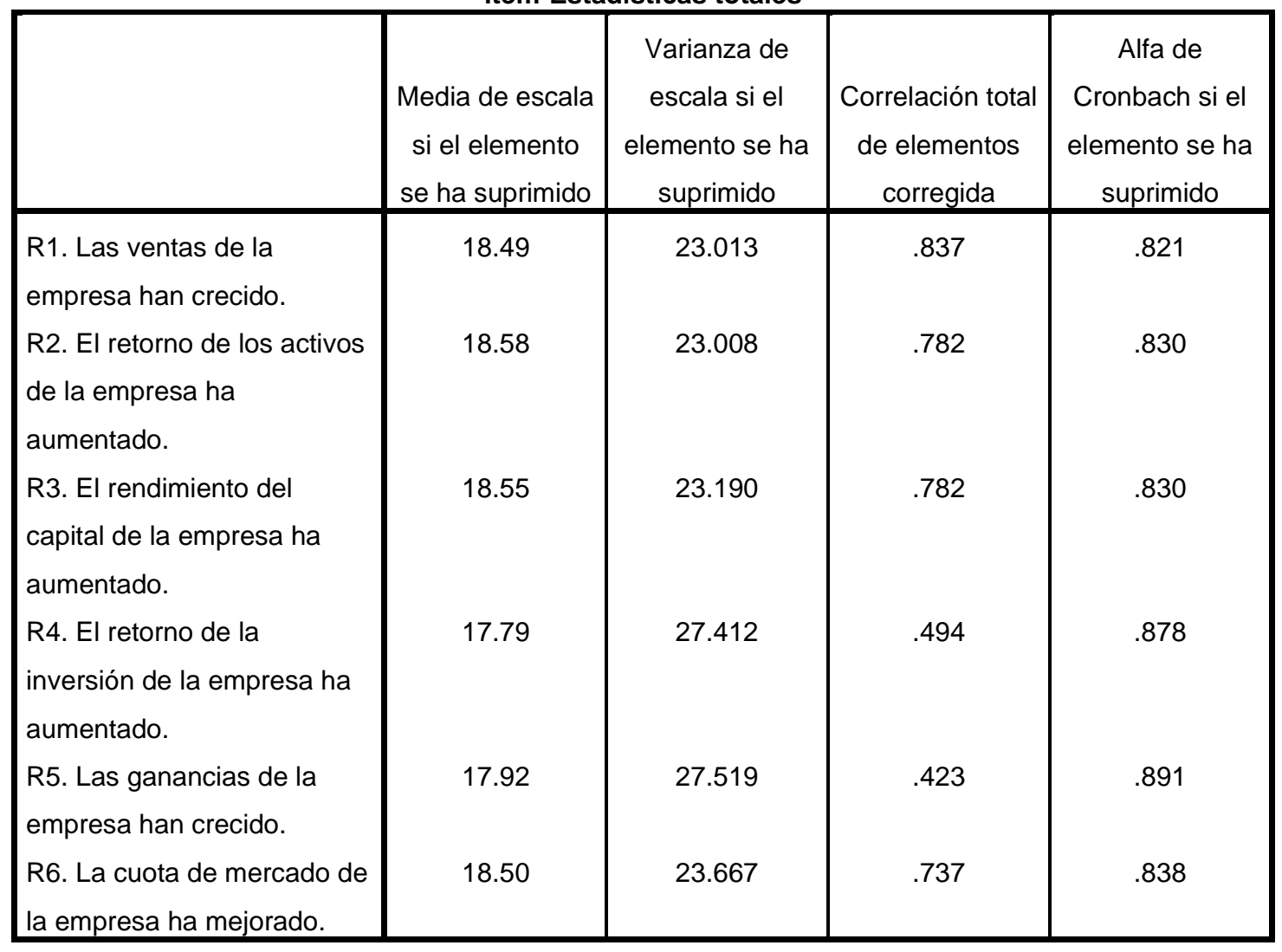




\section{Anexo 11. Prueba de normalidad Kolmogorov-Smirnov de Prácticas de gestión financiera}

Pruebas de normalidad

\begin{tabular}{|l|c|c|c|c|c|c|}
\hline \multirow{2}{*}{\multicolumn{1}{|c|}{ Ítems }} & \multicolumn{3}{|c|}{ Kolmogorov-Smirnov } & \multicolumn{3}{c|}{ Shapiro-Wilk } \\
\cline { 2 - 7 } & Estadístico & gl & Sig. & Estadístico & gl & Sig. \\
\hline $\begin{array}{l}\text { PGF1. La empresa cuenta } \\
\text { con un sistema de gestión } \\
\text { de capital de trabajo. }\end{array}$ & .173 & 203 & .000 & .907 & 203 & .000 \\
\hline $\begin{array}{l}\text { PGF2. Mantiene registros de } \\
\text { inventario que se actualizan } \\
\text { regularmente. }\end{array}$ & .228 & 203 & .000 & .889 & 203 & .000 \\
\hline $\begin{array}{l}\text { PGF3. La empresa mantiene } \\
\text { saldos de efectivo óptimos } \\
\text { en todo momento. }\end{array}$ & .159 & 203 & .000 & .909 & 203 & .000 \\
\hline $\begin{array}{l}\text { PGF4. Mantiene registros } \\
\text { adecuados y oportunos para } \\
\text { todas las cuentas por pagar, } \\
\text { catalogando a sus } \\
\text { acreedores según sus } \\
\text { condiciones de pago. }\end{array}$ & .239 & 203 & .000 & .893 & 203 & .000 \\
\hline $\begin{array}{l}\text { PGF5. Asegura que haya } \\
\text { suficiente flujo de efectivo } \\
\text { para satisfacer las } \\
\text { necesidades diarias. }\end{array}$ & .182 & 203 & .000 & .912 & 203 & .000 \\
\hline $\begin{array}{l}\text { PGF6. Prepara pronósticos } \\
\text { de flujo de efectivo para } \\
\text { identificar futuros } \\
\text { excedentes y déficits. }\end{array}$ & .238 & 203 & .000 & .887 & 203 & .000 \\
\hline $\begin{array}{l}\text { PGF7. Los estados } \\
\text { financieros de la empresa se } \\
\text { preparan de acuerdo con los } \\
\text { estándares de contabilidad } \\
\text { financiera. }\end{array}$ & .213 & 203 & .000 & .908 & 203 & \\
\hline
\end{tabular}




\begin{tabular}{|c|c|c|c|c|c|c|}
\hline $\begin{array}{l}\text { PGF10. El estado financiero } \\
\text { está preparado de acuerdo } \\
\text { con las Normas } \\
\text { Internacionales de } \\
\text { Información Financiera para } \\
\text { las MYPES. }\end{array}$ & .205 & 203 & .000 & .912 & 203 & .000 \\
\hline $\begin{array}{l}\text { PGF11. La empresa utiliza } \\
\text { información contable para la } \\
\text { toma de decisiones. }\end{array}$ & .229 & 203 & .000 & .872 & 203 & .000 \\
\hline $\begin{array}{l}\text { PGF12. Genera informes } \\
\text { periódicos para la toma de } \\
\text { decisiones. }\end{array}$ & .171 & 203 & .000 & .916 & 203 & .000 \\
\hline $\begin{array}{l}\text { PGF13. La empresa tiene } \\
\text { conocimiento de su } \\
\text { estructura de capital. }\end{array}$ & .235 & 203 & .000 & .869 & 203 & .000 \\
\hline $\begin{array}{l}\text { PGF14. La estructura de } \\
\text { capital de la empresa es } \\
\text { adecuada. }\end{array}$ & .222 & 203 & .000 & .894 & 203 & .000 \\
\hline $\begin{array}{l}\text { PGF15. La empresa ha } \\
\text { utilizado eficientemente la } \\
\text { línea de crédito de acuerdo } \\
\text { con sus capacidades. }\end{array}$ & .208 & 203 & .000 & .892 & 203 & .000 \\
\hline $\begin{array}{l}\text { PGF16. La empresa } \\
\text { depende únicamente del } \\
\text { capital social. }\end{array}$ & .214 & 203 & .000 & .842 & 203 & .000 \\
\hline $\begin{array}{l}\text { PGF18. La empresa no tiene } \\
\text { ninguna dificultad en } \\
\text { aumentar el capital social en } \\
\text { comparación con la deuda. }\end{array}$ & .302 & 203 & .000 & .780 & 203 & .000 \\
\hline $\begin{array}{l}\text { PGF19. La empresa puede } \\
\text { aumentar el capital de deuda } \\
\text { fácilmente en comparación } \\
\text { con el capital social. }\end{array}$ & .224 & 203 & .000 & .870 & 203 & .000 \\
\hline $\begin{array}{l}\text { PGF20. La empresa cuenta } \\
\text { con asesoramiento } \\
\text { profesional en inversiones } \\
\text { de capital. }\end{array}$ & .166 & 203 & .000 & .912 & 203 & .000 \\
\hline
\end{tabular}




\begin{tabular}{|l|c|c|c|c|c|c|}
\hline $\begin{array}{l}\text { PGF21. La empresa utiliza la } \\
\text { técnica de presupuesto de } \\
\text { capital como recuperación } \\
\text { de la inversión. }\end{array}$ & .155 & 203 & .000 & .913 & 203 & .000 \\
\hline $\begin{array}{l}\text { PGF22. La empresa utiliza } \\
\text { técnicas de presupuesto de } \\
\text { capital como flujo de caja } \\
\text { descontado. }\end{array}$ & .268 & 203 & .000 & .869 & 203 & .000 \\
\hline $\begin{array}{l}\text { PGF23. La empresa aplica } \\
\text { técnicas de presupuesto de } \\
\text { capital en la toma de } \\
\text { decisiones. }\end{array}$ & .154 & 203 & .000 & .909 & 203 & .000 \\
\hline $\begin{array}{l}\text { PGF24. La empresa } \\
\text { mantiene un registro } \\
\text { adecuado de activos no } \\
\text { corrientes. }\end{array}$ & .243 & 203 & .000 & .885 & 203 & .000 \\
\hline
\end{tabular}




\section{Anexo 12. Prueba de normalidad Kolmogorov-Smirnov de Rentabilidad}

\section{Pruebas de normalidad}

\begin{tabular}{|l|c|c|c|c|c|c|}
\hline \multirow{2}{*}{ Ítems } & \multicolumn{3}{|c|}{ Kolmogorov-Smirnov } & \multicolumn{3}{c|}{ Shapiro-Wilk } \\
\cline { 2 - 7 } & Estadístico & gl & Sig. & Estadístico & gl & Sig. \\
\hline $\begin{array}{l}\text { R1. Las ventas de la } \\
\text { empresa han crecido. }\end{array}$ & .243 & 203 & .000 & .879 & 203 & .000 \\
\hline $\begin{array}{l}\text { R2. El retorno de los activos } \\
\text { de la empresa ha } \\
\text { aumentado. }\end{array}$ & .231 & 203 & .000 & .879 & 203 & .000 \\
\hline $\begin{array}{l}\text { R3. El rendimiento del } \\
\text { capital de la empresa ha } \\
\text { aumentado. }\end{array}$ & .235 & 203 & .000 & .879 & 203 & .000 \\
\hline $\begin{array}{l}\text { R4. El retorno de la inversión } \\
\text { de la empresa ha } \\
\text { aumentado. }\end{array}$ & .333 & 203 & .000 & .738 & 203 & .000 \\
\hline $\begin{array}{l}\text { R5. Las ganancias de la } \\
\text { empresa han crecido. }\end{array}$ & .311 & 203 & .000 & .759 & 203 & .000 \\
\hline $\begin{array}{l}\text { R6. La cuota de mercado de } \\
\text { la empresa ha mejorado. }\end{array}$ & .213 & 203 & .000 & .883 & 203 & .000 \\
\hline
\end{tabular}




\section{Anexo 13. Análisis Factorial de Prácticas de gestión financiera}

\begin{tabular}{|l|l|r|}
\hline \multicolumn{2}{|c|}{ Prueba de KMO y Bartlett } \\
\hline \multicolumn{2}{|c|}{ Medida Kaiser-Meyer-Olkin de adecuación de muestreo. } & .804 \\
\hline \multirow{3}{*}{$\begin{array}{l}\text { Prueba de esfericidad de } \\
\text { Bartlett }\end{array}$} & Aprox. Chi-cuadrado & 2046.859 \\
\cline { 2 - 3 } & gl & 210 \\
\cline { 2 - 3 } & Sig. & .000 \\
\hline
\end{tabular}

Varianza Total Explicada

\begin{tabular}{|c|c|c|c|c|c|c|c|c|c|}
\hline \multirow[b]{2}{*}{ Componente } & \multicolumn{3}{|c|}{ Autovalores Iniciales } & \multicolumn{3}{|c|}{$\begin{array}{l}\text { Sumas de extracción de cargas } \\
\text { al cuadrado }\end{array}$} & \multicolumn{3}{|c|}{$\begin{array}{c}\begin{array}{c}\text { Sumas de rotación de cargas al } \\
\text { cuadrado }\end{array} \\
\end{array}$} \\
\hline & Total & $\begin{array}{c}\% \text { de la } \\
\text { varianza }\end{array}$ & $\begin{array}{c}\% \\
\text { acumulado }\end{array}$ & Total & $\begin{array}{c}\% \text { de la } \\
\text { varianza }\end{array}$ & $\begin{array}{c}\% \\
\text { acumulado }\end{array}$ & Total & $\begin{array}{c}\% \text { de la } \\
\text { varianza }\end{array}$ & $\begin{array}{c}\% \\
\text { acumulado }\end{array}$ \\
\hline 1 & 4.515 & 21.498 & 21.498 & 4.515 & 21.498 & 21.498 & 3.699 & 17.615 & 17.615 \\
\hline 2 & 3.559 & 16.947 & 38.445 & 3.559 & 16.947 & 38.445 & 3.599 & 17.140 & 34.756 \\
\hline 3 & 2.826 & 13.459 & 51.904 & 2.826 & 13.459 & 51.904 & 3.393 & 16.159 & 50.915 \\
\hline 4 & 2.082 & 9.917 & 61.821 & 2.082 & 9.917 & 61.821 & 2.290 & 10.906 & 61.821 \\
\hline 5 & .892 & 4.245 & 66.066 & & & & & & \\
\hline 6 & .843 & 4.014 & 70.081 & & & & & & \\
\hline 7 & .741 & 3.529 & 73.610 & & & & & & \\
\hline 8 & .707 & 3.365 & 76.975 & & & & & & \\
\hline 9 & .698 & 3.324 & 80.299 & & & & & & \\
\hline 10 & .609 & 2.902 & 83.201 & & & & & & \\
\hline 11 & .516 & 2.458 & 85.659 & & & & & & \\
\hline 12 & .475 & 2.262 & 87.921 & & & & & & \\
\hline 13 & .401 & 1.908 & 89.829 & & & & & & \\
\hline 14 & .385 & 1.831 & 91.661 & & & & & & \\
\hline 15 & .367 & 1.749 & 93.409 & & & & & & \\
\hline 16 & .325 & 1.549 & 94.959 & & & & & & \\
\hline 17 & .294 & 1.400 & 96.358 & & & & & & \\
\hline 18 & .233 & 1.108 & 97.466 & & & & & & \\
\hline 19 & .205 & .974 & 98.440 & & & & & & \\
\hline 20 & .184 & .877 & 99.317 & & & & & & \\
\hline 21 & .143 & .683 & 100.000 & & & & & & \\
\hline
\end{tabular}

Método de extracción: Análisis de componentes principales. 
Matriz de componente rotado

\begin{tabular}{|c|c|c|c|c|}
\hline & \multicolumn{4}{|c|}{ Componente } \\
\hline & 1 & 2 & 3 & 4 \\
\hline $\begin{array}{l}\text { PGF3. La empresa mantiene } \\
\text { saldos de efectivo óptimos } \\
\text { en todo momento. }\end{array}$ & .898 & -.003 & .069 & .024 \\
\hline $\begin{array}{l}\text { PGF1. La empresa cuenta } \\
\text { con un sistema de gestión } \\
\text { de capital de trabajo. }\end{array}$ & .870 & .012 & .098 & -.008 \\
\hline $\begin{array}{l}\text { PGF2. Mantiene registros de } \\
\text { inventario que se actualizan } \\
\text { regularmente. }\end{array}$ & .775 & -.008 & .050 & -.149 \\
\hline $\begin{array}{l}\text { PGF6. Prepara pronósticos } \\
\text { de flujo de efectivo para } \\
\text { identificar futuros } \\
\text { excedentes y déficits. }\end{array}$ & .753 & .028 & .037 & .083 \\
\hline $\begin{array}{l}\text { PGF5. Asegura que haya } \\
\text { suficiente flujo de efectivo } \\
\text { para satisfacer las } \\
\text { necesidades diarias. }\end{array}$ & .706 & .054 & .003 & .116 \\
\hline $\begin{array}{l}\text { PGF4. Mantiene registros } \\
\text { adecuados y oportunos para } \\
\text { todas las cuentas por pagar, } \\
\text { catalogando a sus } \\
\text { acreedores según sus } \\
\text { condiciones de pago. }\end{array}$ & .644 & -.025 & .081 & .086 \\
\hline $\begin{array}{l}\text { PGF21. La empresa utiliza la } \\
\text { técnica de presupuesto de } \\
\text { capital como recuperación } \\
\text { de la inversión. }\end{array}$ & .043 & .884 & .141 & .073 \\
\hline $\begin{array}{l}\text { PGF23. La empresa aplica } \\
\text { técnicas de presupuesto de } \\
\text { capital en la toma de } \\
\text { decisiones. }\end{array}$ & -.053 & .875 & .129 & .109 \\
\hline
\end{tabular}




\begin{tabular}{|c|c|c|c|c|}
\hline $\begin{array}{l}\text { PGF20. La empresa cuenta } \\
\text { con asesoramiento } \\
\text { profesional en inversiones } \\
\text { de capital. }\end{array}$ & .070 & .846 & .118 & .058 \\
\hline $\begin{array}{l}\text { PGF24. La empresa } \\
\text { mantiene un registro } \\
\text { adecuado de activos no } \\
\text { corrientes. }\end{array}$ & .005 & .820 & -.035 & .059 \\
\hline $\begin{array}{l}\text { PGF22. La empresa utiliza } \\
\text { técnicas de presupuesto de } \\
\text { capital como flujo de caja } \\
\text { descontado. }\end{array}$ & -.006 & .776 & .027 & .040 \\
\hline $\begin{array}{l}\text { PGF19. La empresa puede } \\
\text { aumentar el capital de deuda } \\
\text { fácilmente en comparación } \\
\text { con el capital social. }\end{array}$ & .135 & .070 & .894 & .039 \\
\hline $\begin{array}{l}\text { PGF15. La empresa ha } \\
\text { utilizado eficientemente la } \\
\text { línea de crédito de acuerdo } \\
\text { con sus capacidades. }\end{array}$ & .015 & .086 & .809 & .032 \\
\hline $\begin{array}{l}\text { PGF13. La empresa tiene } \\
\text { conocimiento de su } \\
\text { estructura de capital. }\end{array}$ & -.015 & .128 & .736 & -.055 \\
\hline $\begin{array}{l}\text { PGF14. La estructura de } \\
\text { capital de la empresa es } \\
\text { adecuada. }\end{array}$ & .067 & .084 & .734 & .040 \\
\hline $\begin{array}{l}\text { PGF18. La empresa no tiene } \\
\text { ninguna dificultad en } \\
\text { aumentar el capital social en } \\
\text { comparación con la deuda. }\end{array}$ & .045 & .006 & .629 & .041 \\
\hline $\begin{array}{l}\text { PGF16. La empresa } \\
\text { depende únicamente del } \\
\text { capital social. }\end{array}$ & .077 & -.004 & .614 & -.031 \\
\hline $\begin{array}{l}\text { PGF7. Los estados } \\
\text { financieros de la empresa se } \\
\text { preparan de acuerdo con los } \\
\text { estándares de contabilidad } \\
\text { financiera. }\end{array}$ & .096 & .077 & -.035 & .848 \\
\hline
\end{tabular}




\begin{tabular}{|c|c|c|c|c|}
\hline $\begin{array}{l}\text { PGF10. El estado financiero } \\
\text { está preparado de acuerdo } \\
\text { con las Normas } \\
\text { Internacionales de } \\
\text { Información Financiera para } \\
\text { las MYPES. }\end{array}$ & .030 & .070 & .078 & .761 \\
\hline $\begin{array}{l}\text { PGF12. Genera informes } \\
\text { periódicos para la toma de } \\
\text { decisiones. }\end{array}$ & .063 & .018 & -.042 & .699 \\
\hline $\begin{array}{l}\text { PGF11. La empresa utiliza } \\
\text { información contable para la } \\
\text { toma de decisiones. }\end{array}$ & -.031 & .101 & .043 & .646 \\
\hline
\end{tabular}

Método de extracción: Análisis de componentes principales.

Método de rotación: Varimax con normalización de Kaiser.

a. La rotación convergió en 5 iteraciones. 


\section{Anexo 14. Análisis Factorial de Rentabilidad}

\begin{tabular}{|l|l|r|}
\hline \multicolumn{2}{|c|}{ Prueba de KMO y Bartlett } \\
\hline \multicolumn{2}{|c|}{ Medida Kaiser-Meyer-Olkin de adecuación de muestreo. } & .861 \\
\hline \multirow{2}{*}{$\begin{array}{l}\text { Prueba de esfericidad de } \\
\text { Bartlett }\end{array}$} & Aprox. Chi-cuadrado & 685.894 \\
\cline { 2 - 3 } & gl & 15 \\
\cline { 2 - 3 } & Sig. & .000 \\
\hline
\end{tabular}

\section{Varianza Total Explicada}

\begin{tabular}{|c|c|c|c|c|c|c|}
\hline \multirow[b]{2}{*}{ Componente } & \multicolumn{3}{|c|}{ Autovalores Iniciales } & \multicolumn{3}{|c|}{ Sumas de extracción de cargas al cuadrado } \\
\hline & Total & $\begin{array}{c}\% \text { de la } \\
\text { varianza }\end{array}$ & $\%$ acumulado & Total & $\begin{array}{c}\% \text { de la } \\
\text { varianza }\end{array}$ & $\%$ acumulado \\
\hline 1 & 3.730 & 62.174 & 62.174 & 3.730 & 62.174 & 62.174 \\
\hline 2 & .784 & 13.062 & 75.236 & & & \\
\hline 3 & .709 & 11.820 & 87.056 & & & \\
\hline 4 & .344 & 5.734 & 92.789 & & & \\
\hline 5 & .261 & 4.353 & 97.142 & & & \\
\hline 6 & .171 & 2.858 & 100.000 & & & \\
\hline
\end{tabular}

Método de extracción: Análisis de componentes principales. 


\section{Matriz de componente}

\begin{tabular}{|c|c|}
\hline & Componente \\
\hline & 1 \\
\hline $\begin{array}{l}\text { R1. Las ventas de la empresa } \\
\text { han crecido. }\end{array}$ & .907 \\
\hline $\begin{array}{l}\text { R2. El retorno de los activos } \\
\text { de la empresa ha aumentado. }\end{array}$ & .876 \\
\hline $\begin{array}{l}\text { R3. El rendimiento del capital } \\
\text { de la empresa ha aumentado. }\end{array}$ & .874 \\
\hline $\begin{array}{l}\text { R6. La cuota de mercado de la } \\
\text { empresa ha mejorado. }\end{array}$ & .839 \\
\hline $\begin{array}{l}\text { R4. El retorno de la inversión } \\
\text { de la empresa ha aumentado. }\end{array}$ & .617 \\
\hline $\begin{array}{l}\text { R5. Las ganancias de la } \\
\text { empresa han crecido. }\end{array}$ & .539 \\
\hline
\end{tabular}

Método de extracción: Análisis de componentes principales.

a. 1 componentes extraído. 


\section{Anexo 15. Correlaciones Spearman}

\begin{tabular}{|c|c|c|c|c|}
\hline \multicolumn{5}{|c|}{ Correlaciones } \\
\hline & & & Pract_gest_financ & Rentabilidad \\
\hline \multirow{6}{*}{ Rho de Spearman } & \multirow{3}{*}{ Pract_gest_financ } & Coeficiente de correlación & 1.000 & $.353^{* *}$ \\
\hline & & Sig. (bilateral) & & .000 \\
\hline & & $\mathrm{N}$ & 203 & 203 \\
\hline & \multirow{3}{*}{ Rentabilidad } & Coeficiente de correlación & $.353^{* *}$ & 1.000 \\
\hline & & Sig. (bilateral) & .000 & \\
\hline & & $\mathrm{N}$ & 203 & 203 \\
\hline
\end{tabular}

\begin{tabular}{|c|c|c|c|c|c|c|c|}
\hline \multicolumn{8}{|c|}{ Correlaciones } \\
\hline & & & $\begin{array}{c}\text { Pract_gest_cap } \\
\text { _trab }\end{array}$ & $\begin{array}{l}\text { Sist_inf_cont_ } \\
\text { pract_ana_inf } \\
\text { financ }\end{array}$ & $\begin{array}{l}\text { Gest_estruc_ } \\
\text { cap_financ }\end{array}$ & $\begin{array}{l}\text { Presup_cap_gest } \\
\text { act_no_ctes }\end{array}$ & Rentabilidad \\
\hline \multirow{15}{*}{\begin{tabular}{|l} 
Rho de \\
Spearman
\end{tabular}} & \multirow{3}{*}{$\begin{array}{l}\text { Pract_gest_ } \\
\text { cap_trab }\end{array}$} & $\begin{array}{l}\text { Coeficiente } \\
\text { de correlación }\end{array}$ & 1.000 & 0.083 & $0.143^{*}$ & 0.029 & .164 \\
\hline & & Sig. (bilateral) & . & 0.240 & 0.042 & 0.676 & 0.019 \\
\hline & & $\mathrm{N}$ & 203 & 203 & 203 & 203 & 203 \\
\hline & \multirow{3}{*}{$\begin{array}{l}\text { Sist_inf_con } \\
\text { t_pract_ana } \\
\text { inf_financ }\end{array}$} & $\begin{array}{l}\text { Coeficiente } \\
\text { de correlación }\end{array}$ & 0.083 & 1.000 & 0.022 & $0.169^{*}$ & .164 \\
\hline & & Sig. (bilateral) & 0.240 & & 0.759 & 0.016 & 0.019 \\
\hline & & $\mathrm{N}$ & 203 & 203 & 203 & 203 & 203 \\
\hline & \multirow{3}{*}{$\begin{array}{l}\text { Gest_estruc } \\
\text { ccap_financ }\end{array}$} & $\begin{array}{l}\text { Coeficiente } \\
\text { de correlación }\end{array}$ & $0.143^{*}$ & 0.022 & 1.000 & $0.153^{*}$ & $.179^{\prime}$ \\
\hline & & Sig. (bilateral) & 0.042 & 0.759 & & 0.029 & 0.011 \\
\hline & & $\mathrm{N}$ & 203 & 203 & 203 & 203 & 203 \\
\hline & \multirow{3}{*}{$\begin{array}{l}\text { Presup_cap } \\
\text { _gest_act_n } \\
\text { o_ctes }\end{array}$} & $\begin{array}{l}\text { Coeficiente } \\
\text { de correlación }\end{array}$ & 0.029 & $0.169^{*}$ & $0.153^{*}$ & 1.000 & $.314^{* *}$ \\
\hline & & Sig. (bilateral) & 0.676 & 0.016 & 0.029 & & 0.000 \\
\hline & & $\mathrm{N}$ & 203 & 203 & 203 & 203 & 203 \\
\hline & \multirow{3}{*}{$\begin{array}{l}\text { Rentabilida } \\
\text { d }\end{array}$} & $\begin{array}{l}\text { Coeficiente } \\
\text { de correlación }\end{array}$ & $0.164^{*}$ & $0.164^{*}$ & $0.179^{*}$ & $0.314^{\star *}$ & 1.000 \\
\hline & & Sig. (bilateral) & 0.019 & 0.019 & 0.011 & 0.000 & \\
\hline & & $\mathrm{N}$ & 203 & 203 & 203 & 203 & 203 \\
\hline \multicolumn{8}{|c|}{ *. La correlación es significativa en el nivel 0,05 (bilateral). } \\
\hline & ín c ca & ativa en el $n$ & 0,01 (bilateral). & & & & \\
\hline
\end{tabular}




\section{Anexo 16. Validación de expertos}

\section{Juez 1}

INSTRUMENTO PARA LA VALIDEZ DE CONTENIDO

(JUICIO DE EXPERTOS)

El objetivo del presente instrumento es validar el cuestionario de prácticas de gestión financiera como instrumento, el cual-será aplicado a los fabricantes Mypes de calzado que laboran en el distrito de Comas y que forman parte del estudio "PRÁCTICAS DE GESTIÓN FINANCIERA Y LA RENTABILIDAD DE LOS FABRICANTES MYPES DE CALZADO DE COMAS 2020", que corresponde a un diseño correlacional no experimental de corte transversal.

Instrucciones

La evaluación requiere de la lectura detallada y completa de cada uno de los ítems propuestos a fin de cotejarlos de manera cualitativa con los criterios propuestos relativos a: Claridad de la redacción, congruencia con el contenido, contexto correcto del ítem y dominio del constructo. Para ello deberá asignar una valoración si el ítem presenta o no los criterios propuestos, y en caso necesario se ofrece un espacio para las observaciones si las hubiera.

Juez No: 1

Fecha actual: $\quad 07-01-2020$

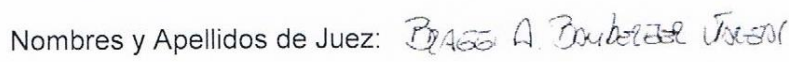

Profesión: Stumasmobs?

Institución donde labora: Favace Cousur

Años de experiencia profesional o científica: 20 siol

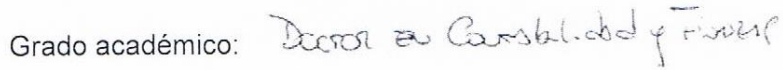

Puesto que desempeña: Casuror Fivacto

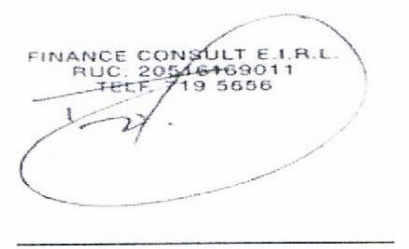

Firma y Sello 
2 CRITERIOS GENERALES PARA VALIDEZ DE CONTENIDO DEL INSTRUMENTO DE PRACTICAS DE GESTIÓN FINANCIERA.

\section{DICTAMINADO POR EL JUEZ}

1) ¿Está de acuerdo con las caracteristicas, forma de aplicación y estructura del INSTRUMENTO?

Muy aceptable (X) Aceptable ( ) Regular () Poco aceptable ( ) Inaceptable (

Observaciones

Observaciones

Sugerencias:

2) A su parecer, ¿el orden de las preguntas es el adecuado?

$\mathrm{SI}(\mathrm{X}) \quad$ NO ( )

Observaciones:

.

(n)

Sugerencias:

3) ¿Existe dificultad para entender las preguntas del INSTRUMENTO?

SI ( )

NO ()

Observaciones:

(n)

Sugerencias:

4) ¿Existen palabras dificiles de entender en los items o reactivos del INSTRUMENTO?

SI ( )

NO ()

Observaciones:

.

Sugerencias:

5) Las opciones de respuesta ¿están suficientemente graduados y pertinentes para cada item cada pregunta) o reactivo del INSTRUMENTO?
$\operatorname{si}(x)$
NO( )

Observaciones: 
Sugerencias

6) ¿Los items o reactivos del instrumento tienen correspondencia con la dimensión al que pertenece en el constructo?

SI $(X)$

NO( )

Observaciones

Sugerencias 


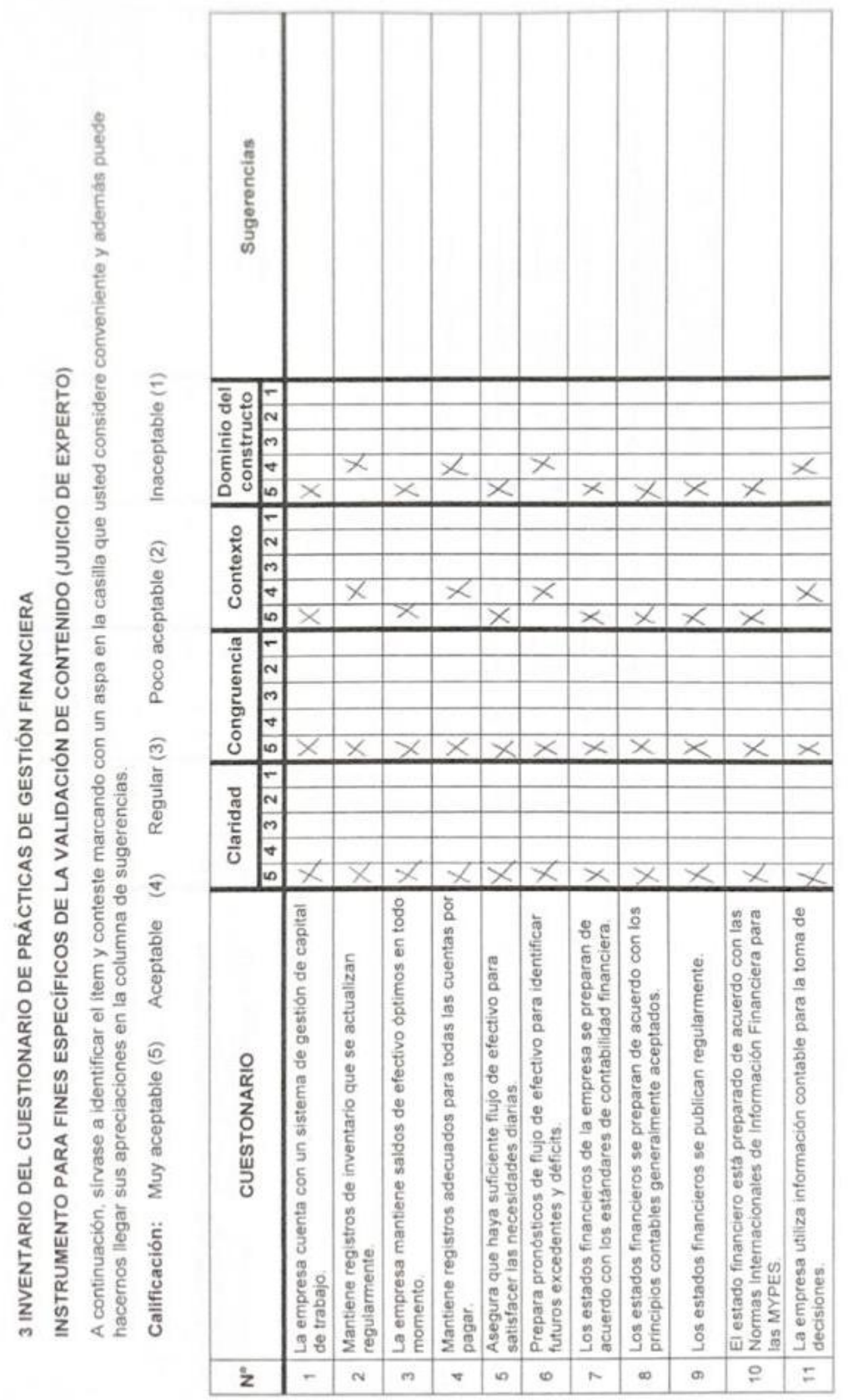




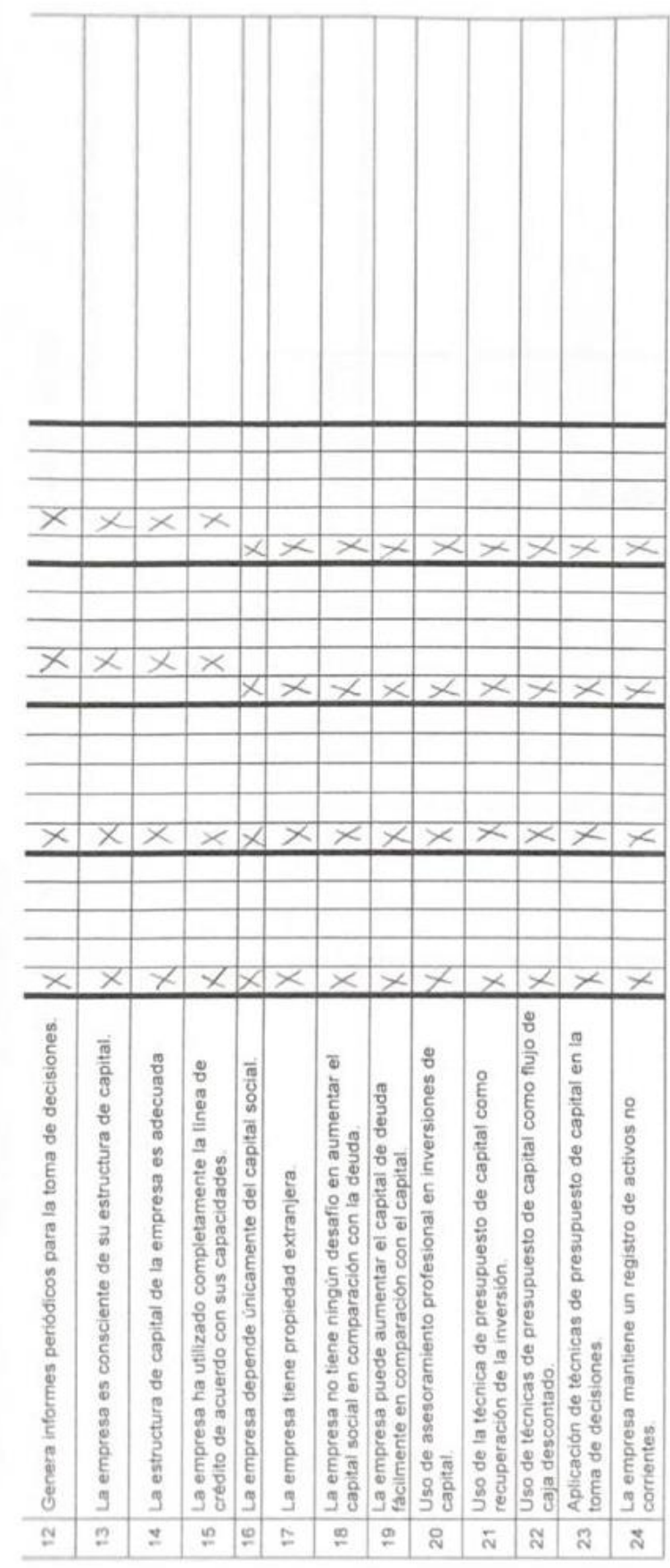




\section{INSTRUMENTO PARA LA VALIDEZ DE CONTENIDO \\ (JUICIO DE EXPERTOS)}

El objetivo del presente instrumento es validar el cuestionario de prácticas de gestión financiera como instrumento, el cual.será aplicado a los fabricantes Mypes de calzado que laboran en el distrito de Comas y que forman parte del estudio "PRÁCTICAS DE GESTIÓN FINANCIERA Y LA RENTABILIDAD DE LOS FABRICANTES MYPES DE CALZADO DE COMAS 2020", que corresponde a un diseño correlacional no experimental de corte transversal.

Instrucciones

La evaluación requiere de la lectura detallada y completa de cada uno de los ítems propuestos a fin de cotejarlos de manera cualitativa con los criterios propuestos relativos a: Claridad de la redacción, congruencia con el contenido, contexto correcto del ítem y dominio del constructo. Para ello deberá asignar una valoración si el ítem presenta o no los criterios propuestos, y en caso necesario se ofrece un espacio para las observaciones si las hubiera.

Juez No: 1

Fecha actual: $07-01-2020$

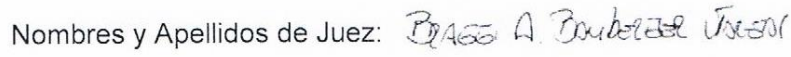

Profesión: Aluenasmobs

Institución donde labora: France Cousur

Años de experiencia profesional o científica: 20 sĩol

Grado académico: Ducror ex Cambl.dod frume

Puesto que desempeña: Caxiror Fivacto

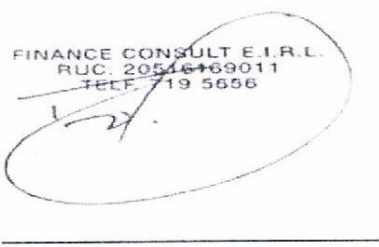

Firma y Sello 
2 CRITERIOS GENERALES PARA VALIDEZ DE CONTENIDO DEL INSTRUMENTO DE PRACTICAS DE GESTIÓN FINANCIERA.

\section{DICTAMINADO POR EL JUEZ}

1) ¿Está de acuerdo con las caracteristicas, forma de aplicación y estructura del INSTRUMENTO?

Muy aceptable $(X)$ Aceptable ( ) Regular () Poco aceptable ( ) Inaceptable (

Observaciones

Observaciones

Sugerencias:

2) A su parecer, ¿el orden de las preguntas es el adecuado?

$\mathrm{SI}(\mathrm{X}) \quad$ NO ( )

Observaciones:

.

(n)

Sugerencias:

3) ¿Existe dificultad para entender las preguntas del INSTRUMENTO?

SI ( )

NO ()

Observaciones:

(n)

Sugerencias:

4) ¿Existen palabras dificiles de entender en los items o reactivos del INSTRUMENTO?

SI ( )

NO ()

Observaciones:

.

Sugerencias:

5) Las opciones de respuesta ¿están suficientemente graduados y pertinentes para cada item cada pregunta) o reactivo del INSTRUMENTO?
$\operatorname{si}(x)$
NO( )

Observaciones: 
Sugerencias

6) LLos items o reactivos del instrumento tienen correspondencia con la dimensión al que pertenece en el constructo?

$\operatorname{si}(x)$

NO( )

Observaciones:

Sugerencias 


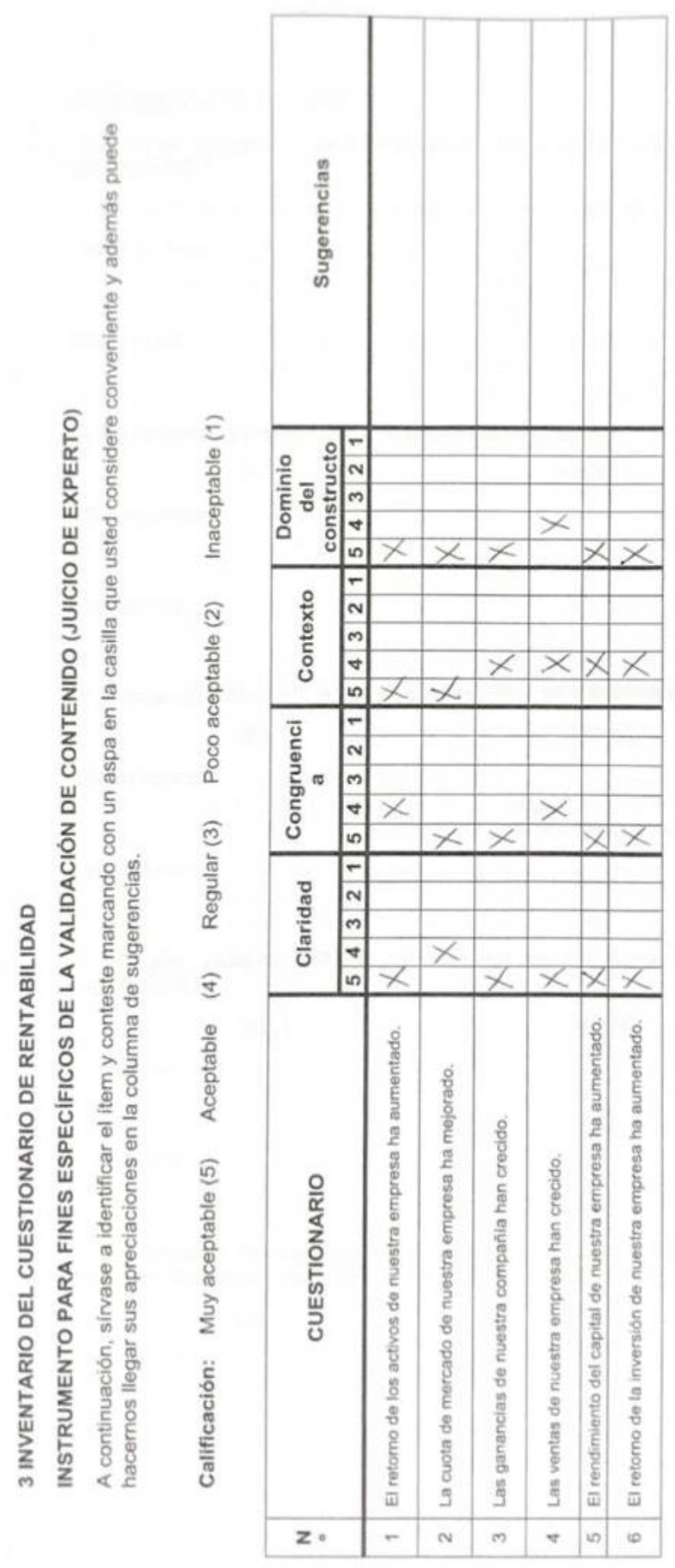




\section{Juez 2}

INSTRUMENTO PARA LA VALIDEZ DE CONTENIDO

(JUICIO DE EXPERTOS)

El objetivo del presente instrumento es validar el cuestionario de rentabilidad como instrumento, el cual será aplicado a los fabricantes Mypes de calzado que laboran en el distrito de Comas y que forman parte del estudio "PRÁCTICAS DE GESTION FINANCIERA Y LA RENTABILIDAD DE LOS FABRICANTES MYPES DE CALZADO $D E$ COMAS 2020", que corresponde a un diseño correlacional no experimental de corte transversal.

\section{Instrucciones}

La evaluación requiere de la lectura detallada y completa de cada uno de los ítems propuestos a fin de cotejarlos de manera cualitativa con los criterios propuestos relativos a: Claridad de la redacción, congruencia con el contenido, contexto correcto del item y dominio del constructo. Para ello deberá asignar una valoración si el ítem presenta o no los criterios propuestos, y en caso necesario se ofrece un espacio para las observaciones si las hubiera.

Juez No: 2

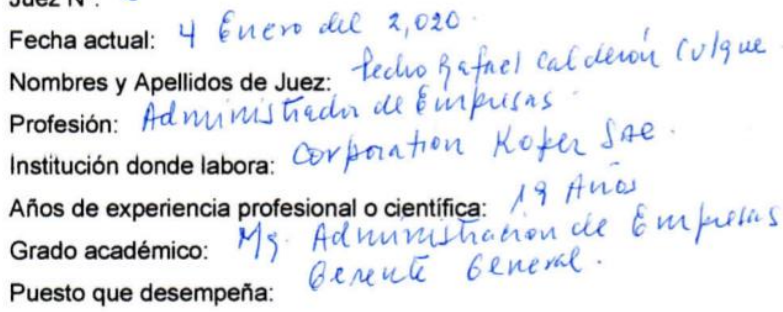

fentom

(a)

cescame ciesta

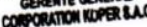

Firma y Sello 
2 CRITERIOS GENERALES PARA VALIDEZ DE CONTENIDO DEL INSTRUMENTO DE PRÁCTICAS DE GESTIÓN FINANCIERA.

DICTAMINADO POR EL JUEZ

1) ¿Está de acuerdo con las características, forma de aplicación y estructura del INSTRUMENTO?

Muy aceptable ( ) Aceptable (X) Regular ( ) Poco aceptable ( ) Inaceptable ( )

Observaciones:

(n)

Sugerencias

2) A su parecer, ¿el orden de las preguntas es el adecuado?
si $(1)$
NO ( )

Observaciones

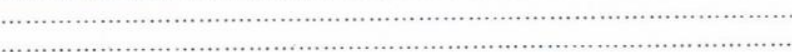

Sugerencias

3) ¿Existe dificultad para entender las preguntas del INSTRUMENTO?

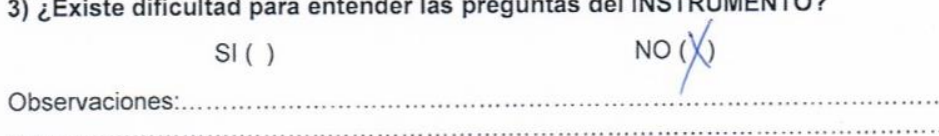

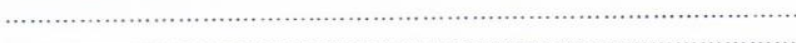

Sugerencias:

4) ¿Existen palabras difíciles de entender en los ítems o reactivos del INSTRUMENTO?

$$
\mathrm{SI}\left(\mathrm { N } \quad \mathrm { NO } \left(\mathrm{X}_{\mathrm{N}}\right.\right.
$$

Observaciones:

Sugerencias

5) Las opciones de respuesta ¿están suficientemente graduados y pertinentes para cada ítem cada pregunta) o reactivo del INSTRUMENTO?
$\sin$
$\mathrm{NO}($ ) 
Observaciones:

Sugerencias:

6) ¿Los ítems o reactivos del instrumento tienen correspondencia con la dimensión al que pertenece en el constructo?

Observaciones $\sin$ NO( )

Sugerencias: 


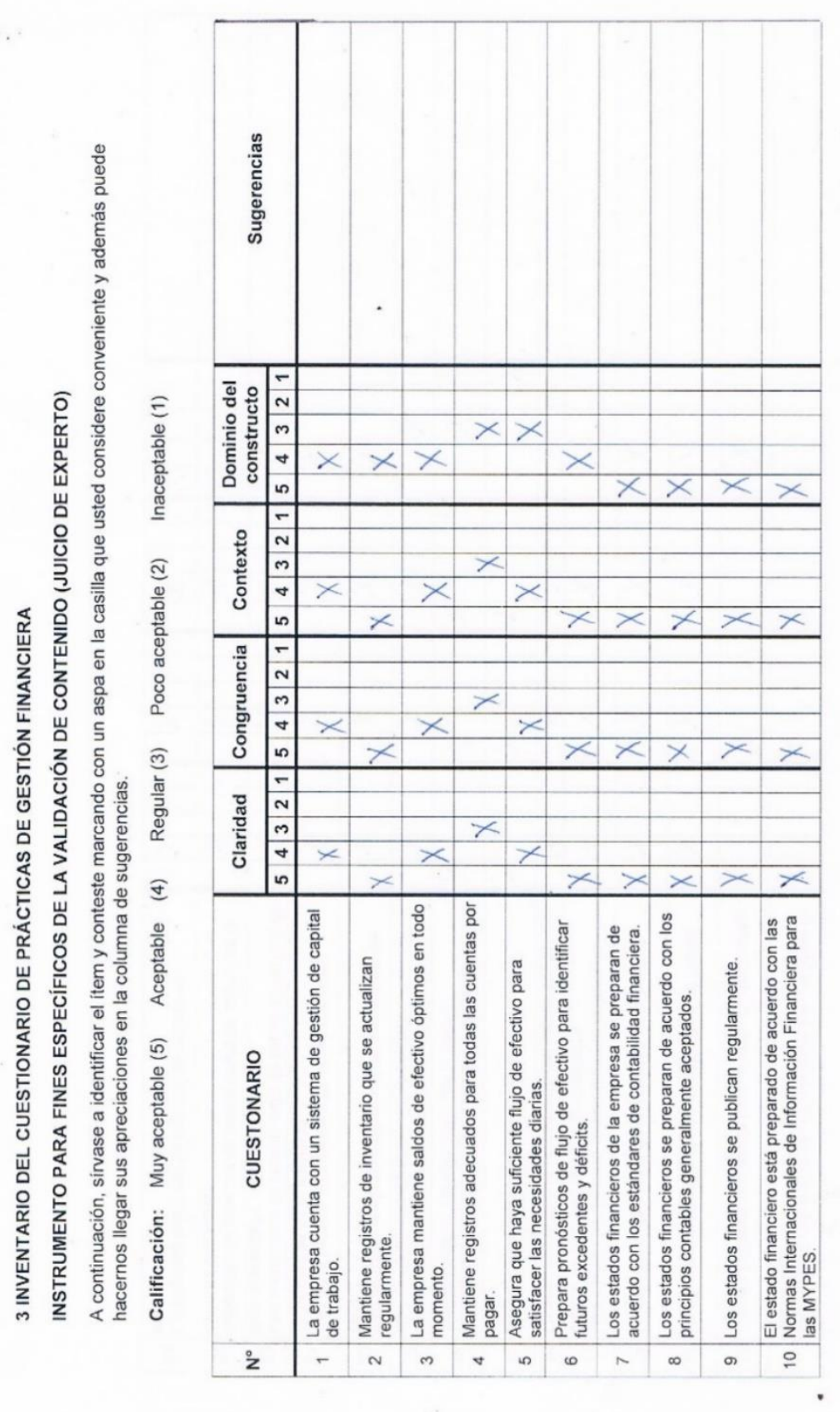


$\frac{3}{2}$

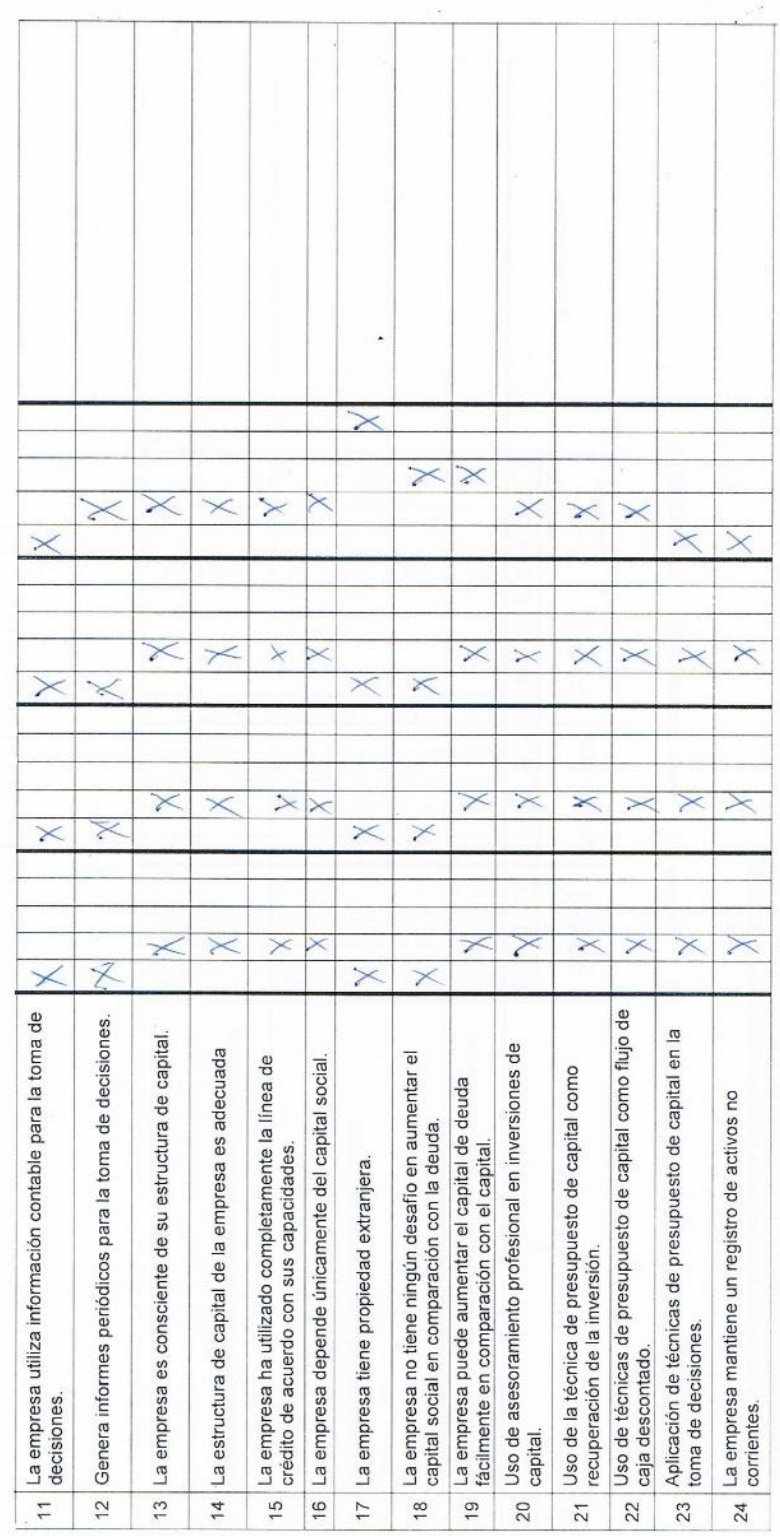




\section{INSTRUMENTO PARA LA VALIDEZ DE CONTENIDO}

\section{(JUICIO DE EXPERTOS)}

El objetivo del presente instrumento es validar el cuestionario de prácticas de gestión financiera como instrumento, el cual será aplicado a los fabricantes Mypes de calzado que laboran en el distrito de Comas y que forman parte del estudio "PRACTICAS DE GESTION FINANCIERA Y LA RENTABILIDAD DE LOS FABRICANTES MYPES DE CALZADO DE COMAS 2020", que corresponde a un diseño correlacional no experimental de corte transversal.

Instrucciones

La evaluación requiere de la lectura detallada y completa de cada uno de los items propuestos a fin de cotejarlos de manera cualitativa con los criterios propuestos relativos a: Claridad de la redacción, congruencia con el contenido, contexto correcto del ítem y dominio del constructo. Para ello deberá asignar una valoración si el ítem presenta o no los criterios propuestos, y en caso necesario se ofrece un espacio para las observaciones si las hubiera

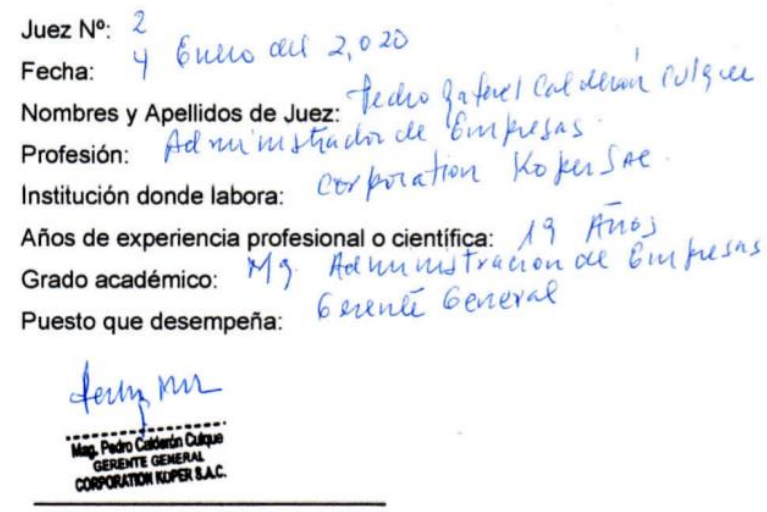

Firma y Sello 


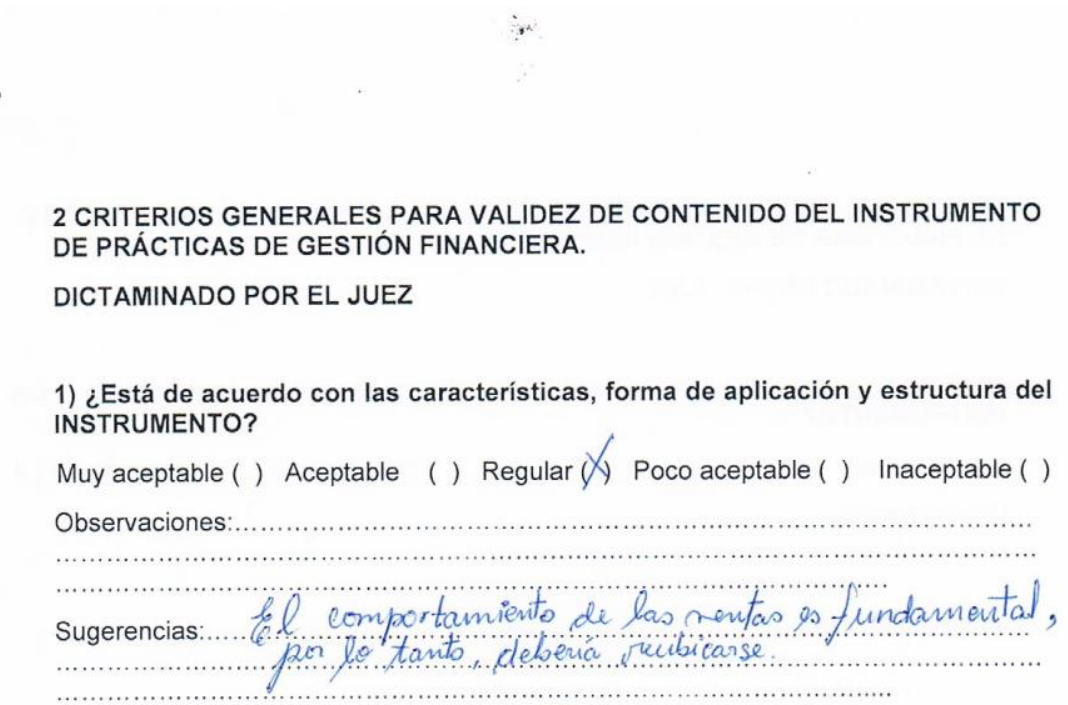

2) A su parecer, ¿el orden de las preguntas es el adecuado?
SI ( )
NO (X)

Observaciones:

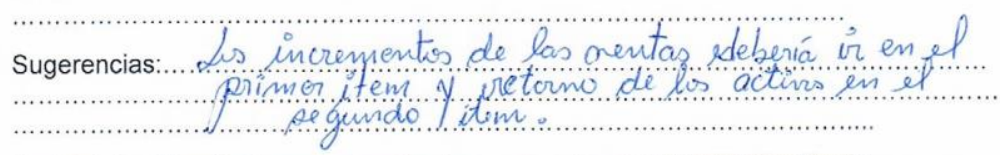

3) ¿Existe dificultad para entender las preguntas del INSTRUMENTO?

SI ( )

NO (X)

Observaciones:

Sugerencias:

4) ¿Existen palabras difíciles de entender en los ítems o reactivos del INSTRUMENTO?
SI ( )
NOW

Observaciones:

Sugerencias:

5) Las opciones de respuesta ¿están suficientemente graduados y pertinentes para cada ítem cada pregunta) o reactivo del INSTRUMENTO?
SIX)
$\mathrm{NO}(\mathrm{s}$ 
Observaciones:

Sugerencias:

6) ¿Los ítems o reactivos del instrumento tienen correspondencia con la dimensión al que pertenece en el constructo?

Observaciones $\sin$ NO( )

Sugerencias: 


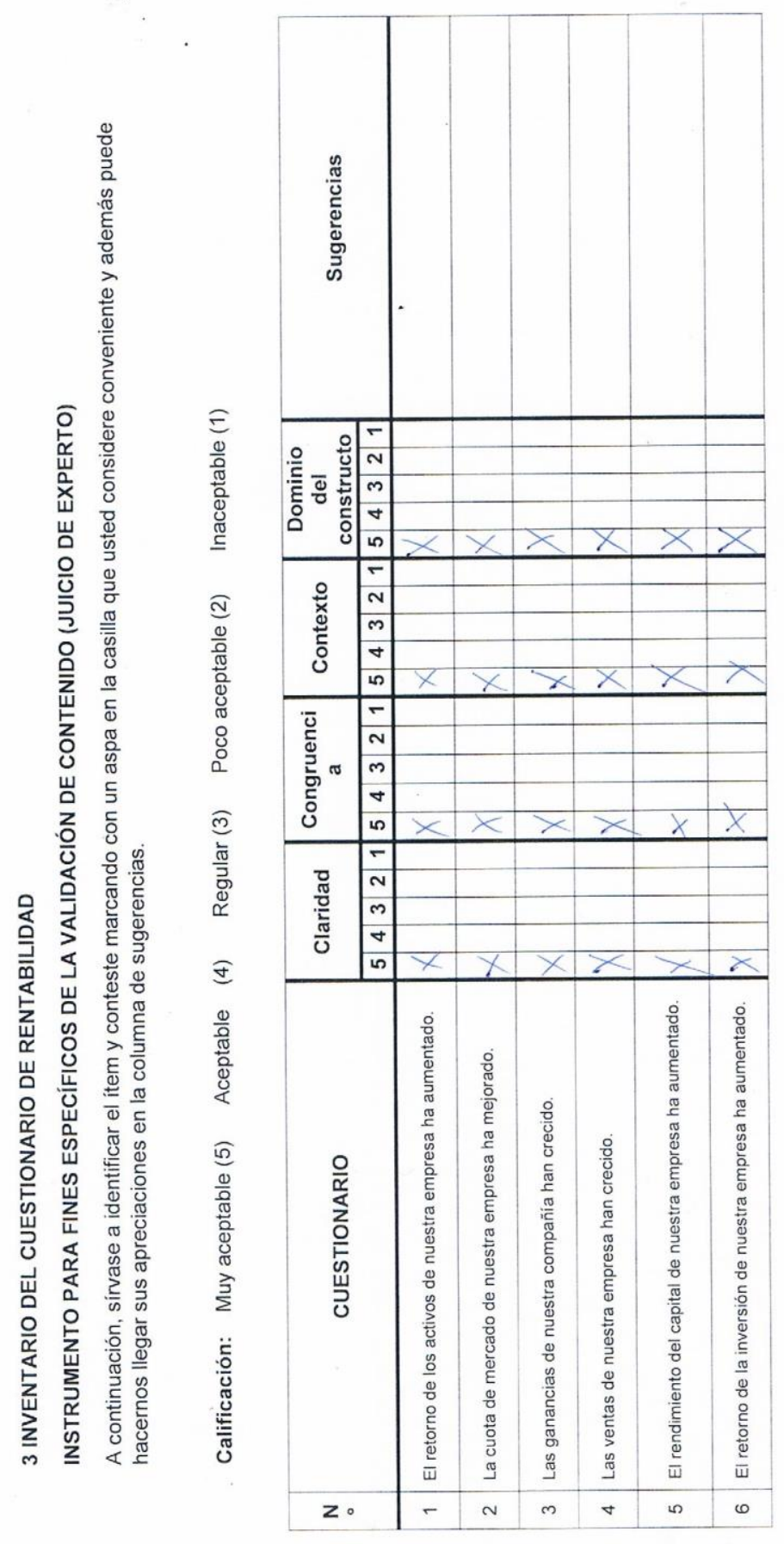


Juez 3

INSTRUMENTO PARA LA VALIDEZ DE CONTENIDO

(JUICIO DE EXPERTOS)

El objetivo del presente instrumento es validar el cuestionario de rentabilidad como instrumento, el cual será aplicado a los fabricantes Mypes de calzado que laboran en el distrito de Comas y que forman parte del estudio "PRÁCTICAS DE GESTIÓN FINANCIERA Y LA RENTABILIDAD DE LOS FABRICANTES MYPES DE CALZADO DE COMAS 2020", que corresponde a un disento correlacional no experimental de corte transversal

Instrucciones

La evaluación requiere de la lectura detallada y completa de cada uno de los items propuestos a fin de cotejarios de manera cualitativa con los criterios propuestos relativos a: Claridad de la redacción, congruencia con el contenido, contexto correcto del item y dominio del constructo. Para ello deberá asignar una valoración si el item presenta o no los criterios propuestos, y en caso necesario se ofrece un espacio para las observaciones si las hubiera.

Juez $\mathrm{N}^{0}$

03

Fecha actual: $\quad 28-12 \cdot 2019$

Nombres y Apellidos de Juez FARAH DE LOVDOES YZQUETA NAVEDA

Profesión CQUTAOOOA PÚBLILA

Institución donde labora: CORPODACIÓN DE SERViCiOS OR S.A.

Años de experiencia profesional o cientifica: 15 Años

Grado académico: MAGISTRR

Puesto que desempeña: JEF DE GESTION DE OAERACIONES FACTUDACWÓN Y contra dE GESTIÓN

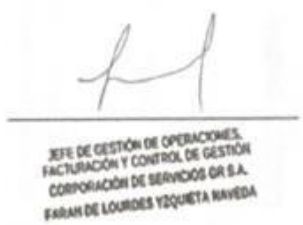


DICTAMINADO POR EL JUEZ

1) Está de acuerdo con las caracteristicas, forma de aplicación y estructura del INSTRUMENTO?

Muy aceptable QS Aceptable ( ) Regular ( ) Poco aceptable ( ) Inaceptable ( )

Observaciones:

Sugerencias

2) A su parecer, ¿el orden de las preguntas es el adecuado?

$\operatorname{si}(X)$

NO( )

Observaciones:

(n)

Sugerencias:

3) ¿Existe dificultad para entender las preguntas del INSTRUMENTO?

SI (

NO (X)

Observaciones:

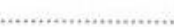

Sugerencias:

4) ¿Existen palabras dificiles de entender en los items o reactivos del INSTRUMENTO?
SI ( )
NOX

Observaciones....

Sugerencias:

5) Las opciones de respuesta ¿están suficientemente graduados y pertinentes para cada item cada pregunta) o reactivo del INSTRUMENTO?
$\sin (\alpha)$
NO( )

Observaciones:... 
Sugerencias:

6) ¿Los items o reactivos del instrumento tienen correspondencia con la dimensión al que pertenece en el constructo?

$\operatorname{SIN}$

NO( )

Observaciones:

Sugerencias: 


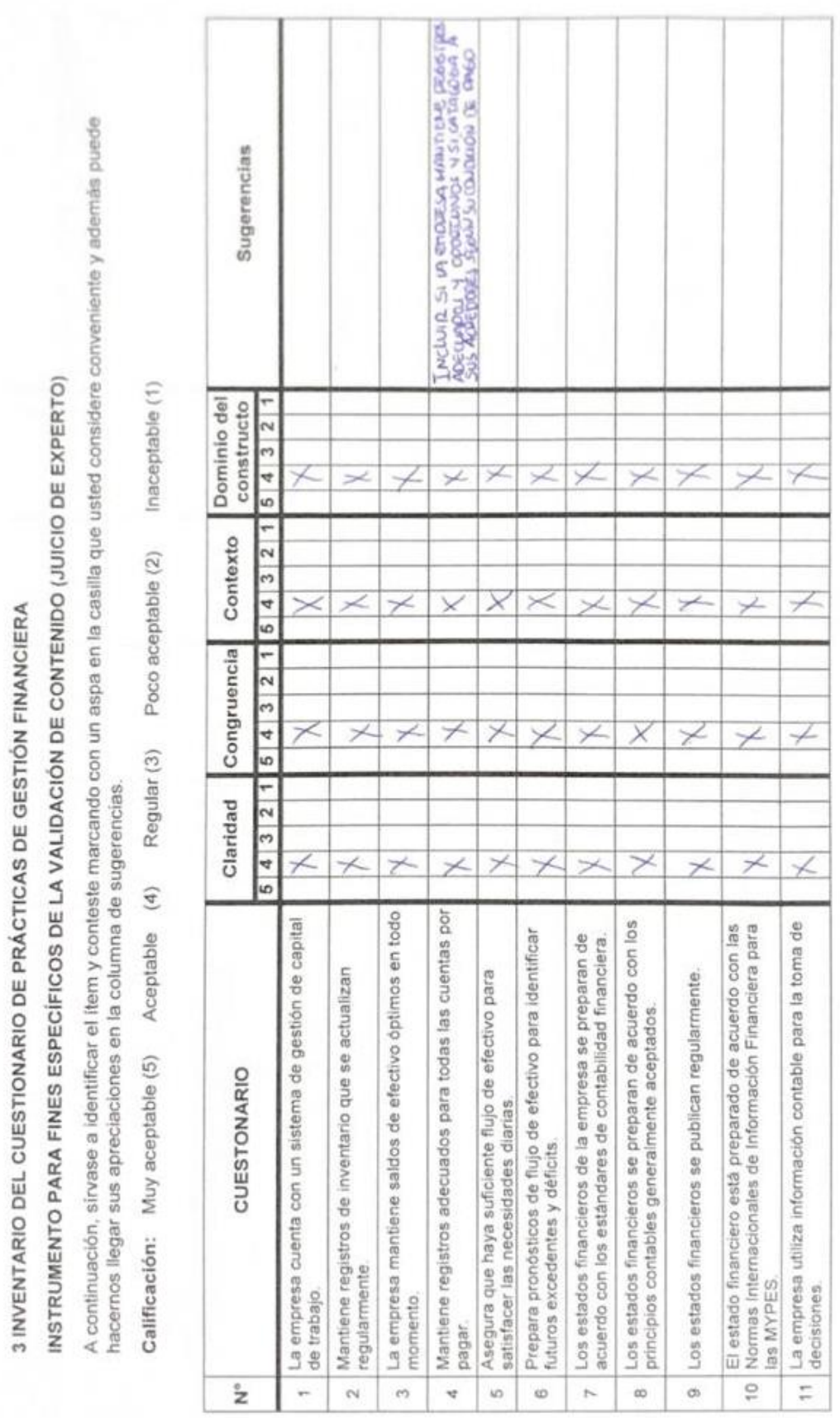




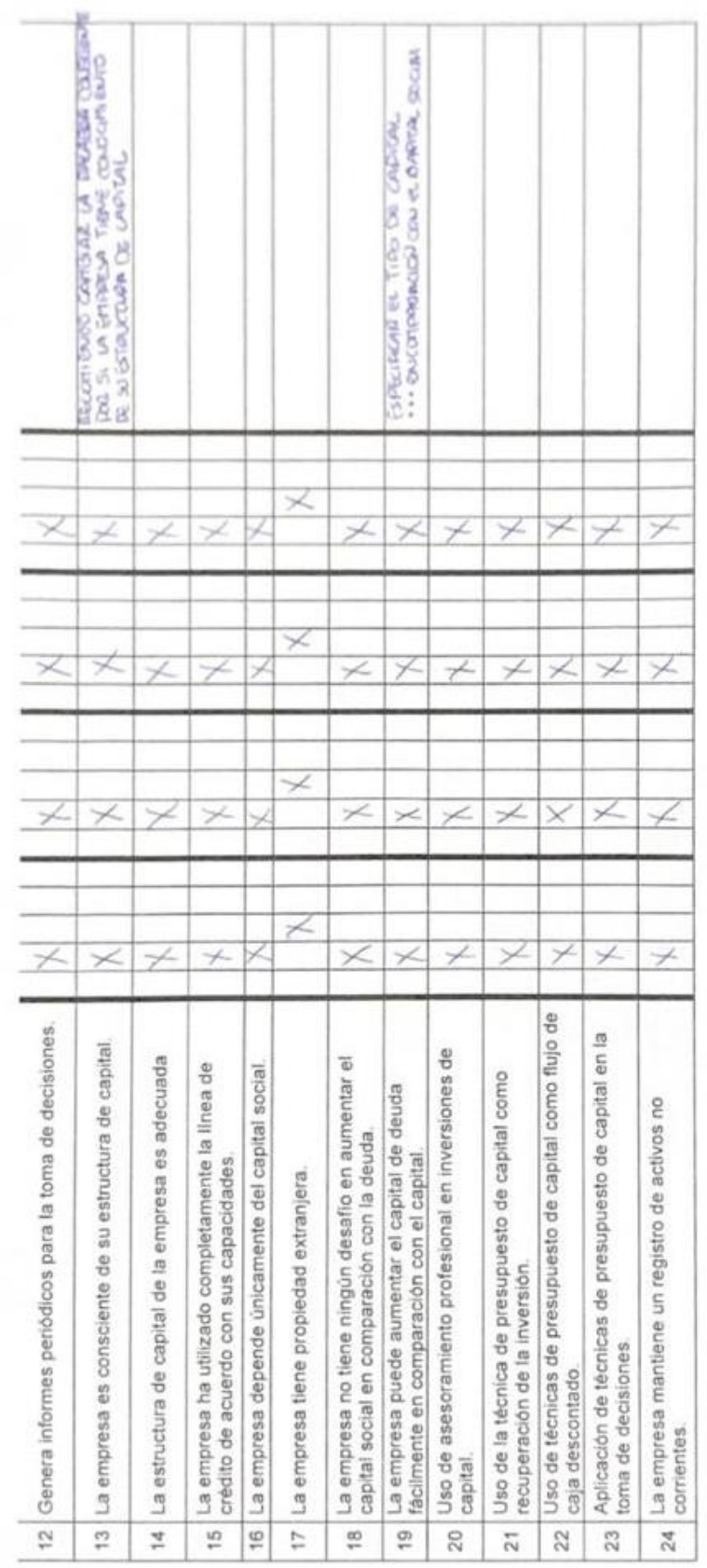


INSTRUMENTO PARA LA VALIDEZ DE CONTENIDO

(JUICIO DE EXPERTOS)

El objetivo del presente instrumento es validar el cuestionario de rentabilidad como instrumento, el cual será aplicado a los fabricantes Mypes de calzado que laboran en el distrito de Comas y que forman parte del estudio "PRACTICAS DE GESTIÓN FINANCIERA Y LA RENTABILIDAD DE LOS FABRICANTES MYPES DE CALZADO DE COMAS 2020", que corresponde a un diserlo correlacional no experimental de corte transversai

\section{Instrucciones}

La evaluación requiere de la lectura detallada y completa de cada uno de los items propuestos a fin de cotejarios de manera cualitativa con los criterios propuestos relativos a: Claridad de la redacción, congruencia con el contenido, contexto correcto del item y dominio del constructo. Para ello deberá asignar una valoración si el item presenta o no los criterios propuestos, y en caso necesario se ofrece un espacio para las observaciones si las hubiera

Juez $\mathrm{N}^{0}$

Fecha actual: $28-12 \cdot 2019$

Nombres y Apellidos de Juez: FADAH DE LOVDOES YZQUETA NAVEDA

Profesión CQUTAOOOA PÚBLICA

Institución donde labora: CORPODACIÓN DE SERVicios OR S.A.

Años de experiencia profesional o cientifica: 15 Años

Grado académico: MAGISTER

Puesto que desempeña: JEFE DE GESTION DE COERACIONES FACTUDACLÓN Y CONTRO DE GESTON

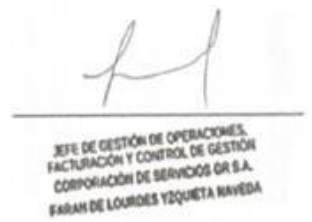


DICTAMINADO POR EL JUEZ

1) ¿Está de acuerdo con las caracteristicas, forma de aplicación y estructura del INSTRUMENTO?

Muy acoptable QS Aceptable (1) Regular () Poco acoptable ( ) Inaceptable ( )

Observaciones

$\ldots$

Sugerencias

2) A su parecer, ¿el orden de las preguntas es el adecuado?

$\sin (X)$

NO( )

Observaciones:

(n)

Sugerencias:

3) ¿Existe dificultad para entender las preguntas del INSTRUMENTO?

SI ( )

NO $(x)$

Observaciones:

(n)

Sugerencias:

4) ¿Existen palabras dificiles de entender en los items o reactivos del INSTRUMENTO?

$$
\mathrm{SI}(\mathrm{NON}
$$

Observaciones:

Sugerencias:

5) Las opciones de respuesta ¿están suficientemente graduados y pertinentes para cada item cada pregunta) o reactivo del INSTRUMENTO?
$\operatorname{si}(x)$
NO( )

Observaciones: 
Sugerencias:

6) ¿Los items o reactivos del instrumento tienen correspondencia con la dimensión al que pertenece en el constructo?

$\operatorname{SIN}$

NO( )

Observaciones:

Sugerencias: 


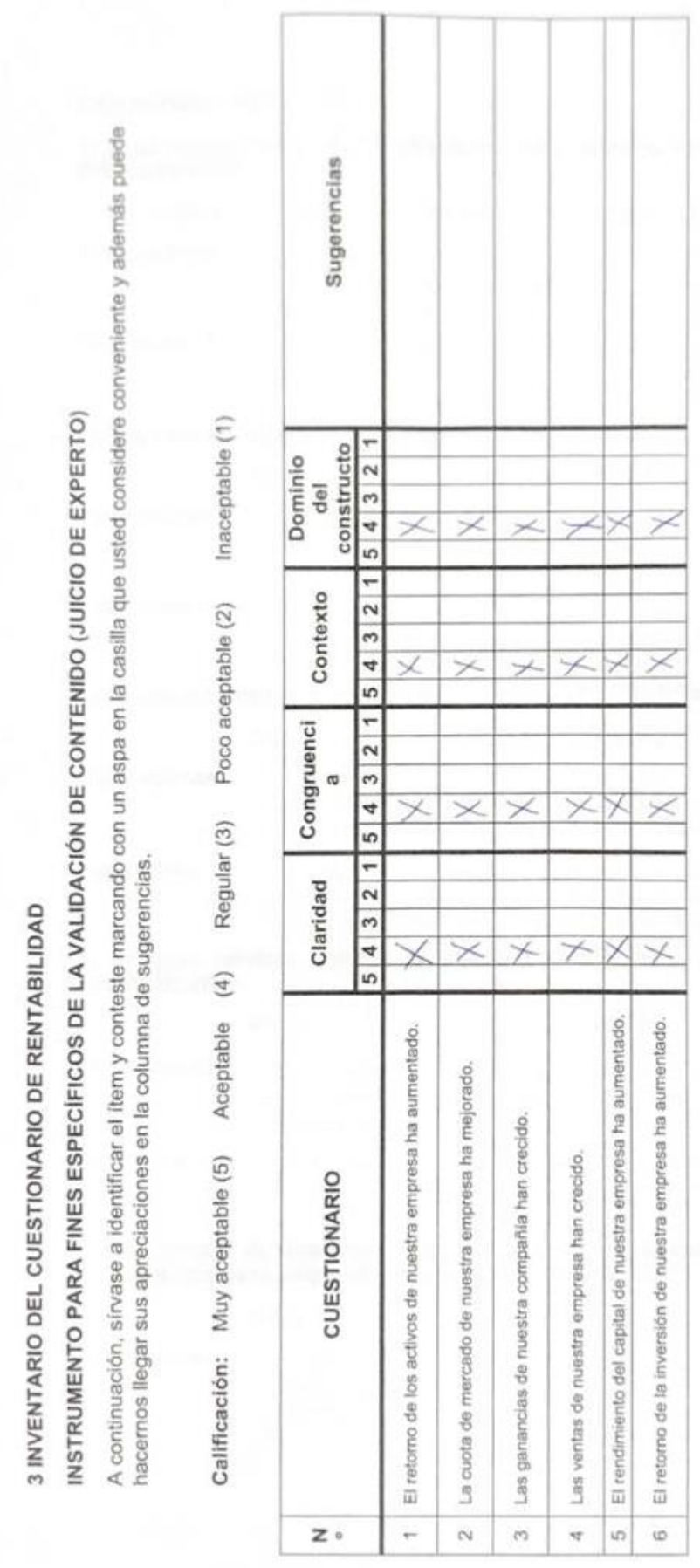

